\title{
THE INNER COURTYARD AND ITS ROLE IN ACTIVATING THE SUSTAINABLE DIMENSION OF RESIDENTIAL BUILDINGS IN HOT REGIONS
}

\author{
Mohamed Wahba Ibrahim*1, Ibraheem N. Albukhari ${ }^{2}$, Abduallah S. Omar Toulah ${ }^{2}$ \\ and Sherif Wahba Ibrahim ${ }^{3}$ \\ ${ }^{1}$ Architecture Department College of Engineering Arab Academy foe Science and \\ Technology, Alexandria, Egypt. \\ ${ }^{2}$ Department of Islamic Architecture College of Engineering and Islamic Architecture \\ Umm Al-Qoura University, Saudi. \\ ${ }^{3}$ Interior design department, Faculty of Fine Arts Alexandria University, Alexandria, \\ Egypt. \\ *Corresponding Author E-mail: Mwahb2003@yahoo.com
}

\begin{abstract}
:
The courtyard is one of the main important elements in religious or civil architecture, especially residential buildings, throughout nearly the ages, and it has continued to be used in all hot and cold regions despite the different environmental, social, religious and cultural influences, which indicates its success as an architectural solution that fulfills various functional needs as the courtyard is in its middle building or wrapping the building elements around it an integrated functional, environmental and social system. In the modern era, the use of the yard was neglected in most public and residential buildings, and some solutions used for the courtyard came as an architectural element in order to give design glimpses away from the philosophy and concept of the courtyard as an organized heart of the building where the person resorts in hot arid zone and especially areas In the summer, mechanical means such as air conditioning inside buildings to achieve the highest thermal efficiency in the building, thus increasing energy consumption. Then the courtyard lost its desired role within the environmental system of the building, especially residential ones of all kinds. The research problem appears in the great decline in the exploitation of the courtyard houses, especially in residential buildings And a clear lack of extrapolation to him in terms of his treatment of climatic and social conditions Especially at the present time despite the increase in global warming, and therefore the research importance lies in showing the role of the yard in achieving the efficiency of the thermal performance of residential buildings and ensuring their sustainability, and therefore the research aims to establish standards and foundations for the design of the courtyard in residential buildings in hot regions to raise the efficiency of this thermal performance in an integrated system With several other elements, such as the morgue, the sheikh, the building materials, the proportions of the openings, and its correlation with the environmental, social, cultural, as well as economic dimensions, in order to achieve the sustainable dimension, and therefore the research follows the descriptive approach by studying a descriptive study of the historical aspect of the emergence of the courtyard and its environmental and social dimensions and values of its appearance in residential buildings in hot areas, passing
\end{abstract}


through the curriculum Comparative analysis by analyzing some local models in which the use of the yard has led to the achievement of efficiency in thermal performance in order to achieve the hypothesis of the research, which stipulates that if a design strategy for the courtyard is developed in residential buildings in hot regions, its role in residential buildings of all kinds will be improved, leading to results Research represents the link between foundations and standards of environmental design and investigation $\mathrm{S}$ the sustainable dimension in our modern cities, and the research ends with future recommendations to achieve improvement and raising the efficiency of thermal performance in residential buildings in hot arid zone to achieve the sustainable dimension.

KEY WORDS: Courtyard, ، Sustainability, Atrium, Simulation, Patio.

$$
\begin{aligned}
& \text { القناء الداخلي ودوره فى تفعيل البعد الاستدامى للمباني السكنية بالمناطق الحارة } \\
& \text { محمد وهبة إبراهيم خليل*'، إبراهيم نور الدين البخارى'، عبدالله صلاح الدين عر طوله 'و شريف وهبه } \\
& \text { "ابرم الثعمارة و التصميم البيئي، كلية الهندسة، الأكاديمية العربية للعلوم و التكنولوجيا بالإسكندرية، الإسكندرية، }
\end{aligned}
$$

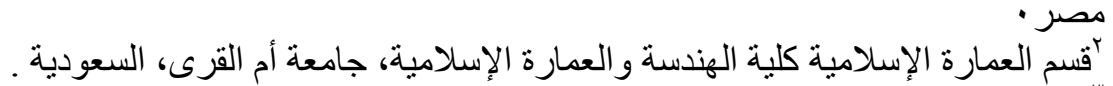

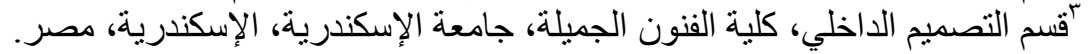

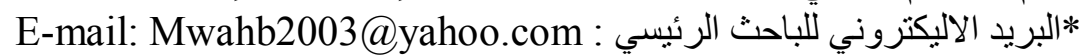

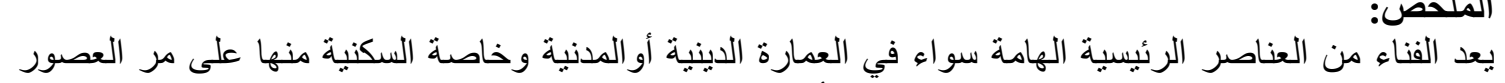

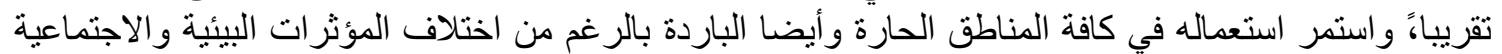

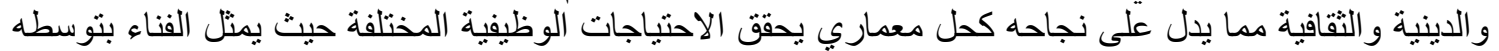

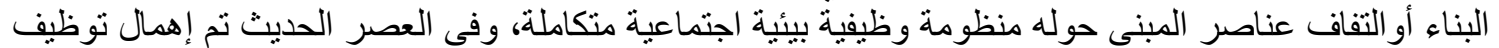

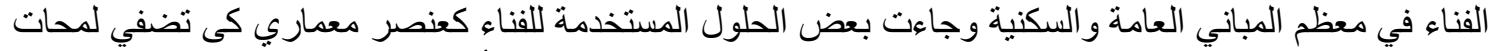

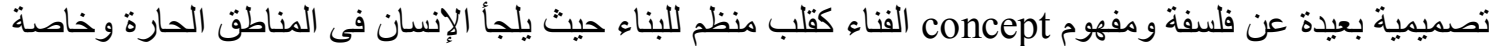

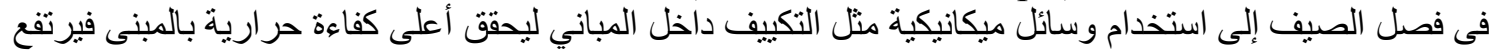

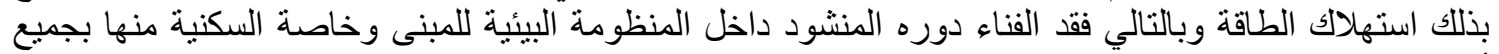

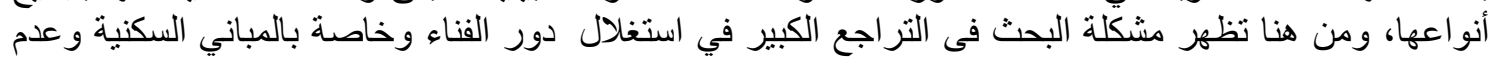

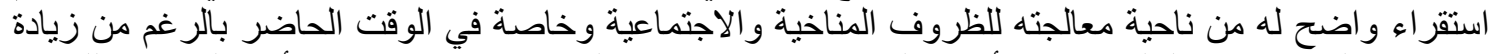

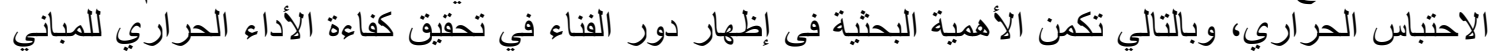

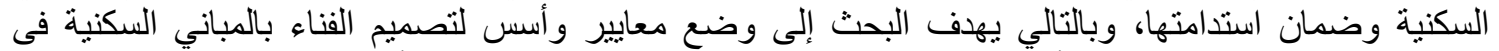

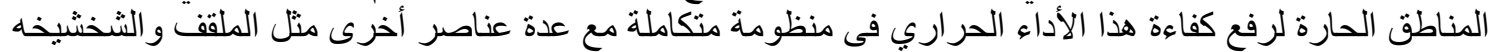

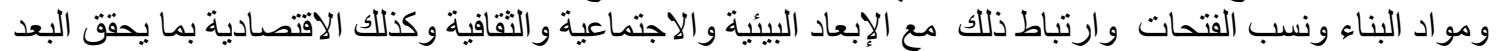

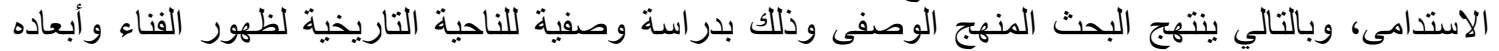

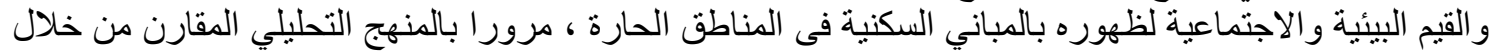

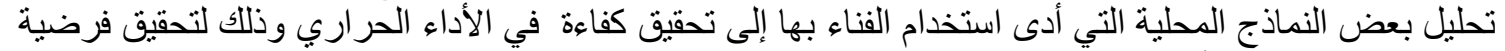

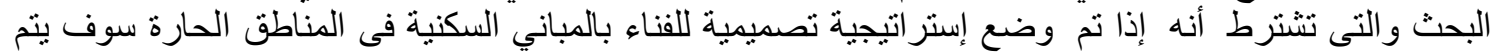

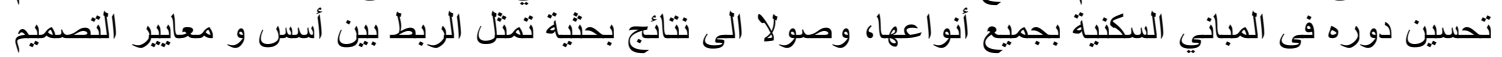

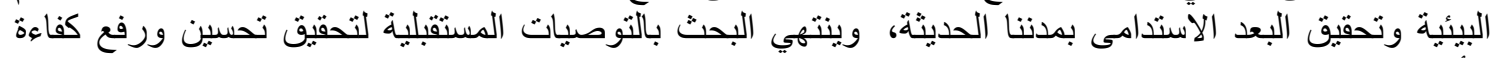

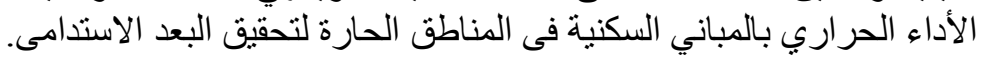

الكلمات المفتاحية : الفناء، الاستذامة، الاتريم، المحاكاة، الباثيو. مقدمة : العمارة هي ذلك الفن الذي يهتم بتطوير احتياجات الإنسان من خلال إدر الك العوامل الخارجية التي تحيطه، والتي إني

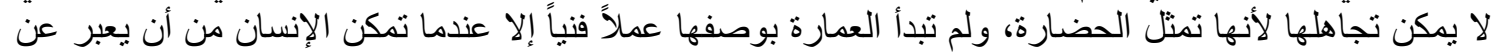


شخصيته فيما بناه ، فعرفت العمارة بأنها تكوين يؤدي أغراضاً إنسانية ومتطلبات حياتية مكانية ومادية مرتبطة

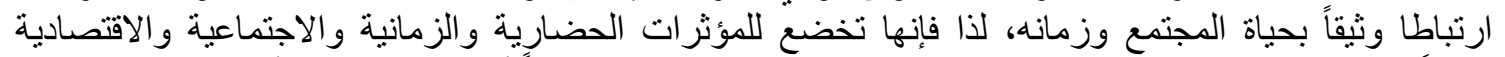

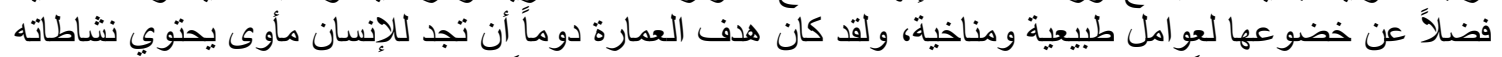

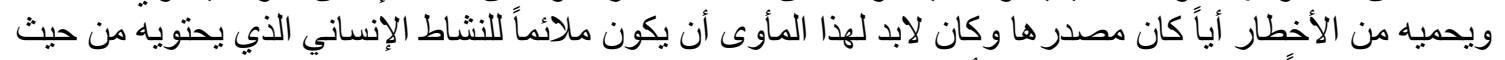

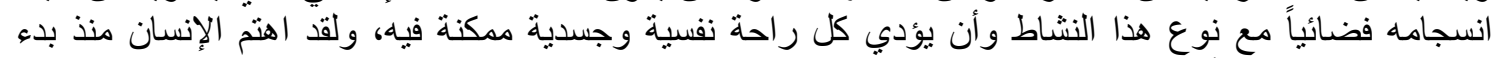

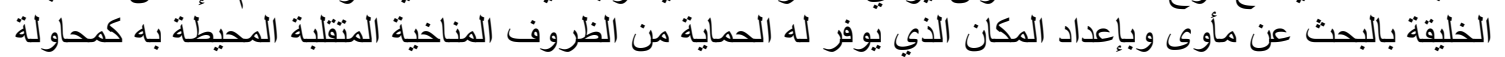

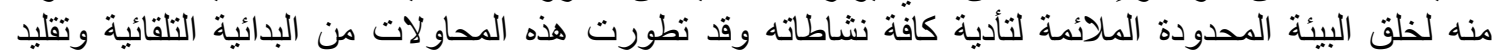

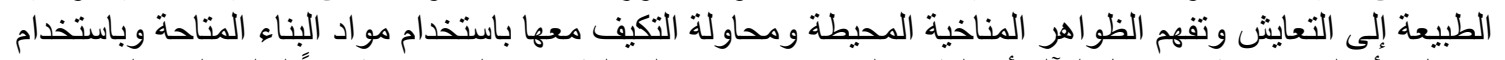

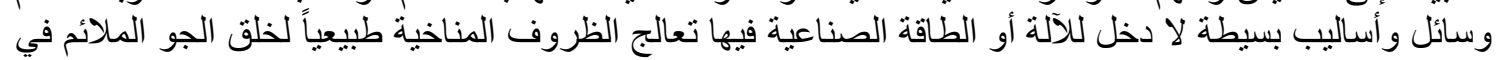
الحيز الداخلي.

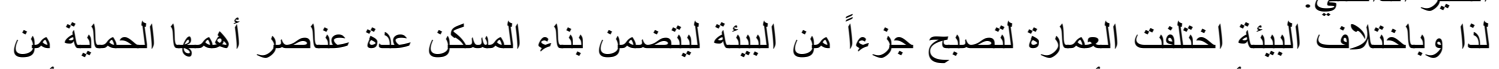

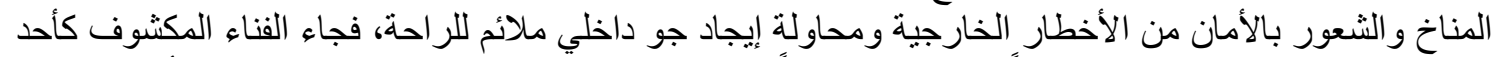

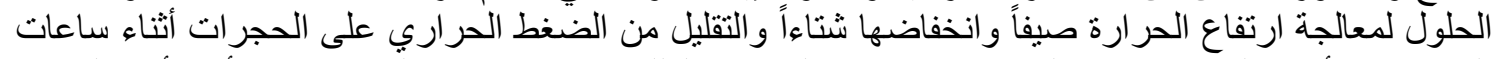

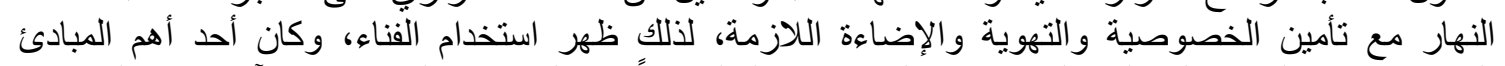

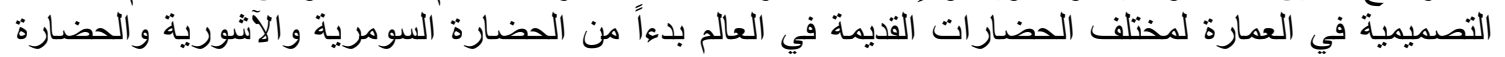

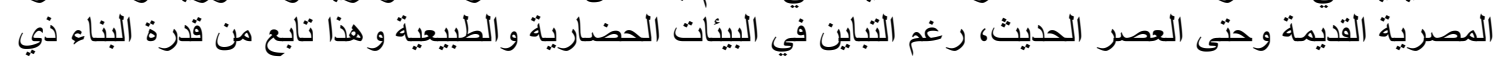

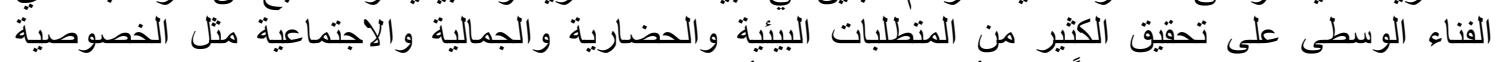

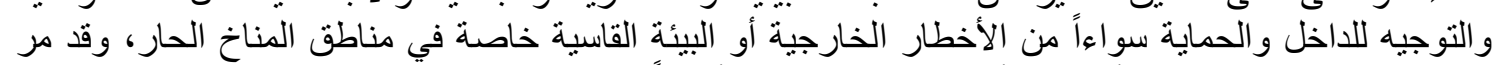

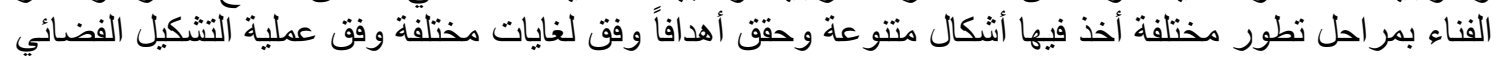

للمبنى ووظبيفته.

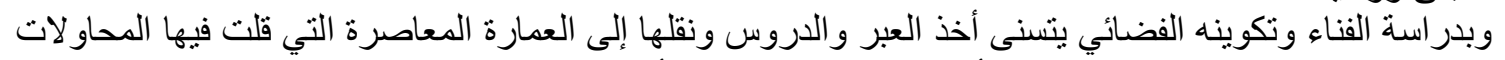

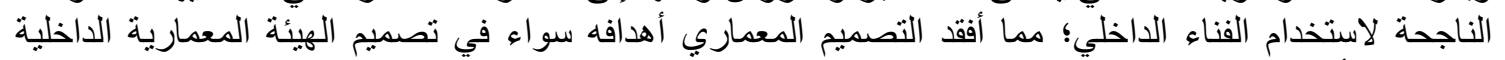

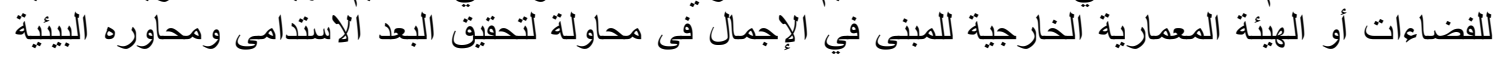

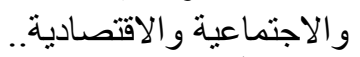

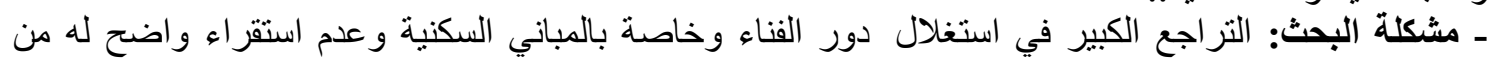

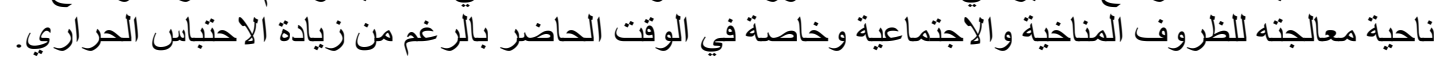

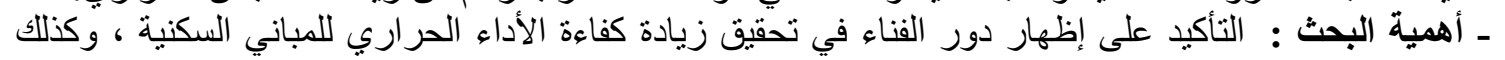

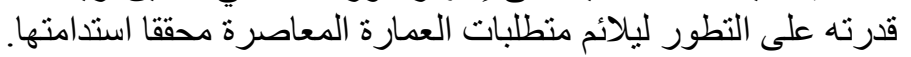

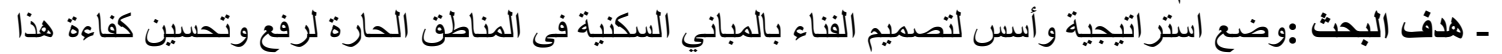

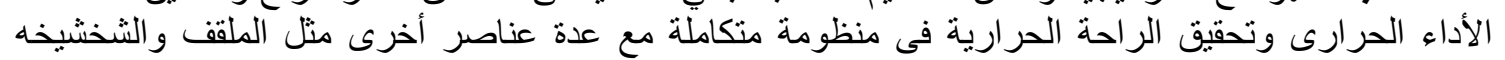

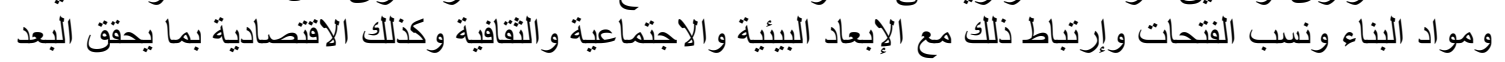

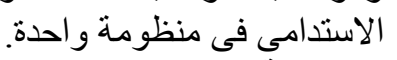

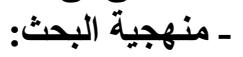

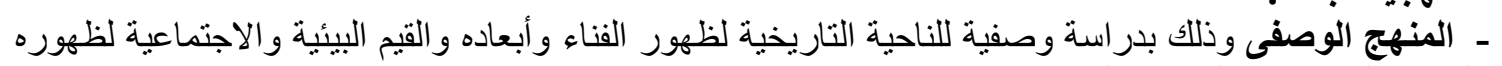
بالمباني السكنية في المناطق ولاك الحارة .

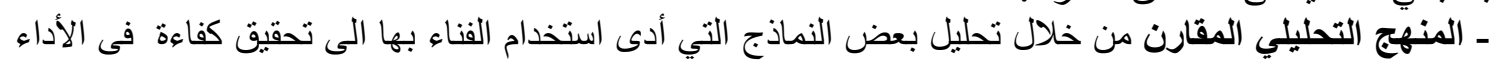

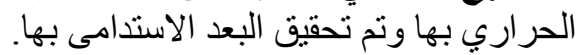

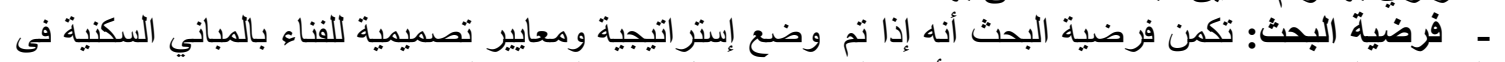

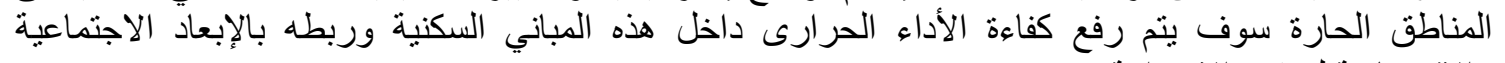

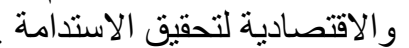

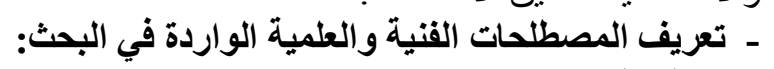
ـ تعريف المسكن House:

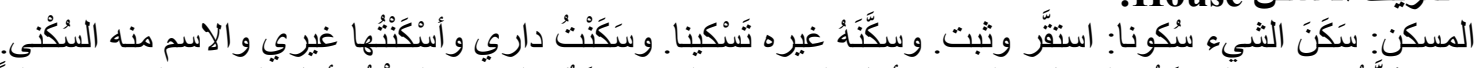

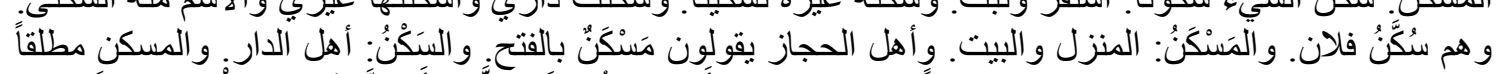

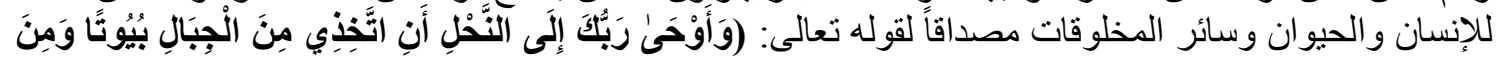

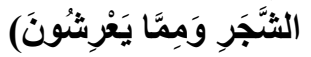

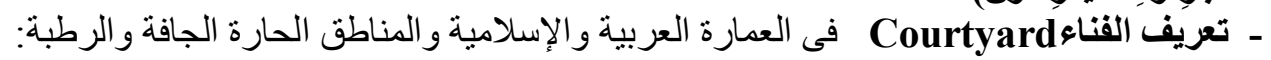


THE INNER COURTYARD AND ITS ROLE IN ACTIVATING THE SUSTAINABLE DIMENSION OF RESIDENTIAL BUILDINGS IN HOT REGIONS

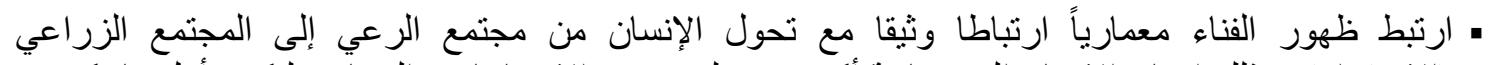

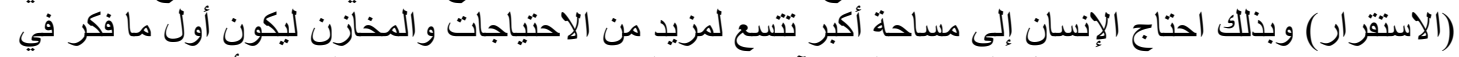

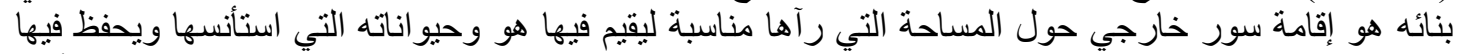

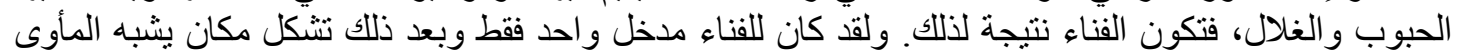

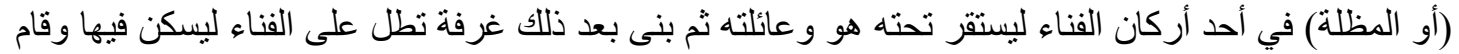

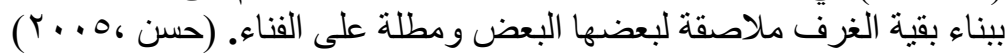

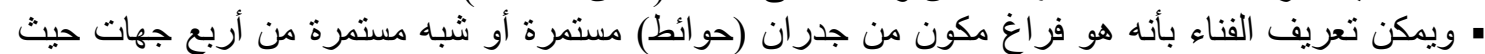

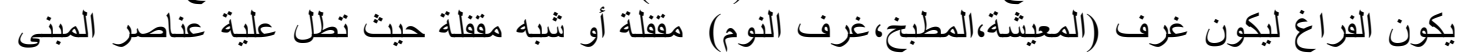

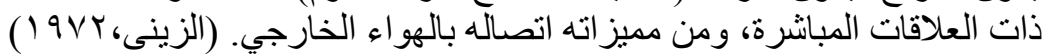

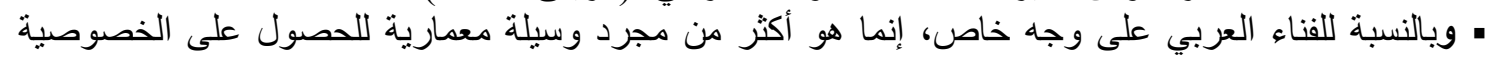

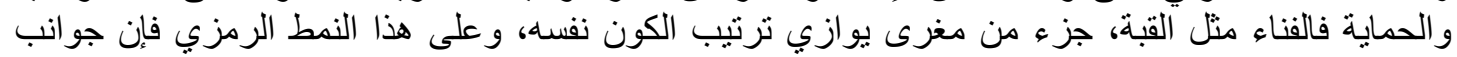

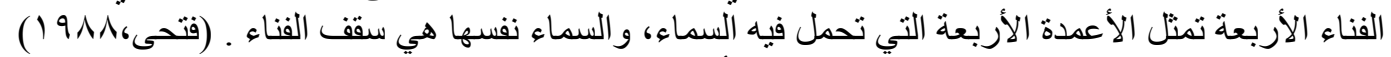

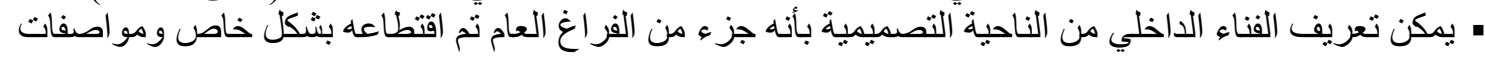

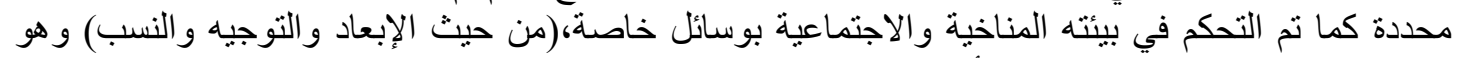

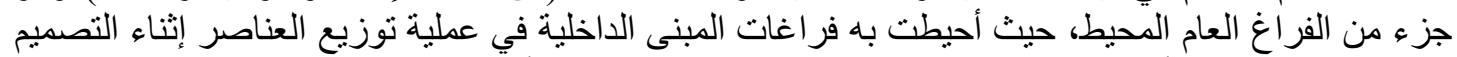

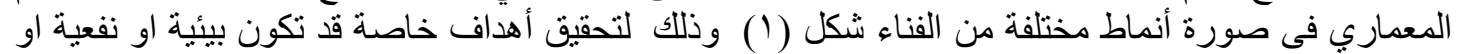

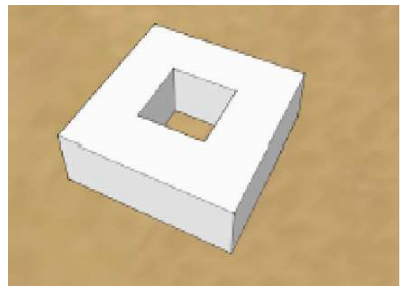

ج) الفناء فى وسط المبنى

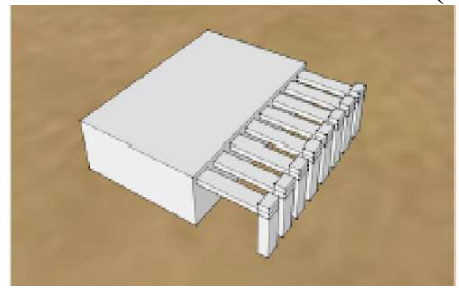

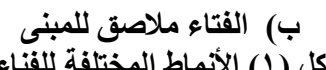

تشكيلية او اجتماعية (Chadirji, 2008).

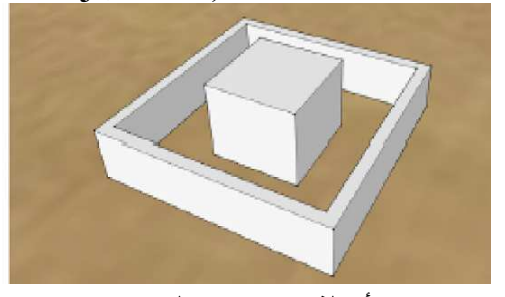

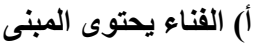

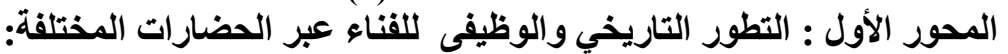

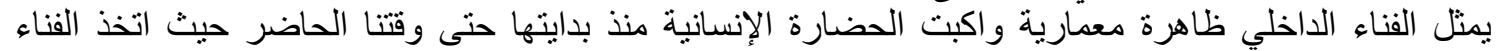

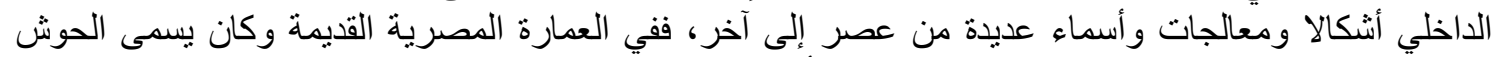
(Court)

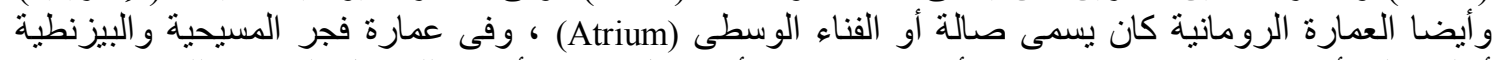

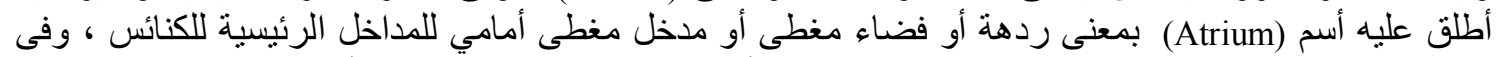

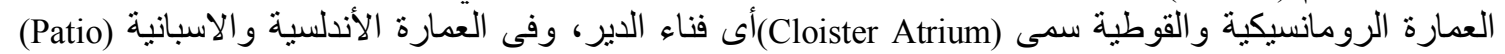
وفى العمارة العربية والإسلامية سمى الصحن أو الفناء، وأخيرًا اتخذ في العمارة الحديثة العدية العديد من الأسماء مثل

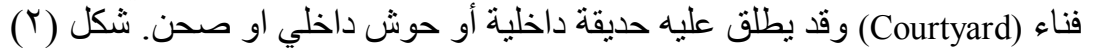

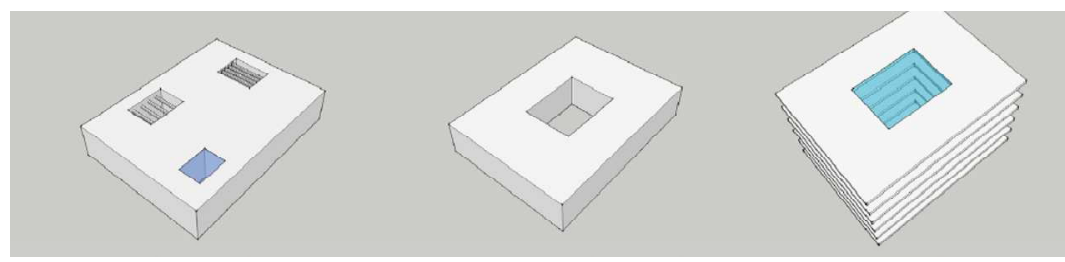
(a): a courtyard,
(b): a patio,
(c): an atrium.

شكل (r) التطور التاريخي والوظيفى للفناء عبر الحضارات المختلفة

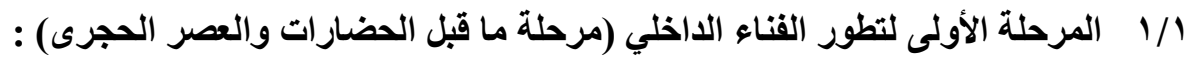

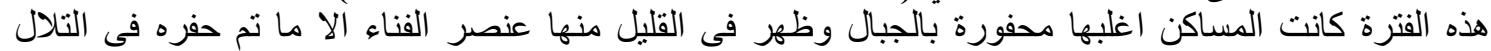

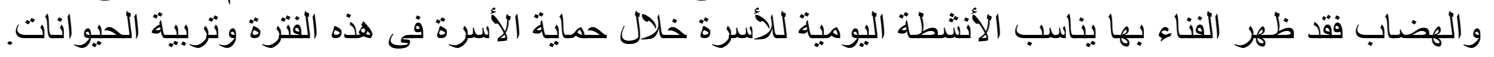

(r) شكل (Ching,2010) 
THE INNER COURTYARD AND ITS ROLE IN ACTIVATING THE SUSTAINABLE DIMENSION OF RESIDENTIAL BUILDINGS IN HOT REGIONS

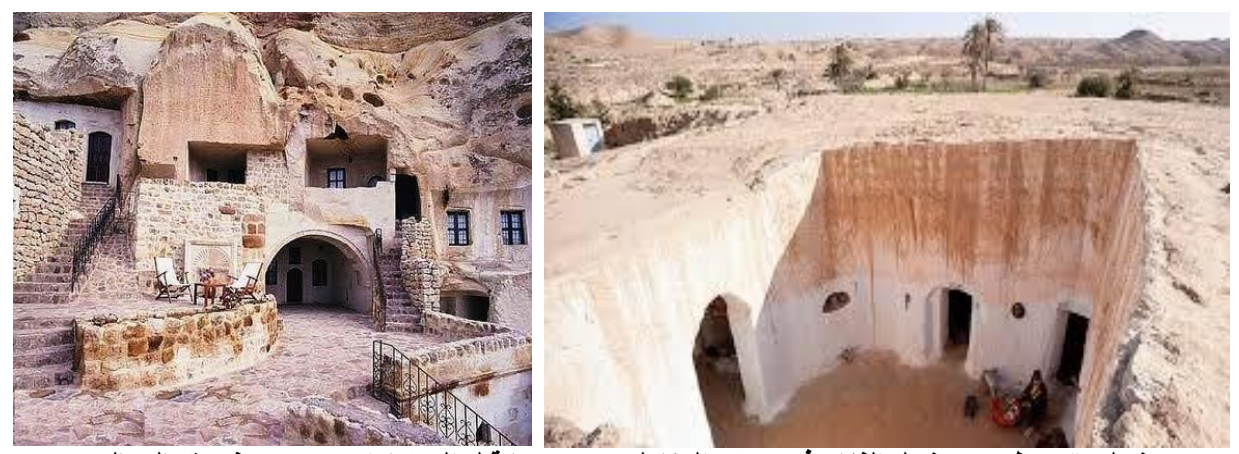

شكل (rّ) يظهر به شكل الفناء فى بعض المنازل بعصور ما قبل الحضارات وهى محفورة بالجبال.

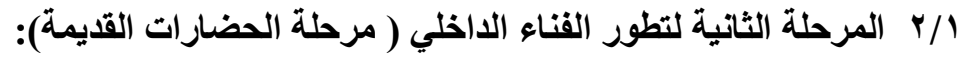

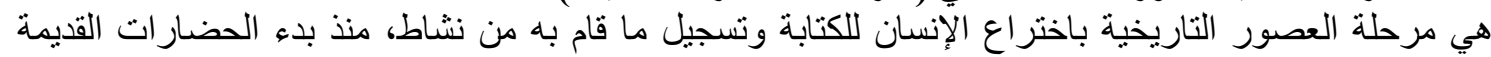

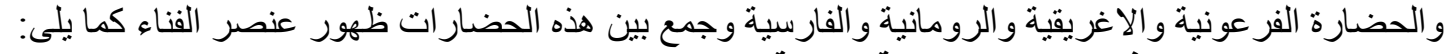

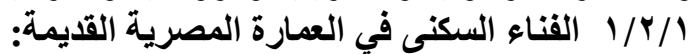

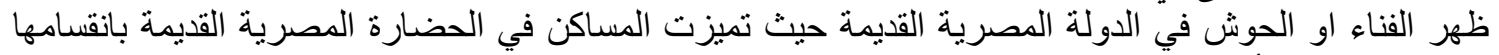

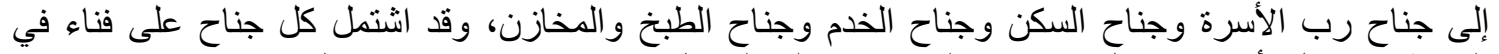

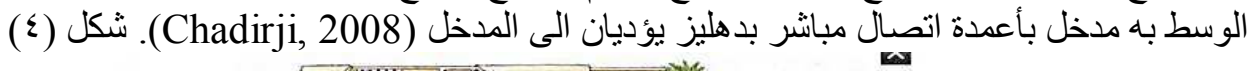

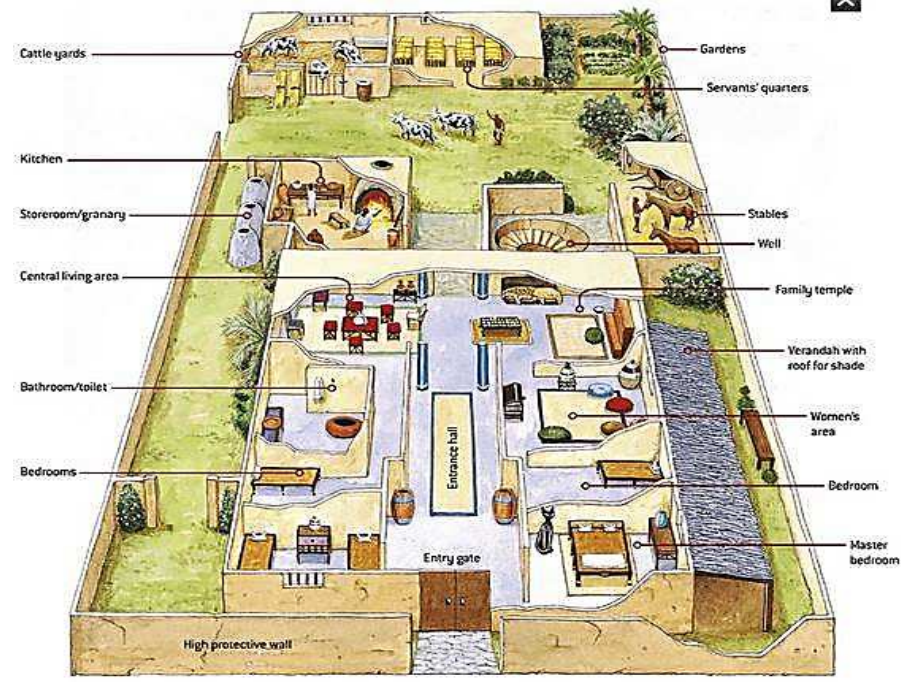

شكل (ء) تخيل لشكل توزيع عناصر المسكن حول الفناء فى العصر الفرعونى

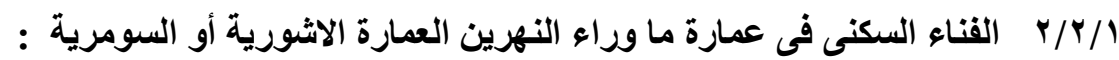

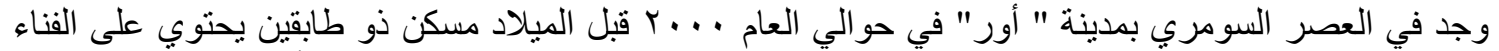

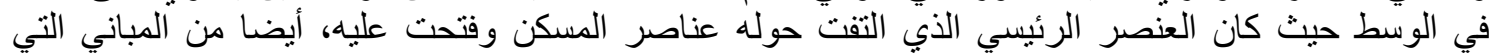

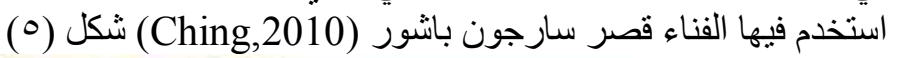

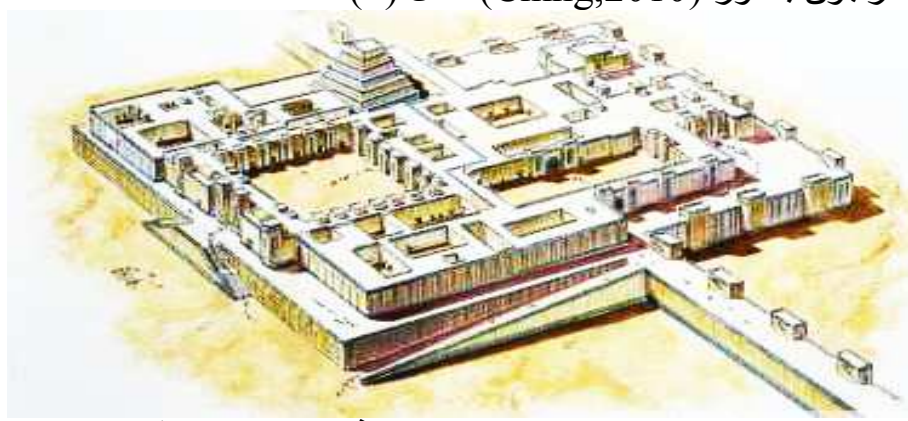

شكل (0) قصر سارجون باشور موضح به الفناء العنصر الرئيسي الذي التفت حوله وطلت عليه عناصر المسكن. 
THE INNER COURTYARD AND ITS ROLE IN ACTIVATING THE SUSTAINABLE DIMENSION OF RESIDENTIAL BUILDINGS IN HOT REGIONS

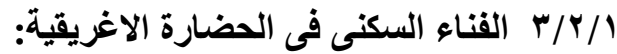

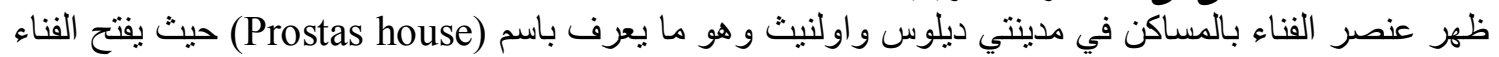

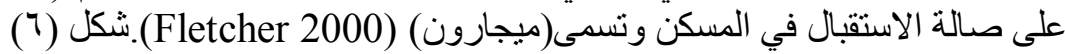

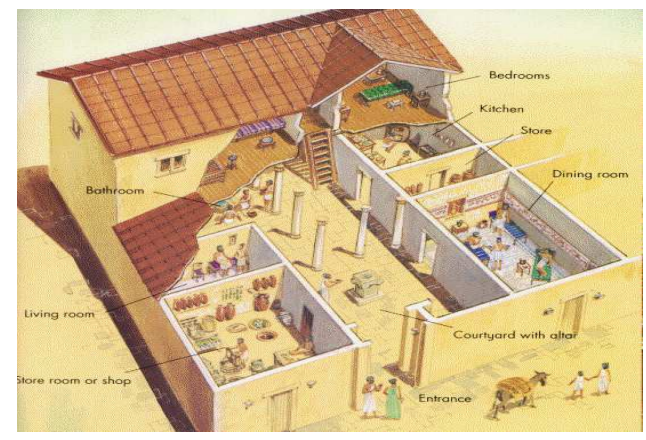

The 'typical' Greek house

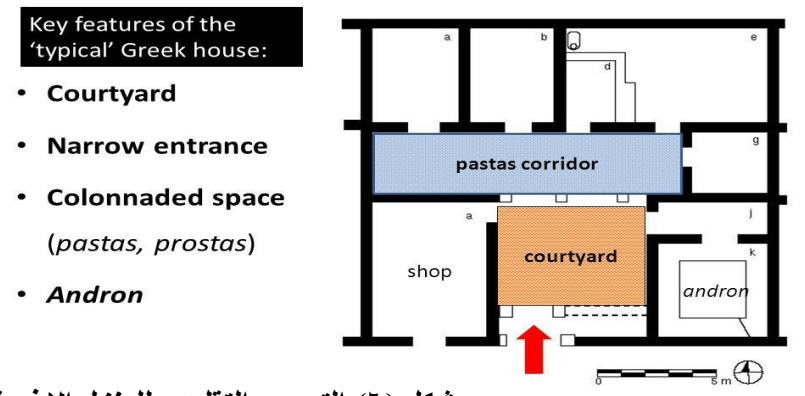

شكل (7) التصميم التقليدى للمنزل الاغريقى القديم ويه عنصر الفناء .

(الفناء السكنى فى العمارة الرومانية:

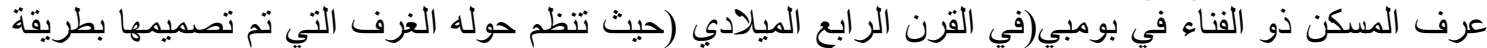

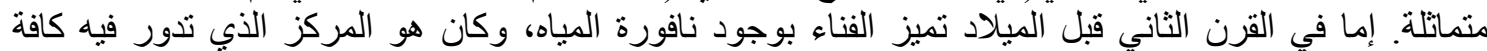

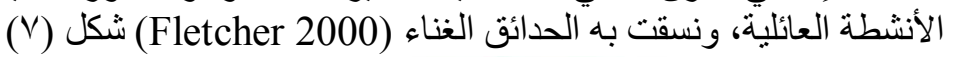
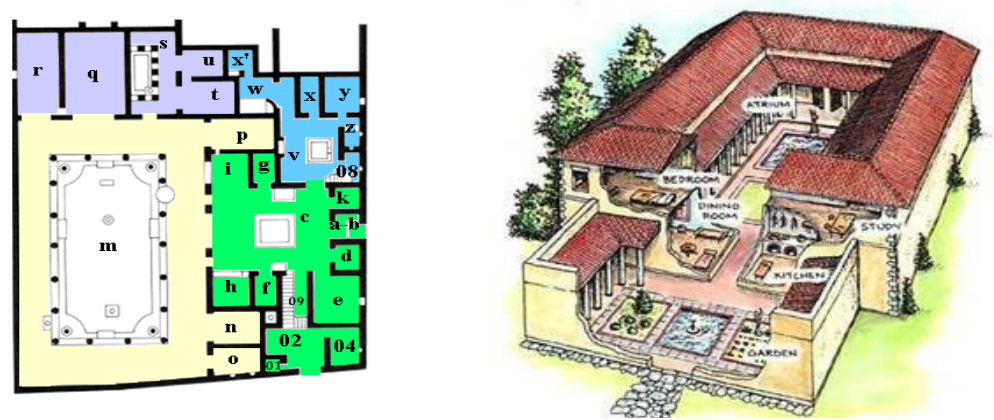

شكل (V) المنازل الرومانية متعددة الاحواش ويظهر به الفناء الوسطي ذو الوظائف الاجتماعية والمناخية .

وها

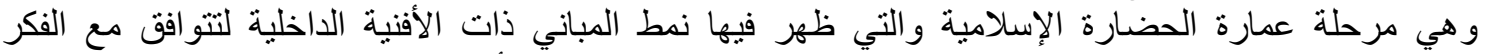

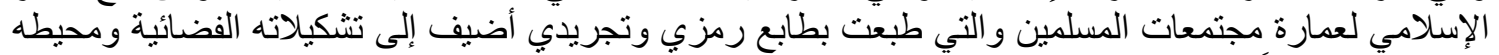

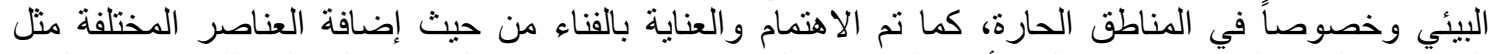

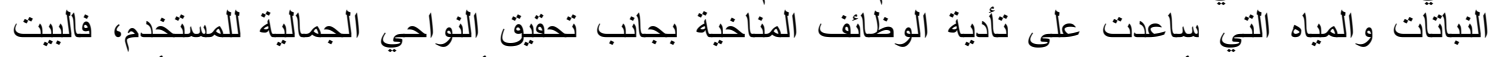

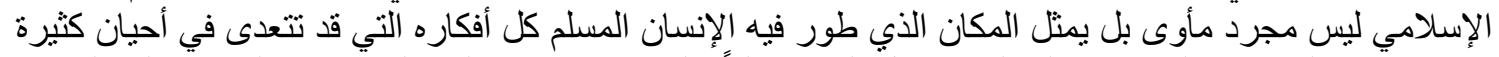

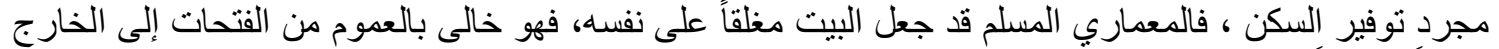

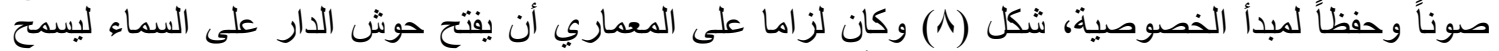

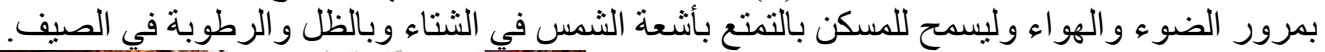

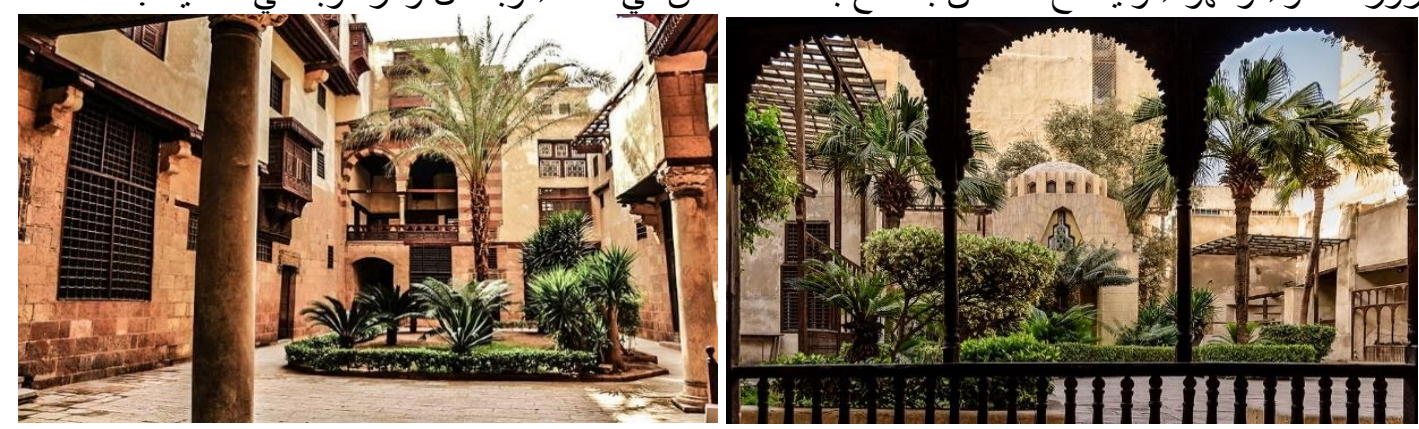

شكل (^) توافق الفناء السكنى مع احتياجات الإنسان المسلم فى البيت الاسلامى . 
THE INNER COURTYARD AND ITS ROLE IN ACTIVATING THE SUSTAINABLE DIMENSION OF RESIDENTIAL BUILDINGS IN HOT REGIONS

ـ الإبعاد المؤثرة على تصميم وتكوين الفناء الأخلي للمسكن الإسلامي:

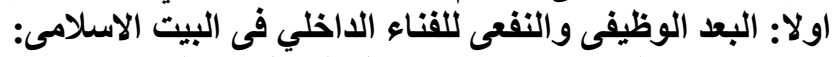

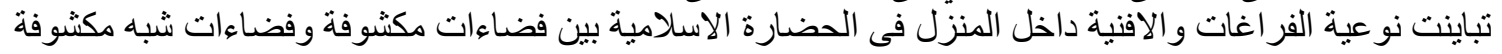

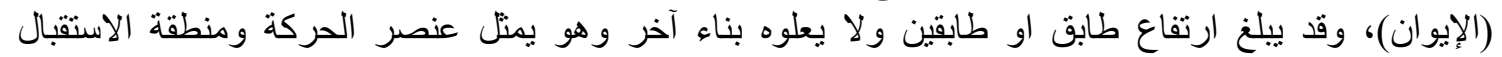

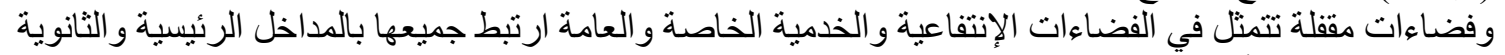

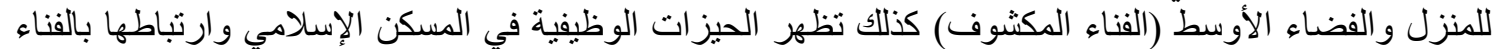

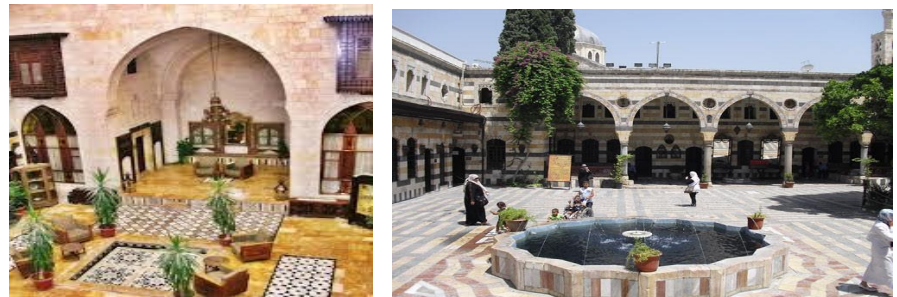

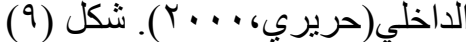

شكل (9) إيوان السلاملك والاطلاله على الفناء الداخلى للبيث الاسلامى ·

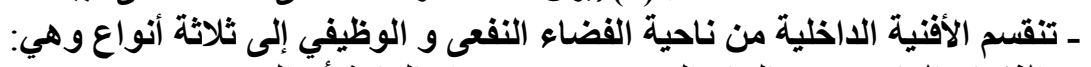

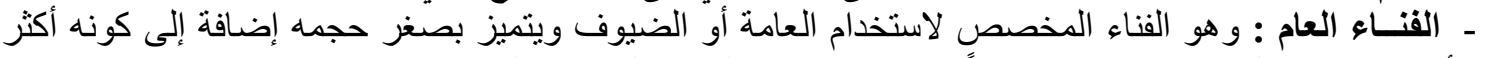

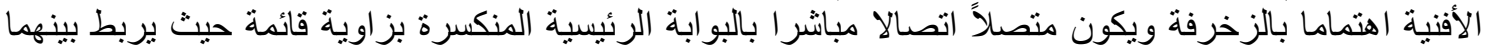

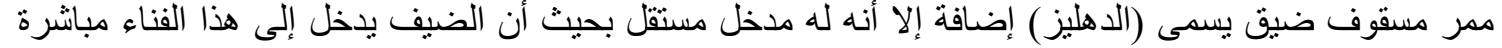
ويصل إلى قاعة جلوس الضيوف دون كثف البيت ويحتوي هذا الفناء عادة على فسقية ماء مزخرفة ويطل أيضا على الإيوان. ـ الفنـاء الخاص : الإيوان الفناء المخصص للعائلة أو أهل البيت ويطل عيه حرم البيت ويسمى (الحرملك) ويحتوي على الئ

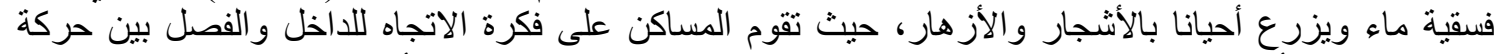

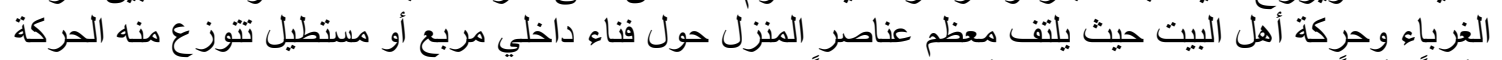

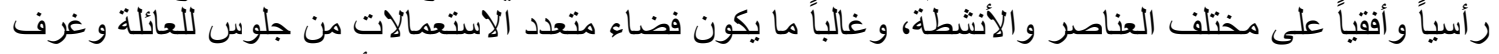

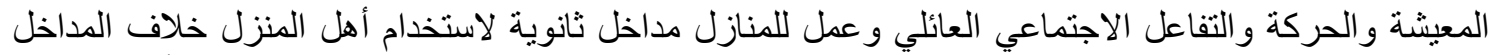
الرئيسية ، كما وجدت سلالم بين الطوابق وكذلك وجدت مدرات بدئ بديلة وذلك لتوفير الخصوصية لأهل المنزل.

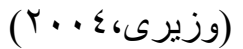
- الفتـاء الخدمي : وهو هو الفناء المخصص للخدمة والخدم ويسمى (الخدملك) أو (بيت المطبخ) و غالبا ما يكون

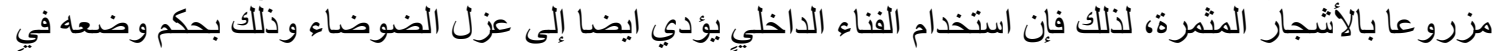

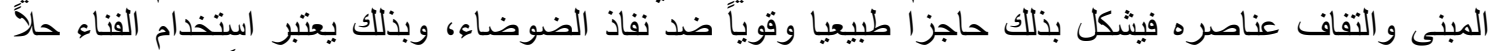

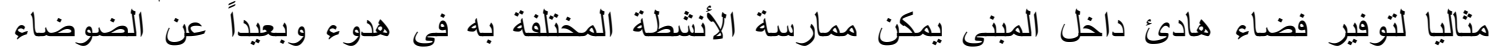

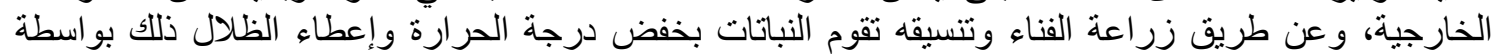

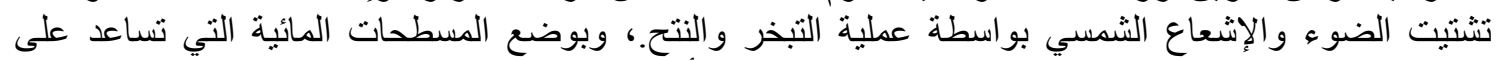

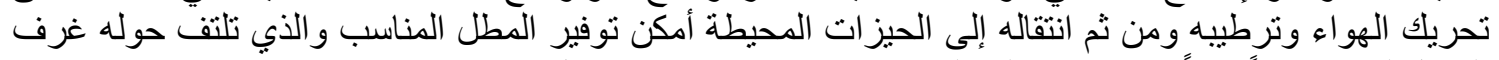

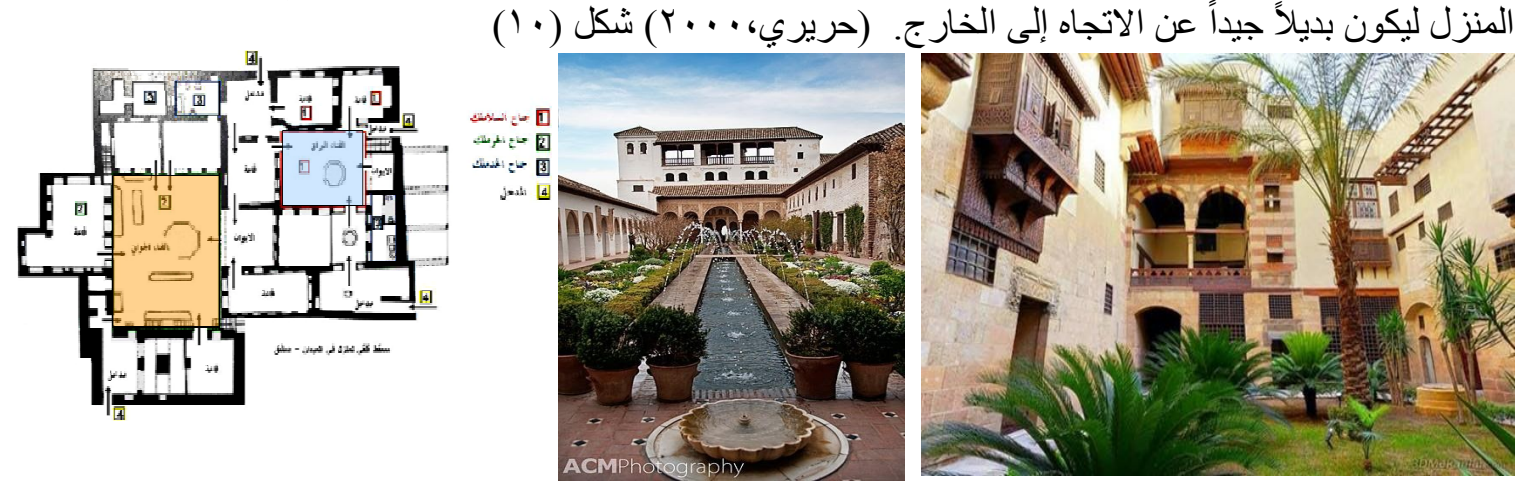

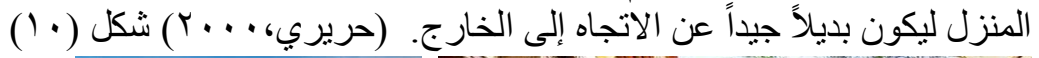

شكل (• (1) تعدد الافنية الداخلية فى المسكن الاسلامى بين العام والخاص والخدمى وظيفة الأثجار 
THE INNER COURTYARD AND ITS ROLE IN ACTIVATING THE SUSTAINABLE DIMENSION OF RESIDENTIAL BUILDINGS IN HOT REGIONS

ثانياً : البعد التشكيلي للقناء الداخلي فى البيت الاسلامى:

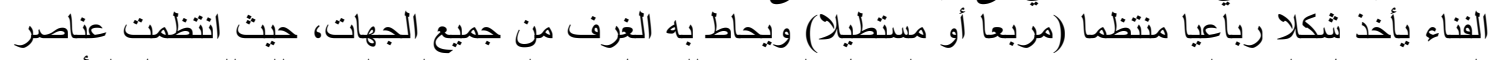

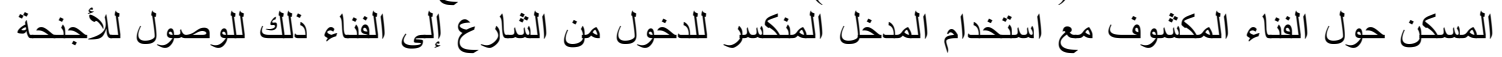

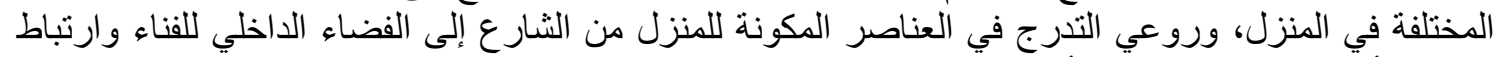

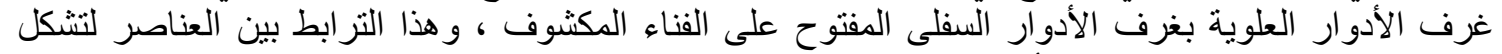

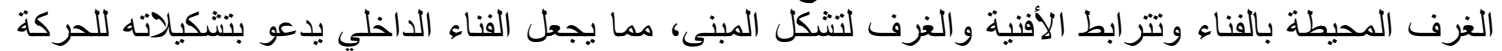

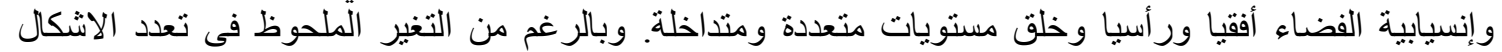

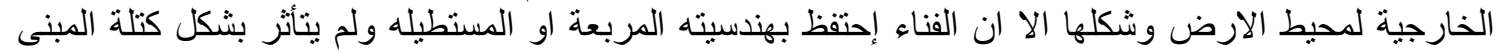

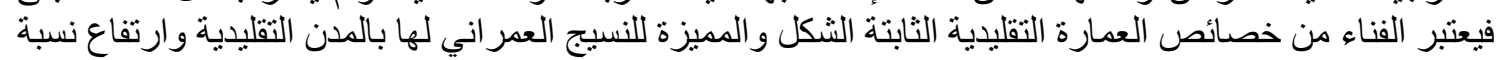

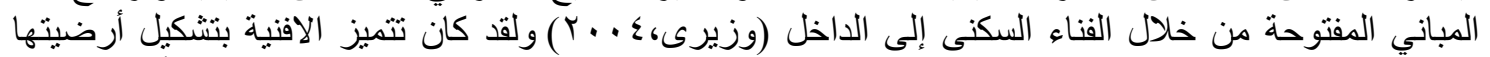

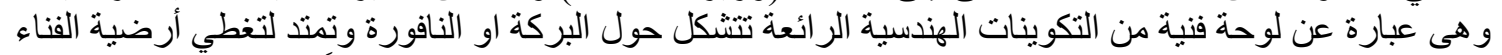

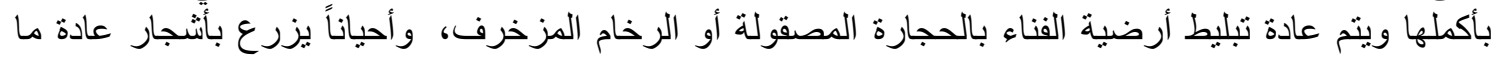

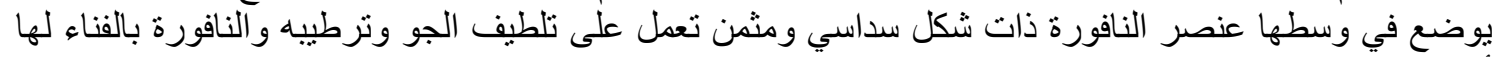

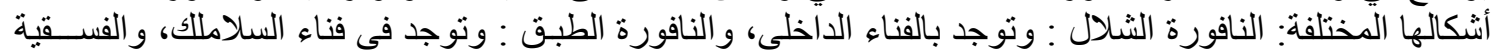

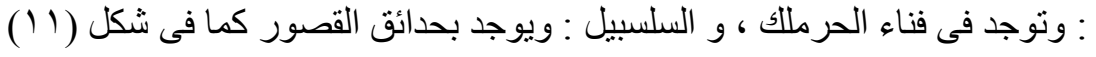
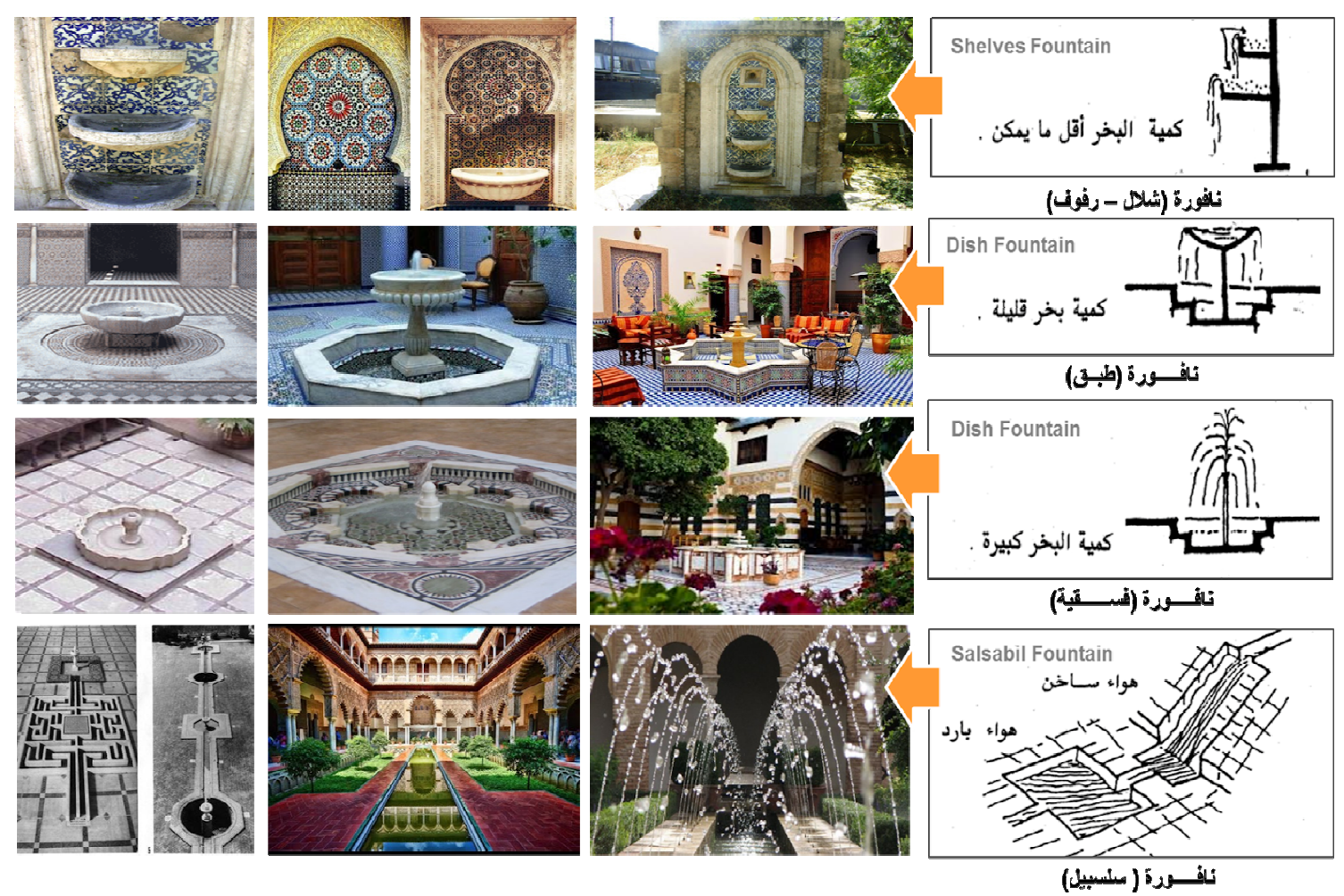

شكل ( ' ') الإشكال المختلفة لعنصر النافورة فى الفناء السكنى بالعمارة الإسلامية.

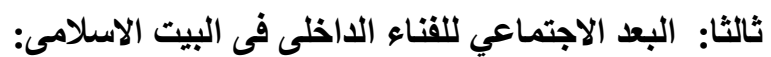

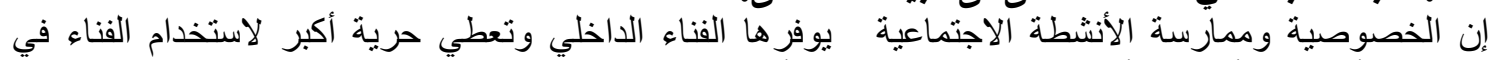

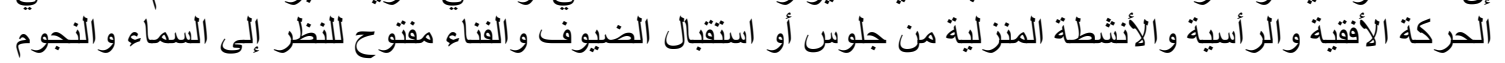

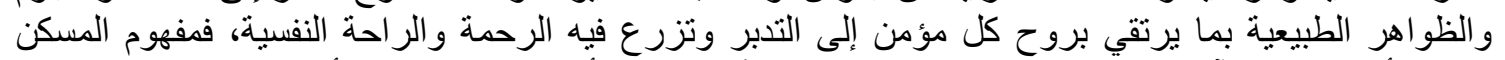

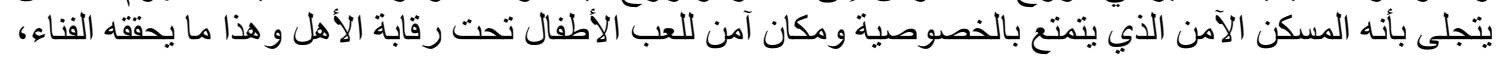

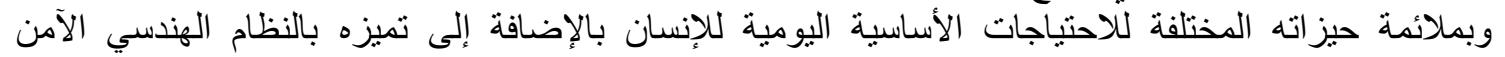

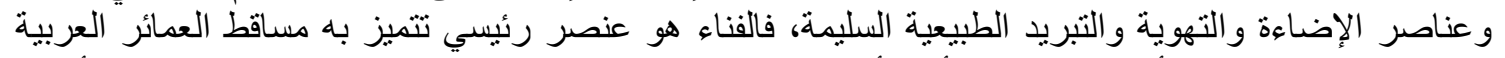

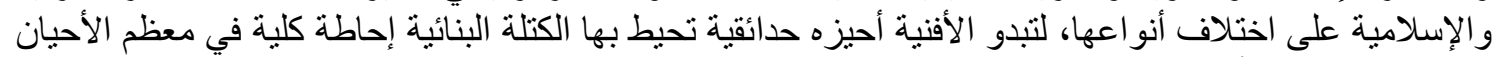

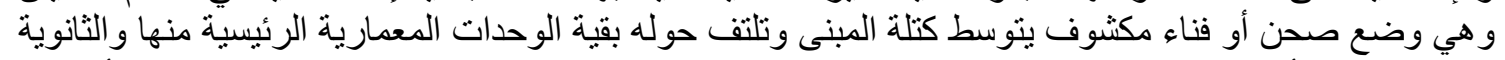

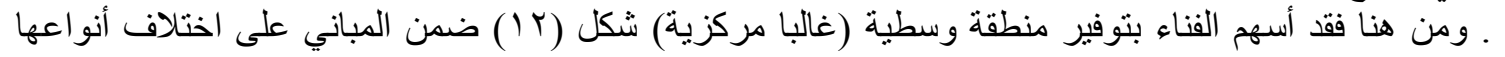


THE INNER COURTYARD AND ITS ROLE IN ACTIVATING THE SUSTAINABLE DIMENSION OF RESIDENTIAL BUILDINGS IN HOT REGIONS

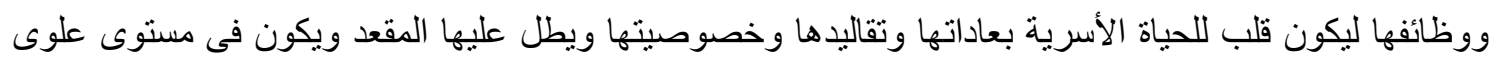

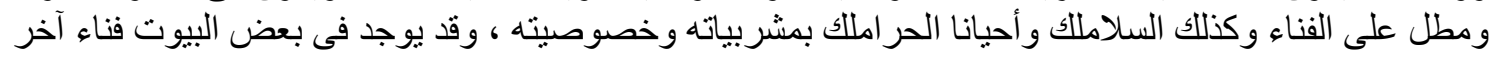
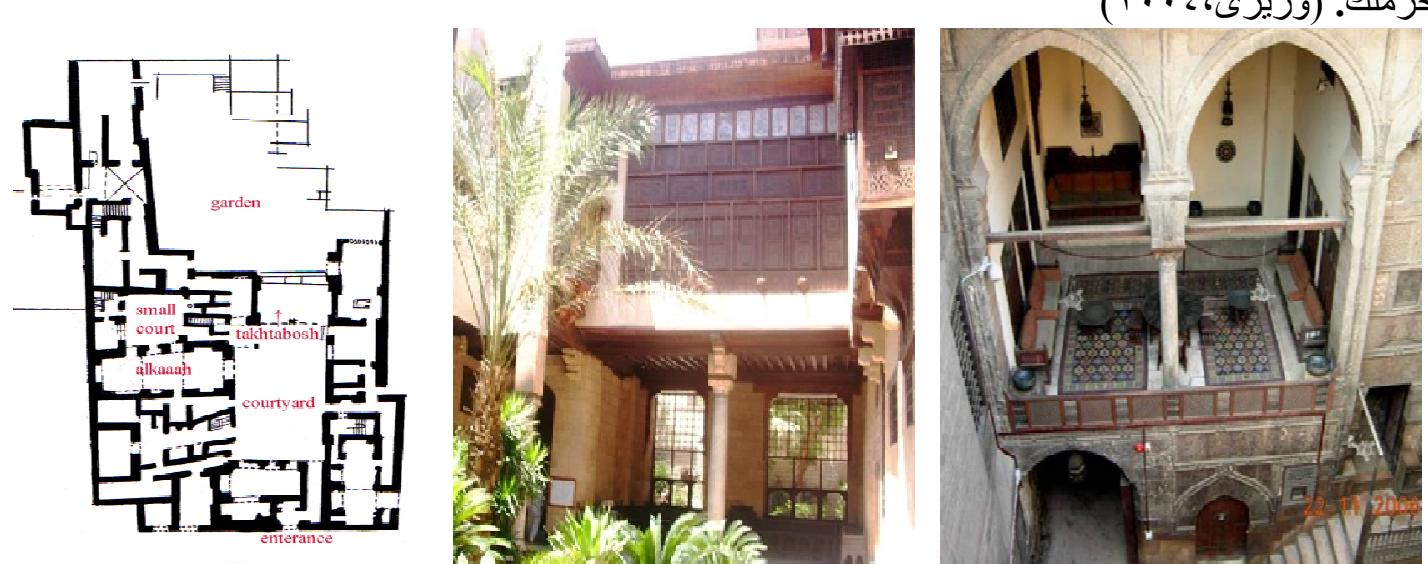

شكل (r I) المقعد المطل على القناء والحرملك بمشربياته والتختبوش والمدخل المنكسر لتحقيق الخصوصية.

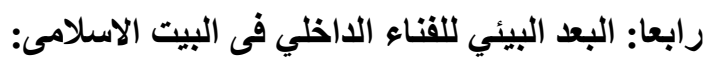

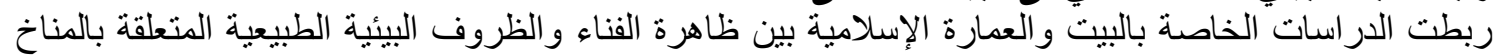

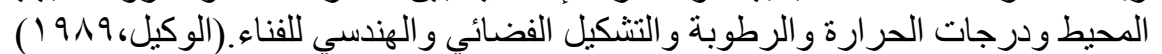

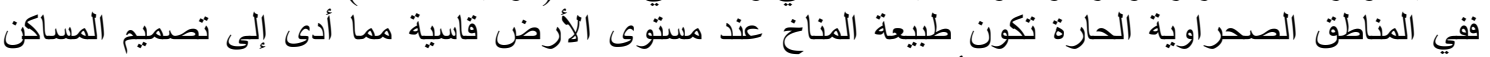

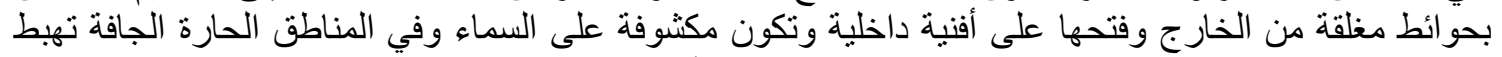

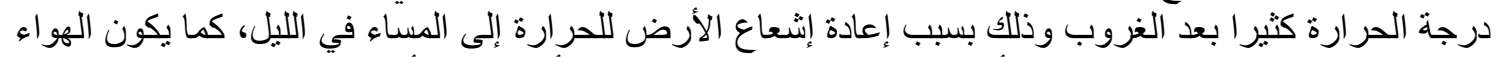

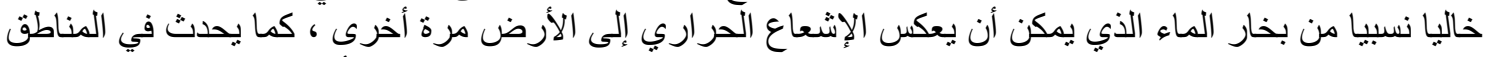

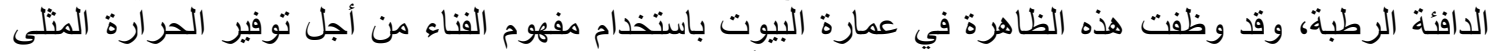

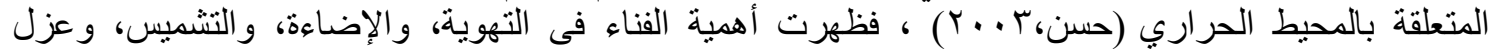

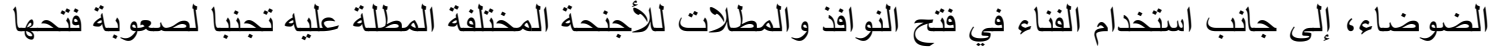

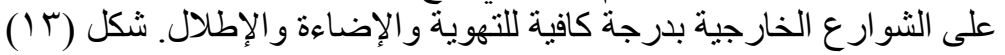
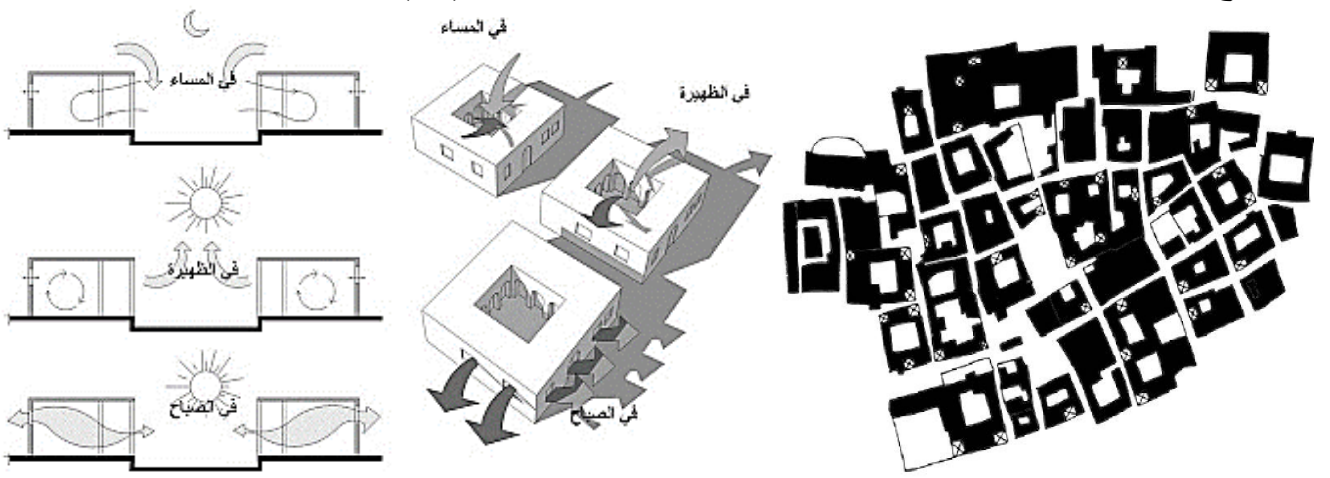

شكل (r I ) الفناء فى النسيج العمرانى للمدينة الإسلامية ودوره بيئيا كمنظم للحرارة ليلا ونهارا.

المرحلة الثالثة لتطور الفناء الاخلي ( مرحلة العصر الحديث) :

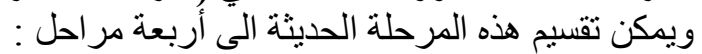

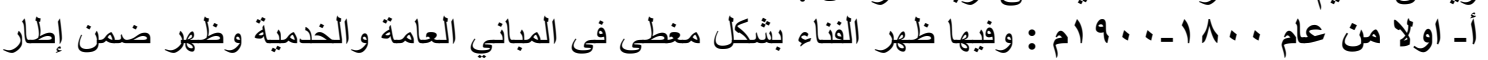

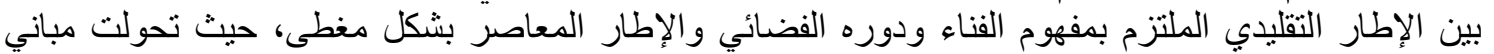

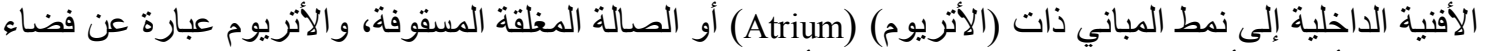

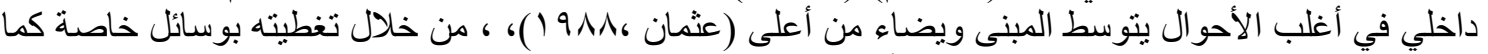

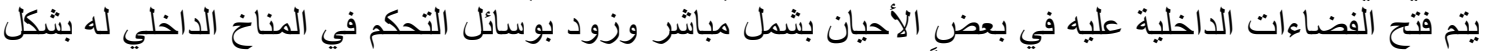
طبيعي وصناعي ، ويمكن أن يكون مفتوحاً على عدة مستويات (بكامل الارتفاع) أو أن يغطى بنو الفي الف واسعة من أجل الجل

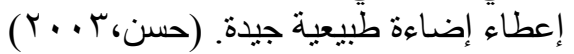


THE INNER COURTYARD AND ITS ROLE IN ACTIVATING THE SUSTAINABLE DIMENSION OF RESIDENTIAL BUILDINGS IN HOT REGIONS

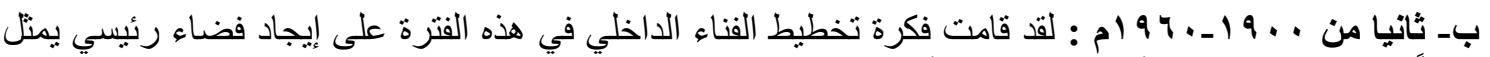

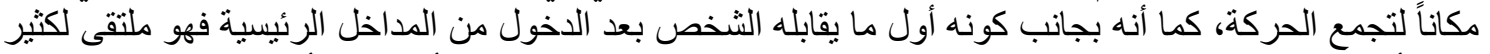

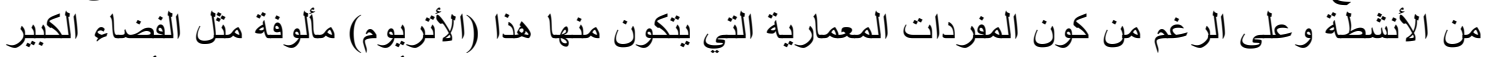

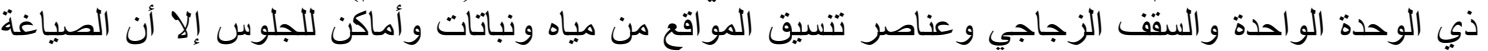

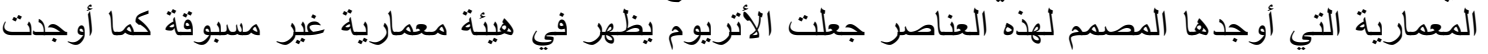
صورة ذهنية مميزة ورمزية للمكان في ذاكرة المشاهد، فقد سعى المصمم في توظيف العناصر المئة المعمارية في خدمة

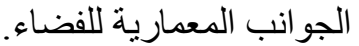
ومنها الاعمال الخاصة بالمعماريين العالميين مثل فر انك لويد الكيد رايت ولوكوربوزييه حيث مرحلة الحداثة واستخدام

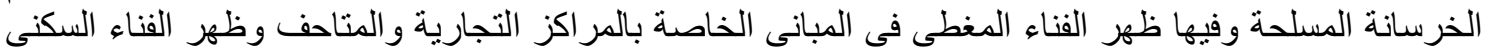
بطريقة مبسطة مثل فيلا سافوى بفرنسا للمعمارى لوكئل الوكوربوزييه ـ (Saini, 2010)

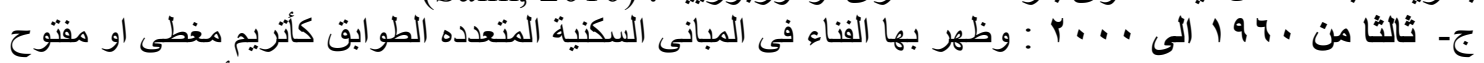

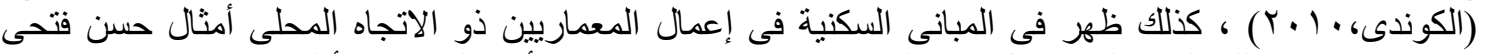

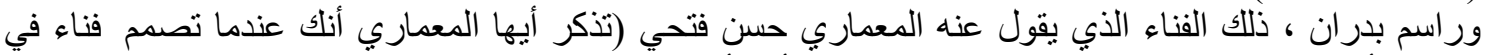

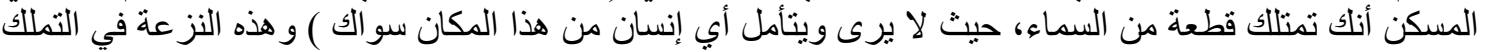

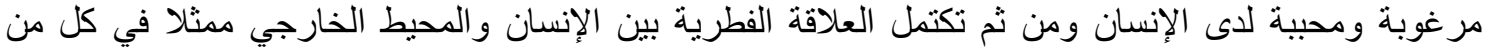

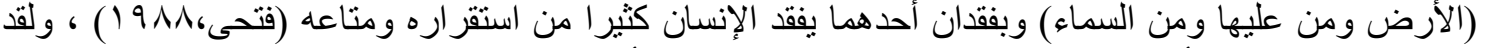

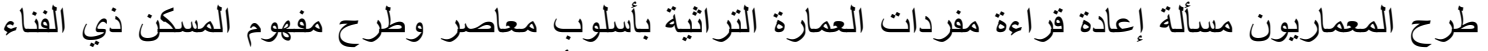

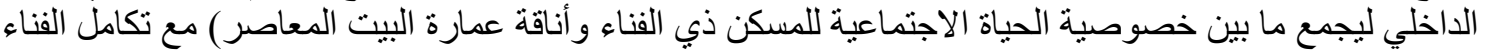

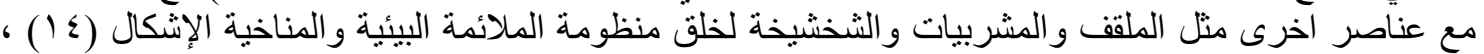

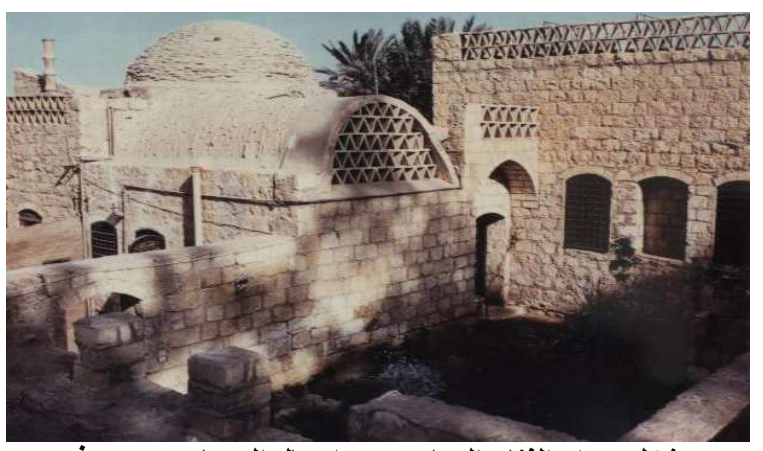

$(17)$ ، (10)

شكل (10) الفناء المعاصر من اعمال المعماري حسن فتحي.
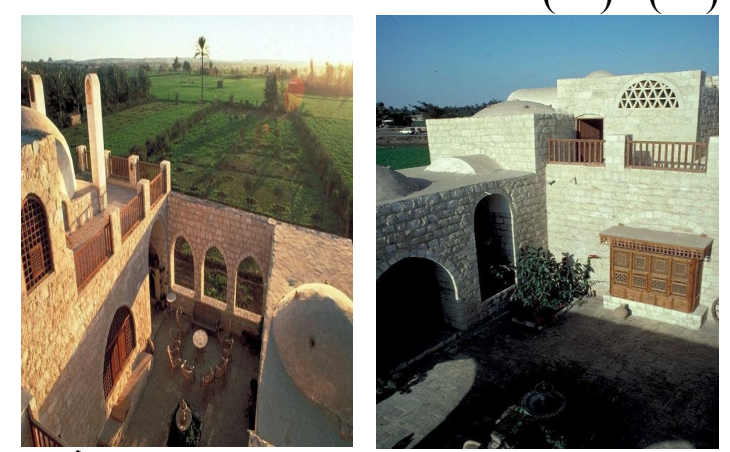

شكل (؛ ا ) الفناء المعاصر من اعمال المعماري حسن فتحي.

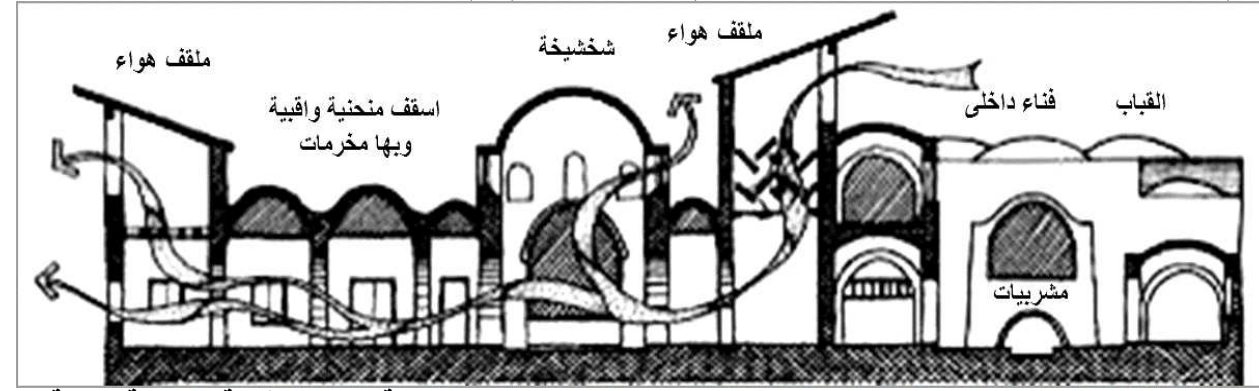

شكل (1 1 ) تكامل الفناء مع عناصر اخرى مثل الملقف والمشربيات والثخشيخة لخلق منظومة الملائمة البيئية.

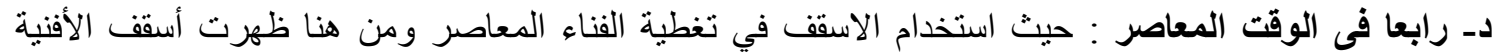

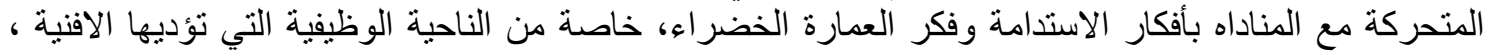

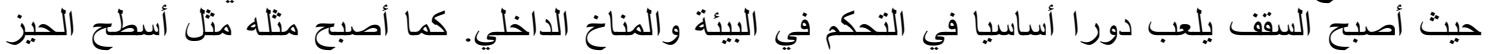

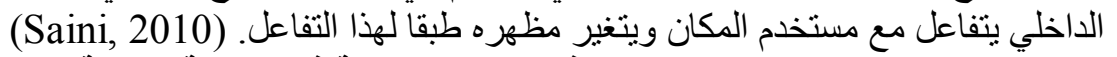

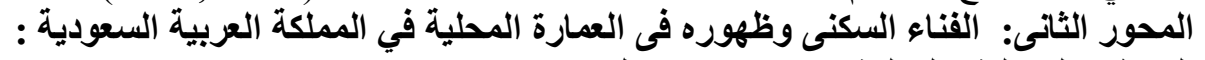

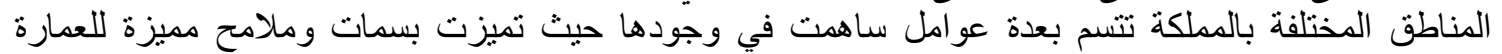

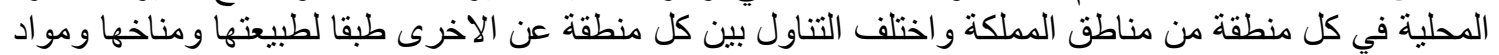
بنائها كالتالى : 
THE INNER COURTYARD AND ITS ROLE IN ACTIVATING THE SUSTAINABLE DIMENSION OF RESIDENTIAL BUILDINGS IN HOT REGIONS

ب/ المنطقة الثمالية (المناخ الحار الجاف): بمتاز طراز و هوية التراث المعماري في المنطقة الثمالية بإستخدام

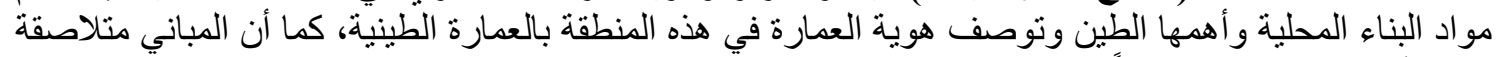

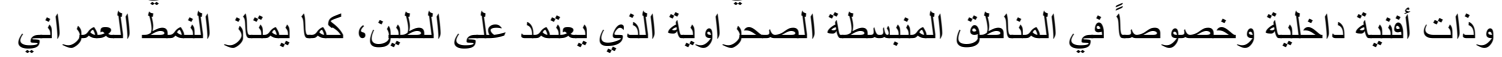

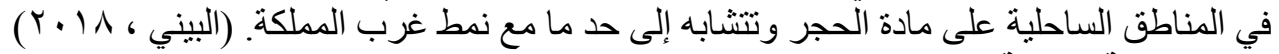

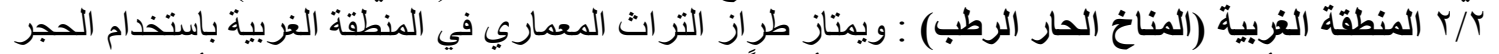

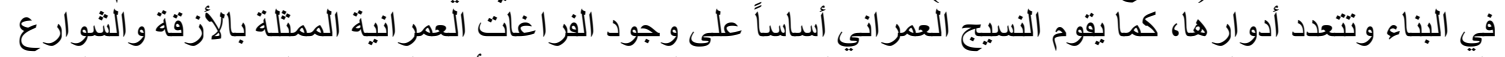

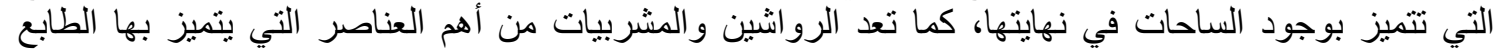

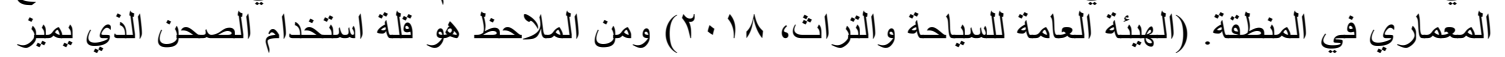

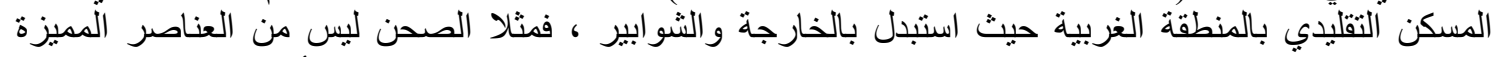

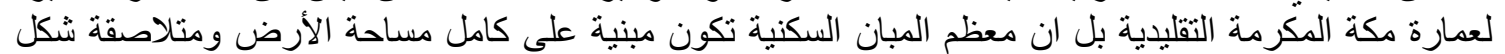

(IV)

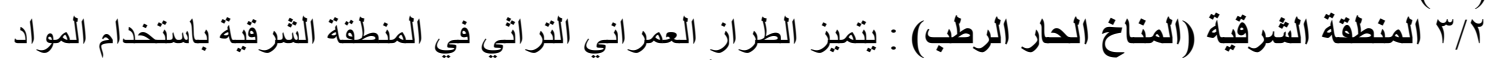

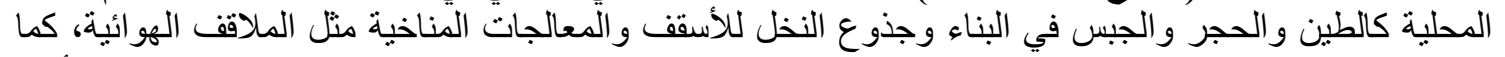

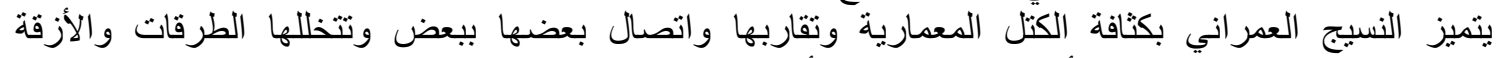

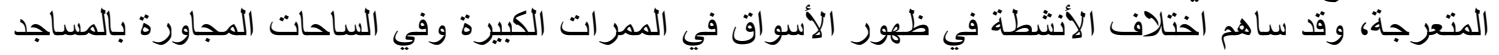

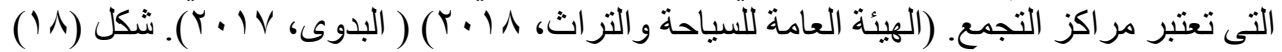
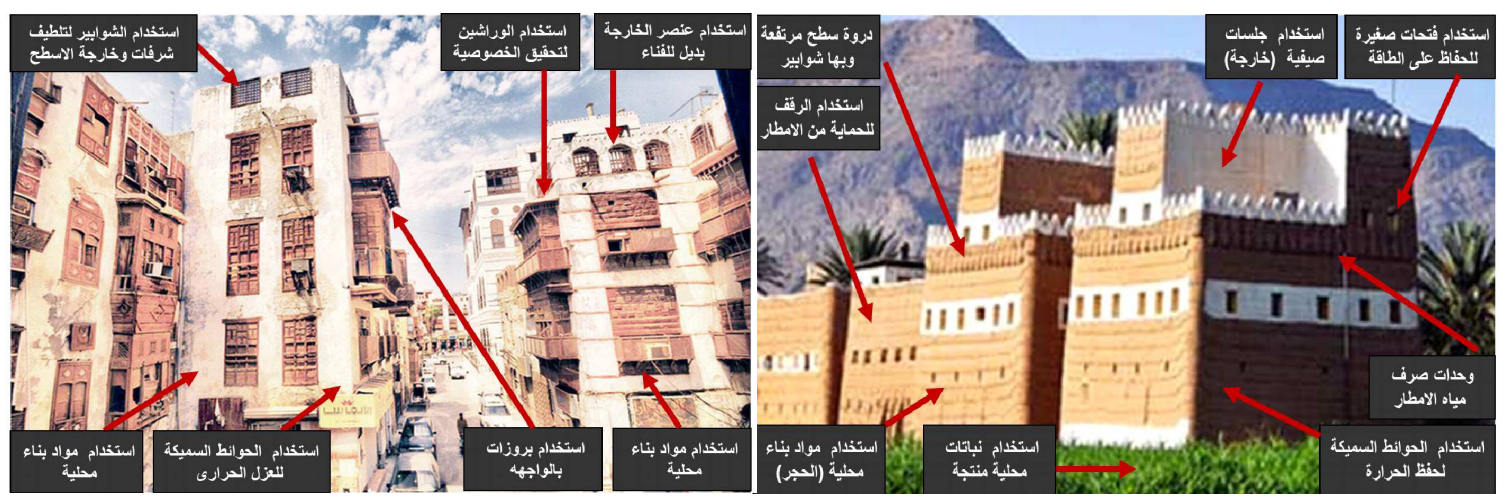

شكل (^ا1) ملامح المناطق الحار الممطرة (الجنوبية الثرقية)

شكل (V V ا ملامح المناطق الحارة الساحلية (المنطقة الغربية)

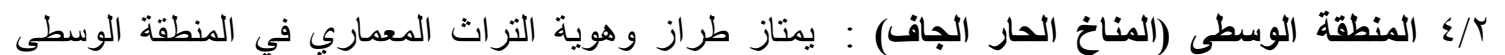

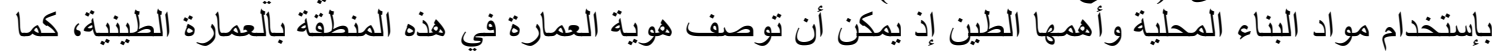

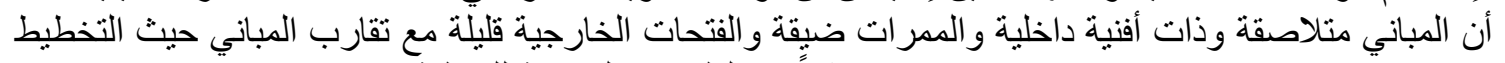

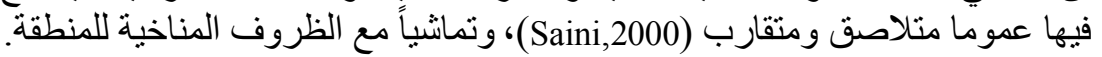

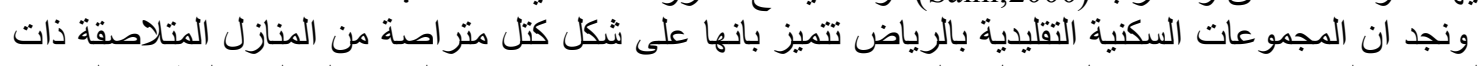

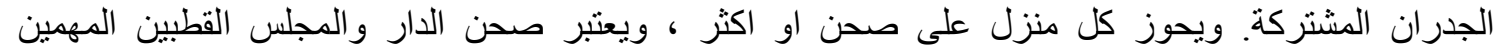

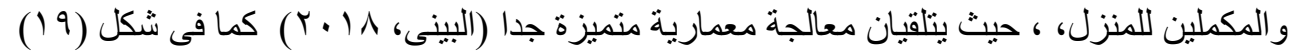

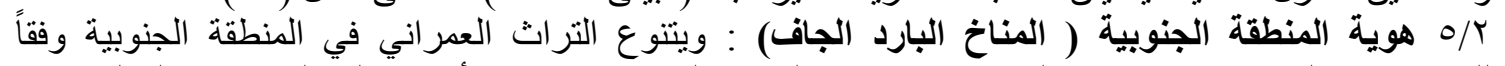

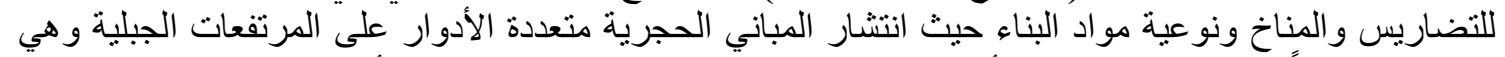

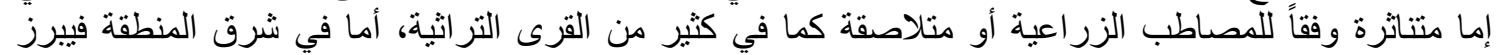

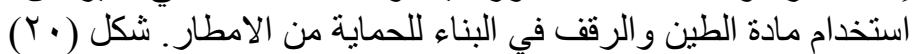




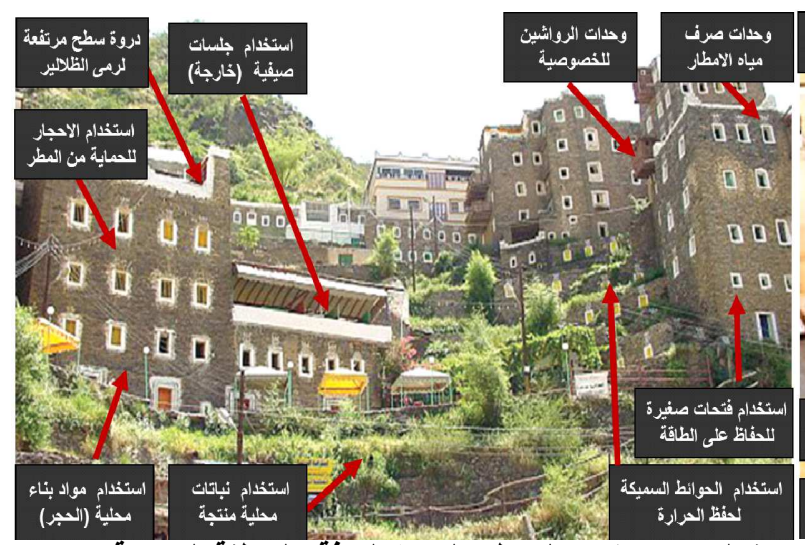

شكل (·r) ملامح المناطق الباردة الجافة (المنطقة الجنوبية)

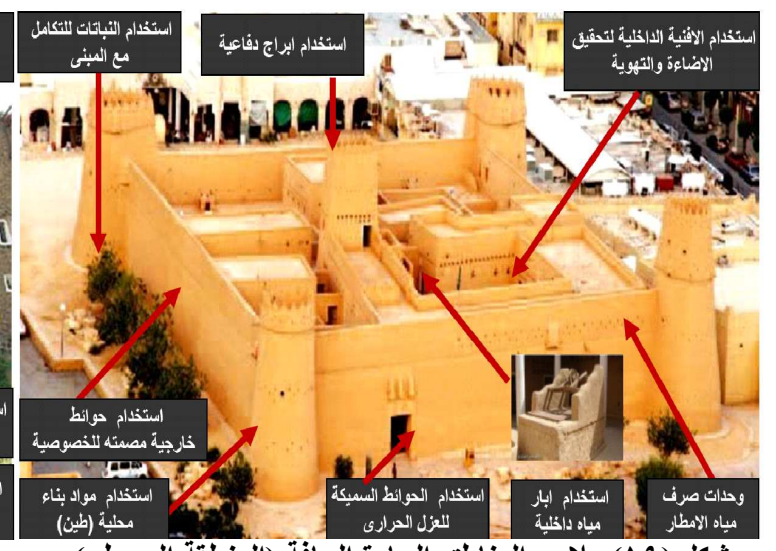

شكل (9 1) ملامح المناطق الحارة الجافة (المنظقة الوسطى)

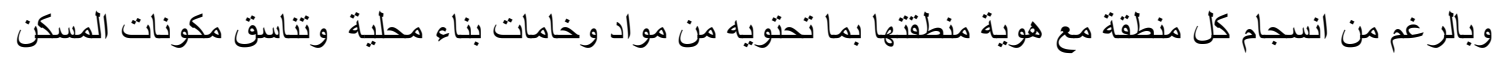

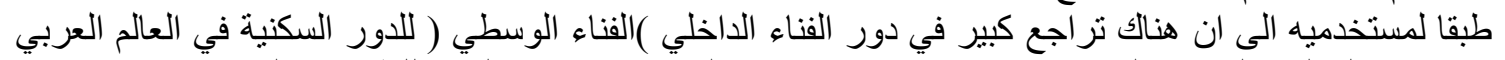

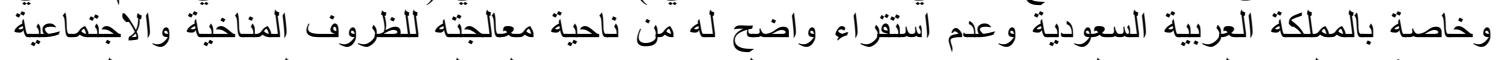

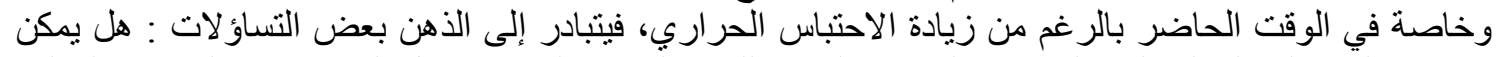

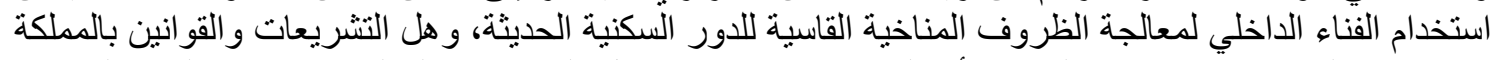

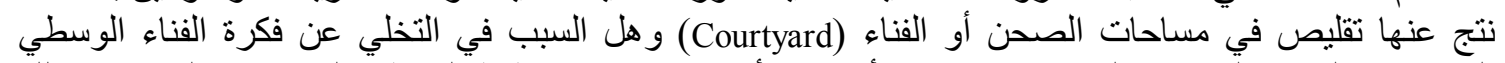

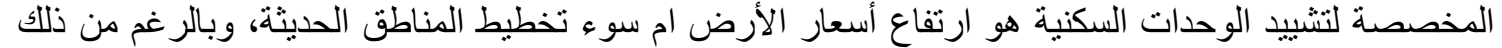

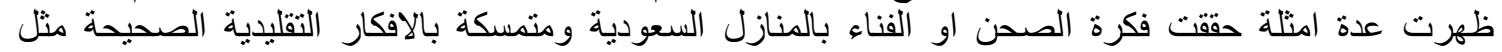

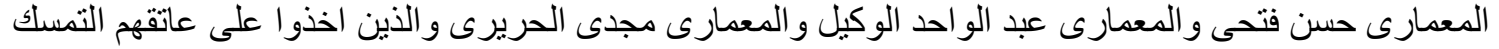

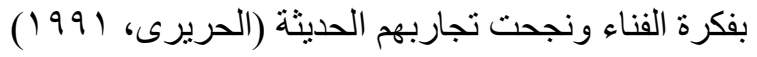

آ T/ منزل د/عبد الرحمن نصيف - جدة المملكة العربية السعودية.

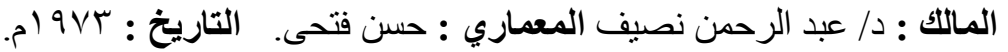

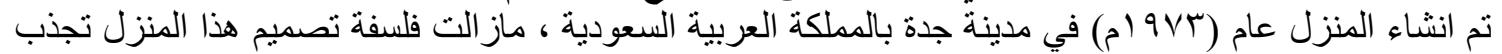

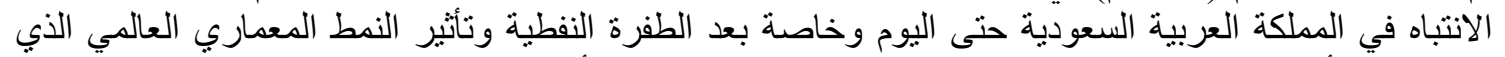

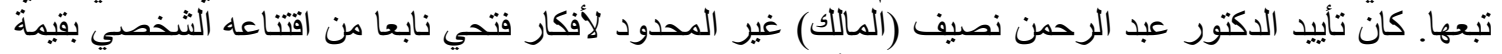

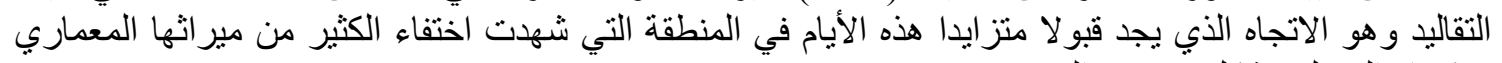
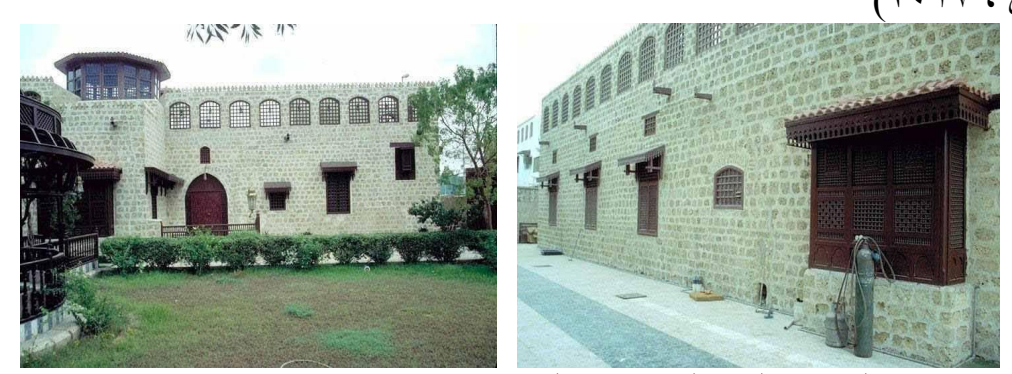

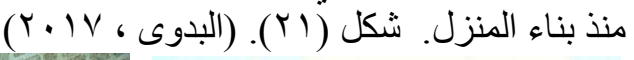

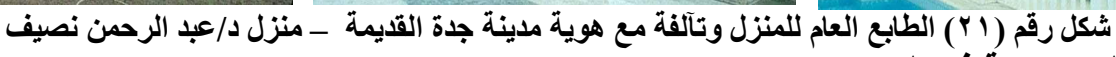

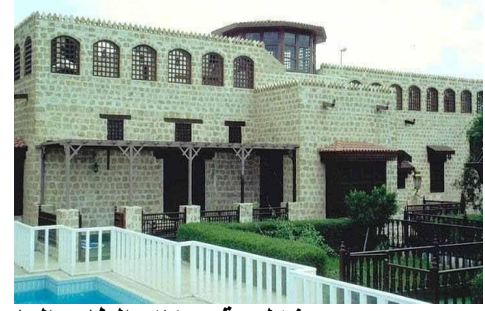

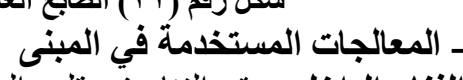

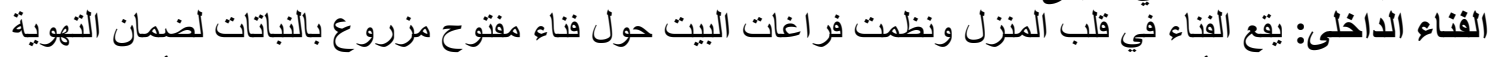

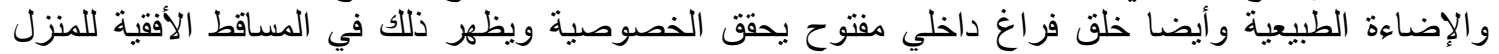

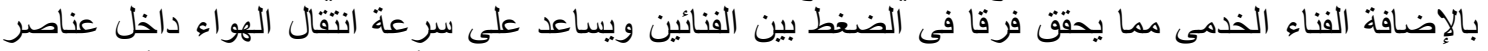

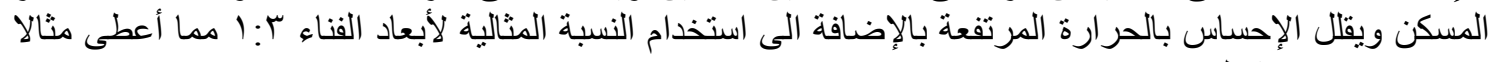
جيدا يحتذى باه ، شكل رقم (Y) (Y) 

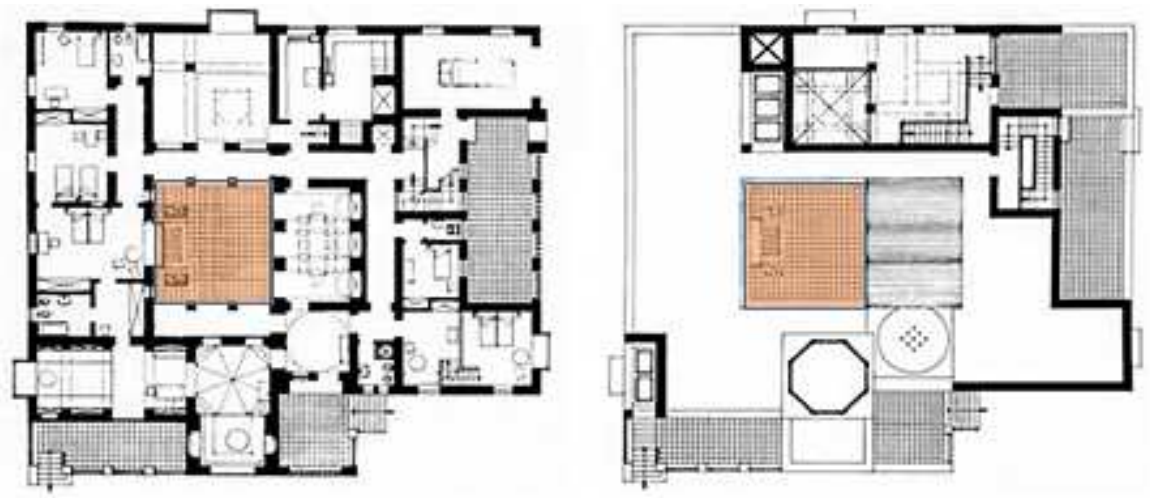

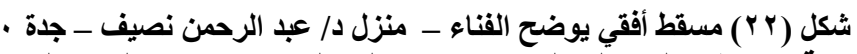

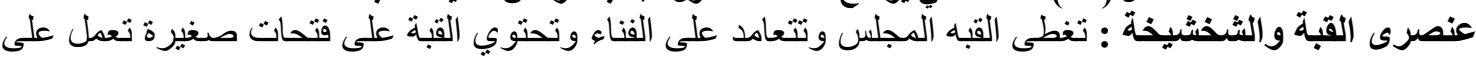

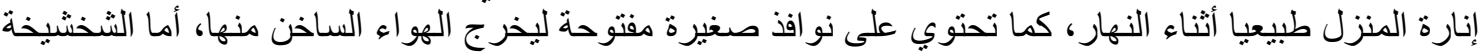

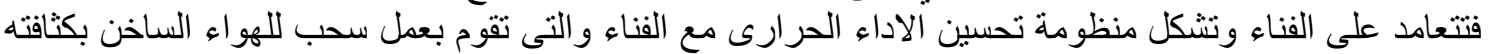

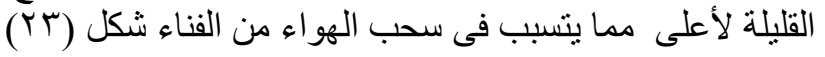
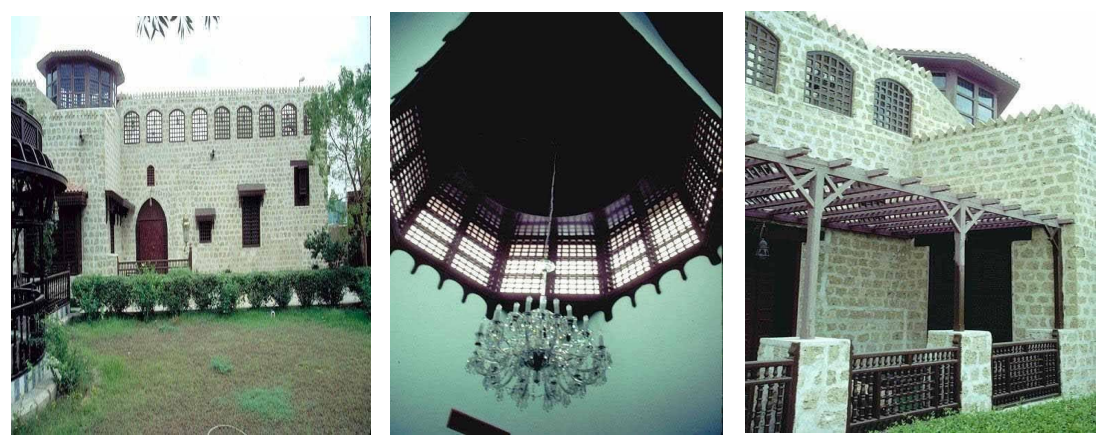

شكل رقم (YrT) الشخشيخة الرئيسية بمنزل داعبد الرحمن نصيف.

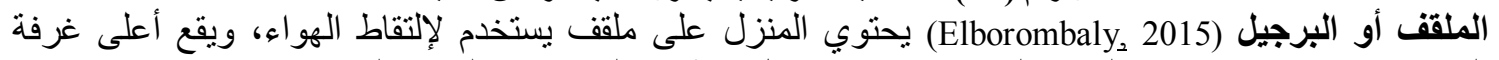
الضيوف، ويتم توجيهه نحو الرياح البارده نو عا ما ويكمل منظومة التهوية التهوية مع الفناء و الثخشيخة.

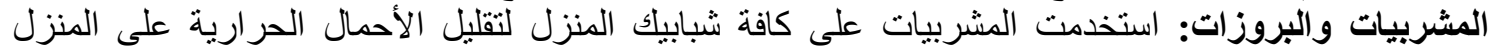
وتنو عت إثكال المشربيات والفتحات لتتناسب مع توجيه المبنى وخاصة التفاعل مع هوية جدة التى تتميز بإنتشار

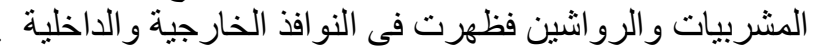

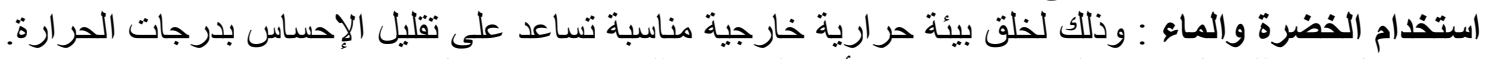

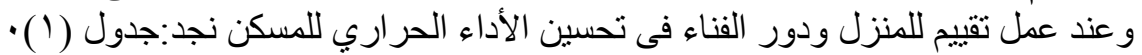


THE INNER COURTYARD AND ITS ROLE IN ACTIVATING THE SUSTAINABLE DIMENSION OF RESIDENTIAL BUILDINGS IN HOT REGIONS

جدول ( 1 ) تقييم لمنزل د/ عبد الرحمن نصيف ـ للمعمارى حسن فتحى - جدة ـ المملكة العربية السعودية.

\begin{tabular}{|c|c|c|c|c|c|c|c|c|c|}
\hline \multirow{2}{*}{\multicolumn{5}{|c|}{$\begin{array}{l}\text { Location: Jeddah - KSA } 1973 \\
\text { Project : Abdrahman Hasief house }\end{array}$}} & & \multirow{2}{*}{\multicolumn{3}{|c|}{ 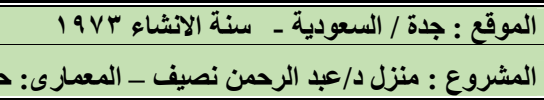 }} & \multirow{3}{*}{1} \\
\hline & & & & & \multirow{2}{*}{\multicolumn{4}{|c|}{ 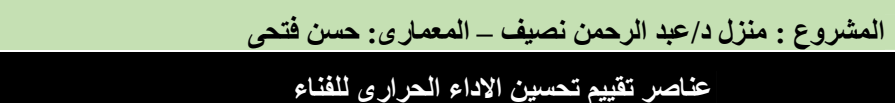 }} & \\
\hline 。 & $\varepsilon$ & $r$ & r & 1 & & & & & \\
\hline$(0)$ & $\mathrm{O}$ & $\mathrm{O}$ & $\mathrm{O}$ & $\mathrm{O}$ & \multicolumn{3}{|c|}{ توجيه المبنى والفناء } & 1 & \multirow{30}{*}{$E$} \\
\hline (0) & $\mathrm{O}$ & $\mathrm{O}$ & $\mathrm{O}$ & $\mathrm{O}$ & \multicolumn{3}{|c|}{ تثثكيل كتلة المبنى و علاقتة بالقناء } & r & \\
\hline & & & & & \multicolumn{3}{|c|}{ | تصميم الغلاف الخارجى للفناء } & $r$ & \\
\hline (o) & $\mathrm{O}$ & $\mathrm{O}$ & $\mathrm{O}$ & $\mathrm{O}$ & منحنى أو مزدوج & \multirow{3}{*}{ السقف المبنى } & \multirow{3}{*}{$1 / \pi$} & \multirow{12}{*}{ الخلافيم } & \\
\hline (0) & $\mathrm{O}$ & $\mathrm{O}$ & $\mathrm{O}$ & $\mathrm{O}$ & الخامة عازله & & & & \\
\hline $\mathrm{O}$ & $\mathrm{O}$ & $\mathrm{O}$ & $\mathrm{O}$ & $\mathrm{O}$ & سقف مزروع & & & & \\
\hline$(0)$ & $\mathrm{O}$ & $\mathrm{O}$ & $\mathrm{O}$ & $\mathrm{O}$ & مزدوجة او سميكة & \multirow{3}{*}{ حوائط الفناء } & \multirow{3}{*}{$r / r$} & & \\
\hline$(0)$ & $\mathrm{O}$ & $\mathrm{O}$ & $\mathrm{O}$ & $\mathrm{O}$ & الوان عاكسة & & & & \\
\hline$\left({ }^{\circ}\right)$ & $\mathrm{O}$ & $\mathrm{O}$ & $\mathrm{O}$ & $\mathrm{O}$ & خامات عازلة & & & & \\
\hline$(0)$ & $\mathrm{O}$ & $\mathrm{O}$ & $\mathrm{O}$ & $\mathrm{O}$ & تصميمها مناسب & \multirow{6}{*}{ الفتحات المطله على } & \multirow{6}{*}{$r / r$} & & \\
\hline $\mathrm{O}$ & $(\varepsilon)$ & $\mathrm{O}$ & $\mathrm{O}$ & $\mathrm{O}$ & توجيهها صحيح & & & & \\
\hline$(0)$ & $\mathrm{O}$ & $\mathrm{O}$ & $\mathrm{O}$ & $\mathrm{O}$ & مساحتها تناسب توجيهها & & & & \\
\hline$(0)$ & $\mathrm{O}$ & $\mathrm{O}$ & $\mathrm{O}$ & $\mathrm{O}$ & التظليل كافى & & & & \\
\hline $\mathrm{O}$ & $(\varepsilon)$ & $\mathrm{O}$ & $\mathrm{O}$ & $\mathrm{O}$ & الزجاج عازل & & & & \\
\hline$(0)$ & $\mathrm{O}$ & $\mathrm{O}$ & $\mathrm{O}$ & $\mathrm{O}$ & الكاسرات تحقق التظليل & & & & \\
\hline (o) & $\mathrm{O}$ & $\mathrm{O}$ & $\mathrm{O}$ & $\mathrm{O}$ & \multicolumn{3}{|c|}{ | البروزات والمشربيات على الفناء } & $\varepsilon$ & \\
\hline$(0)$ & $\mathrm{O}$ & $\mathrm{O}$ & $\mathrm{O}$ & $\mathrm{O}$ & \multicolumn{3}{|c|}{ الثخشيخة /المدخنة وتحقيقها لمنظومة التهوية } & • & \\
\hline$(0)$ & $\mathrm{O}$ & $\mathrm{O}$ & $\mathrm{O}$ & $\mathrm{O}$ & \multicolumn{3}{|c|}{ |الملاقف وضمان استمرارية حركة الهواء } & 9 & \\
\hline $\mathrm{O}$ & $\mathrm{O}$ & $\mathrm{O}$ & $\mathrm{O}$ & $\mathrm{O}$ & \multicolumn{3}{|c|}{ |اساليب الاستدامة والطاقة المتجددة } & $v$ & \\
\hline$(0)$ & $\mathrm{O}$ & $\mathrm{O}$ & $\mathrm{O}$ & $\mathrm{O}$ & \multicolumn{3}{|c|}{ | الخضرة والمياه وتتاسقهم داخل الفناء } & $\wedge$ & \\
\hline \multicolumn{5}{|c|}{ استخدام نوع واحد فقط } & \multicolumn{3}{|c|}{ نوع الفناء } & \multirow{4}{*}{9} & \\
\hline $\mathrm{O}$ & $\mathrm{O}$ & $\mathrm{O}$ & $\mathrm{O}$ & $\mathrm{O}$ & & | الفناء البارد & $1 / 9$ & & \\
\hline $\mathrm{O}$ & $\mathrm{O}$ & $\mathrm{O}$ & $\mathrm{O}$ & $\mathrm{O}$ & & | القناء السلخن & $r / 9$ & & \\
\hline$(0)$ & $\mathrm{O}$ & $\mathrm{O}$ & $\mathrm{O}$ & $\mathrm{O}$ & & |ستخدام فنائين & $r / 9$ & & \\
\hline $\mathrm{O}$ & $(\xi)$ & $\mathrm{O}$ & $\mathrm{O}$ & $\mathrm{O}$ & \multicolumn{3}{|c|}{ تظليل الفناء (مدى تحقيق نسبة التظليل اليومى) } & 1. & \\
\hline & & & & & \multicolumn{3}{|c|}{ | هندسة الفناء } & \multirow{5}{*}{11} & \\
\hline (o) & $\mathrm{O}$ & $\mathrm{O}$ & $\mathrm{O}$ & $\mathrm{O}$ & & عمق الفناء مناسب لأبعاد & $1 / 11$ & & \\
\hline$(0)$ & $\mathrm{O}$ & $\mathrm{O}$ & $\mathrm{O}$ & $\mathrm{O}$ & & | استطالة الفناء بالنسبة للا & $r / 11$ & & \\
\hline (0) & $\mathrm{O}$ & $\mathrm{O}$ & $\mathrm{O}$ & $\mathrm{O}$ & 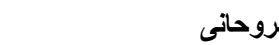 & الانفتاح على السماء والج & $r / 1$ & & \\
\hline$(0)$ & $\mathrm{O}$ & $\mathrm{O}$ & $\mathrm{O}$ & $\mathrm{O}$ & 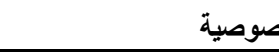 & مدى تحقيق احتواء الفناء & $\varepsilon / 1$ & & \\
\hline \multicolumn{5}{|c|}{ \% \% } & & لجمالى من هץ * • = & & & \\
\hline
\end{tabular}

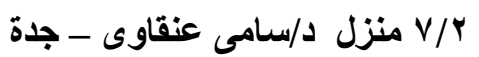

الموقع : جدة - المملكة العربية السعودية

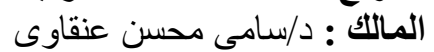

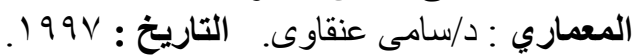
التعريف بالمبنى : 
THE INNER COURTYARD AND ITS ROLE IN ACTIVATING THE SUSTAINABLE DIMENSION OF RESIDENTIAL BUILDINGS IN HOT REGIONS

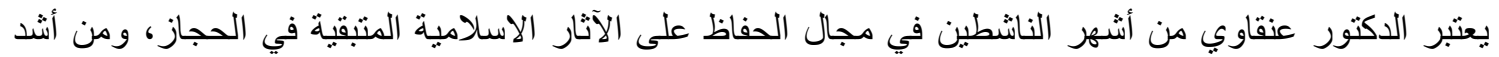

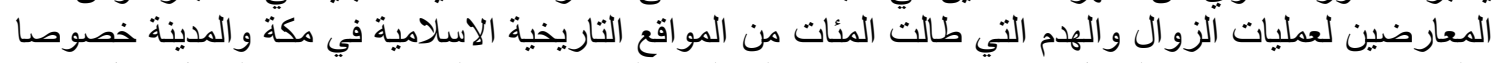

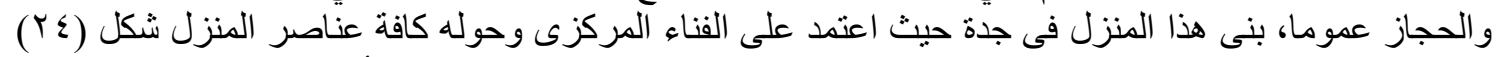

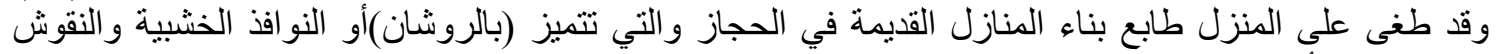

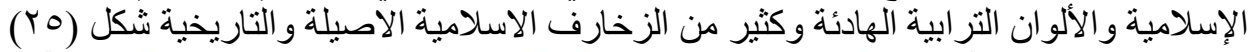

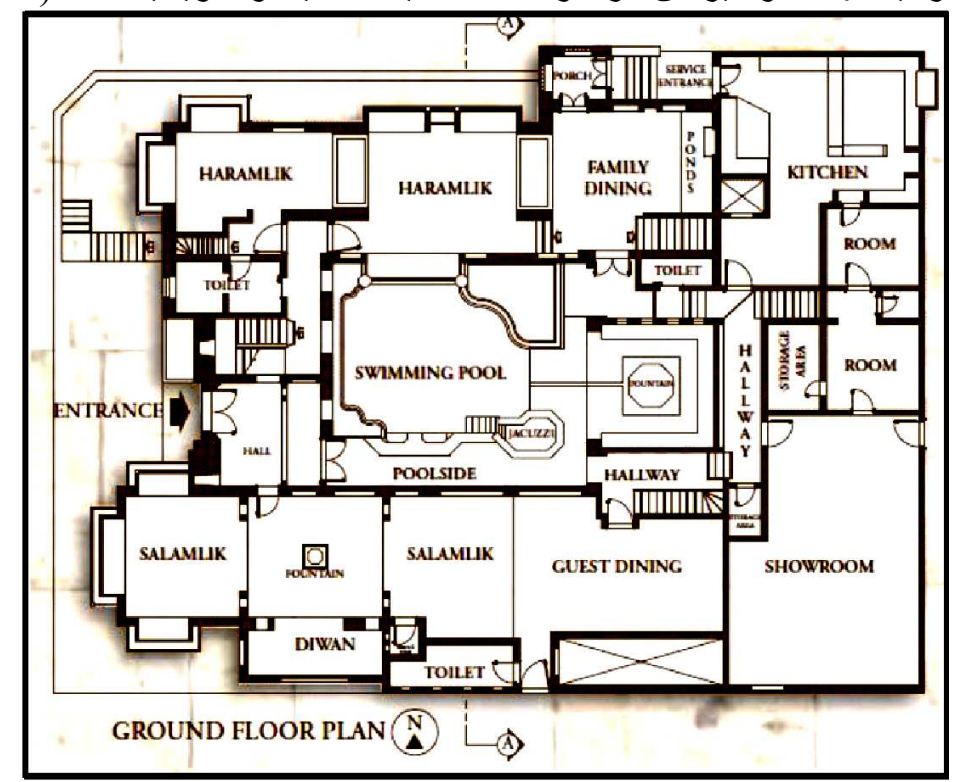

شكل ( ؟ ץ) المسقط الافقى لمنزل د/ سامى عنقاوى ويظهر به التفاف مكونات المسكن حول الفناء الداخلى.
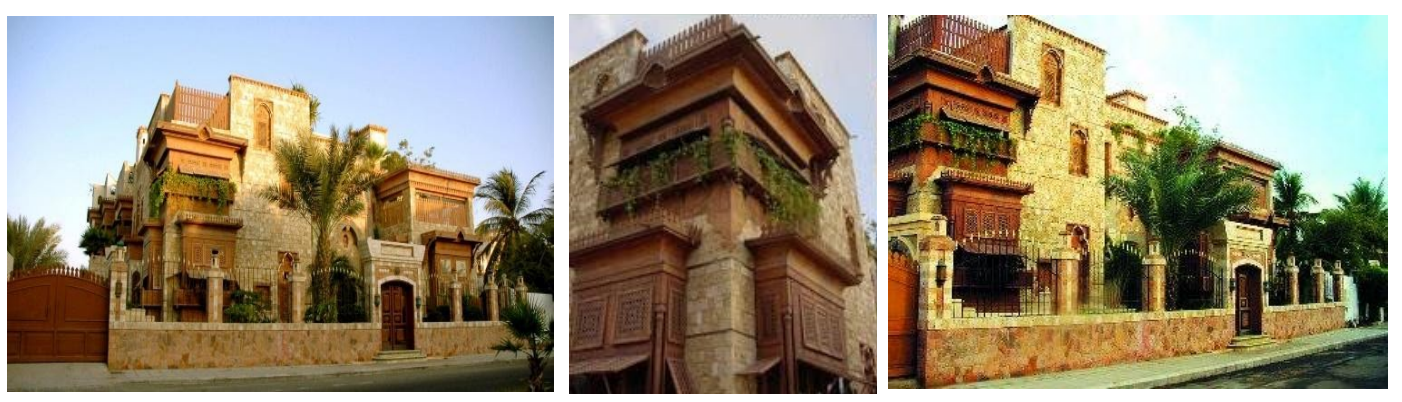

شكل (0) المسقط الافقى لمنزل د/ سامى عنقاوى ويظهر به التفاف مكونات المسكن حول الفناء الداخلى.

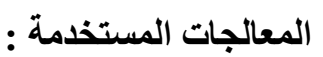

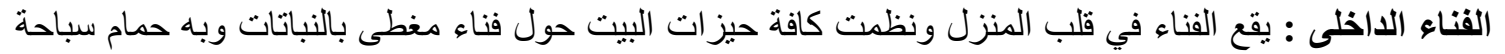

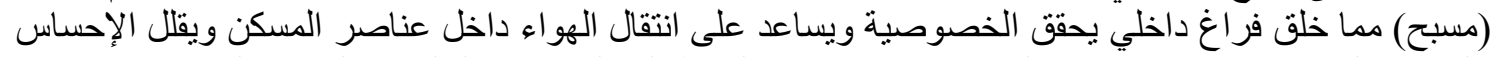

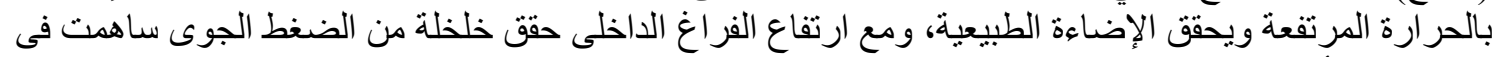

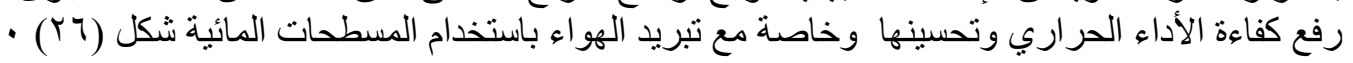

عنصر القبة : وتحتوي القبة على فتحات جانبية تعمل على إنارة المنزل طبيعيا اثناء النهار ، كما تحتوي على نو افذ الذهاء

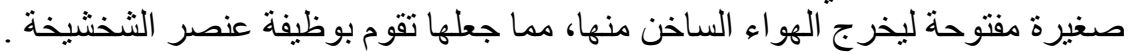

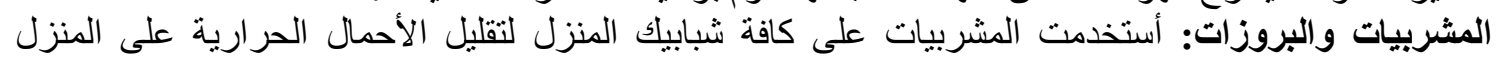

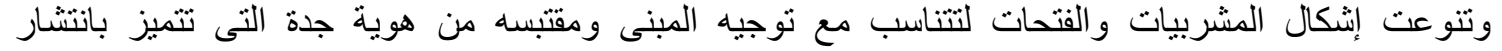

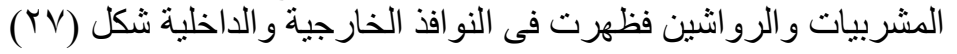


THE INNER COURTYARD AND ITS ROLE IN ACTIVATING THE SUSTAINABLE DIMENSION OF RESIDENTIAL BUILDINGS IN HOT REGIONS
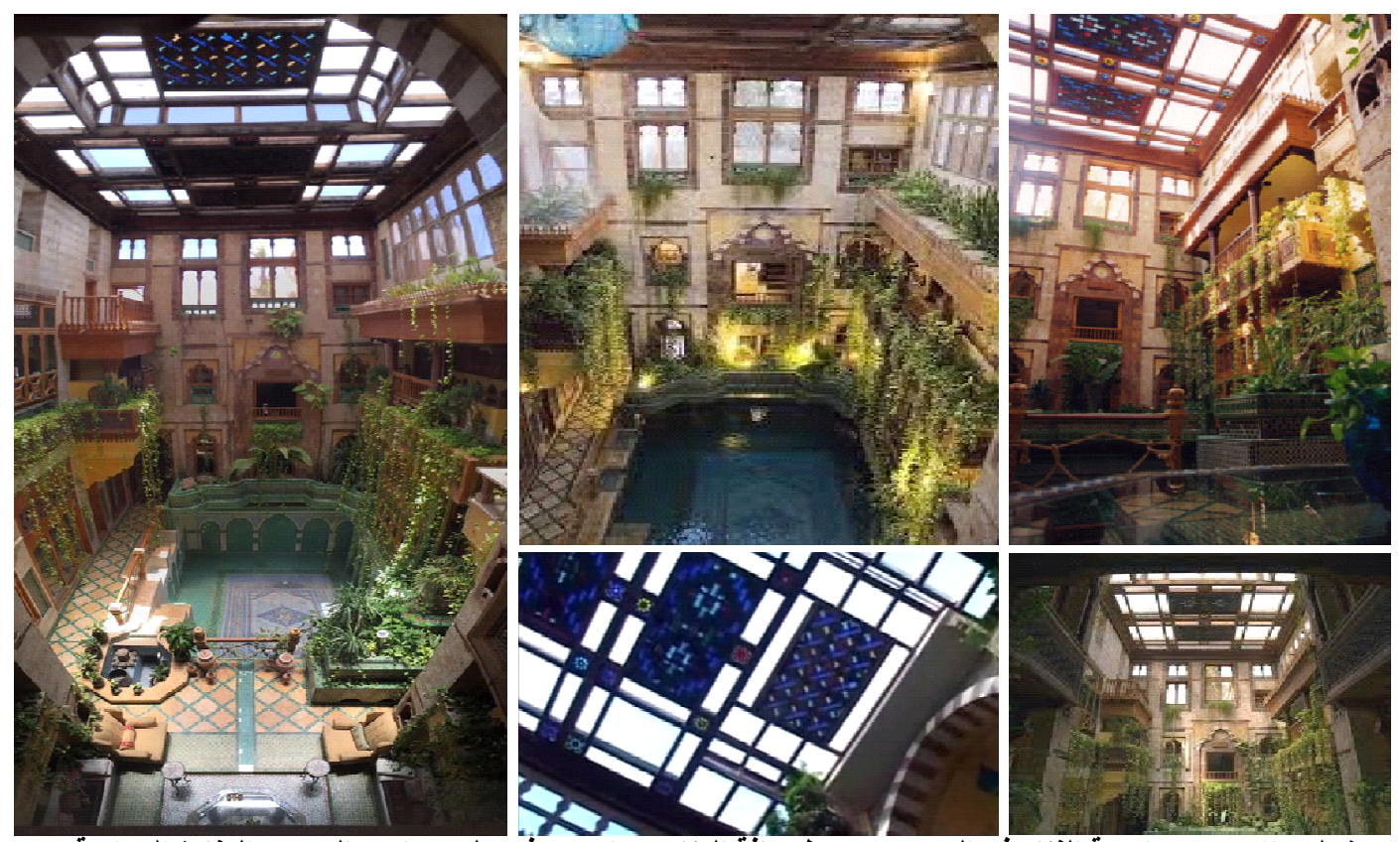

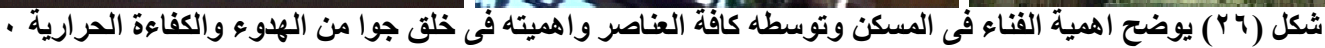

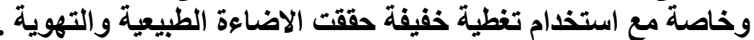

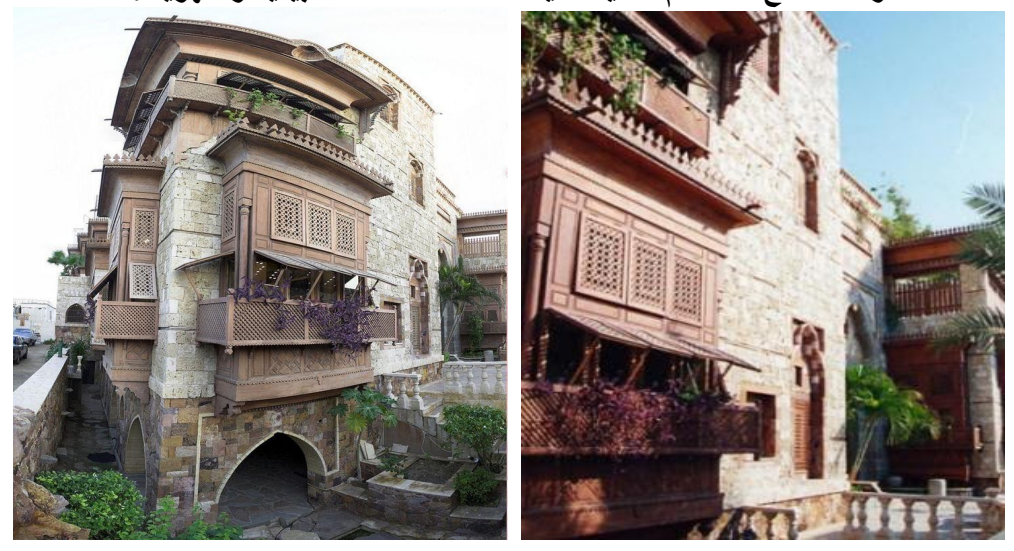

شكل (YV) مزج الهوية المعمارية مع المعالجات البيئية باستخدام الخامات المحلية والرواشين والمشربيات.

استخدام الخضرة والماء : تم استخدام المسطحات الخضر اء والمسطحات المائية وذلك لخلق بيئة حر ارية داخلية

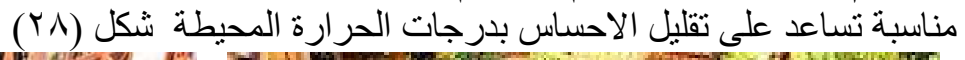
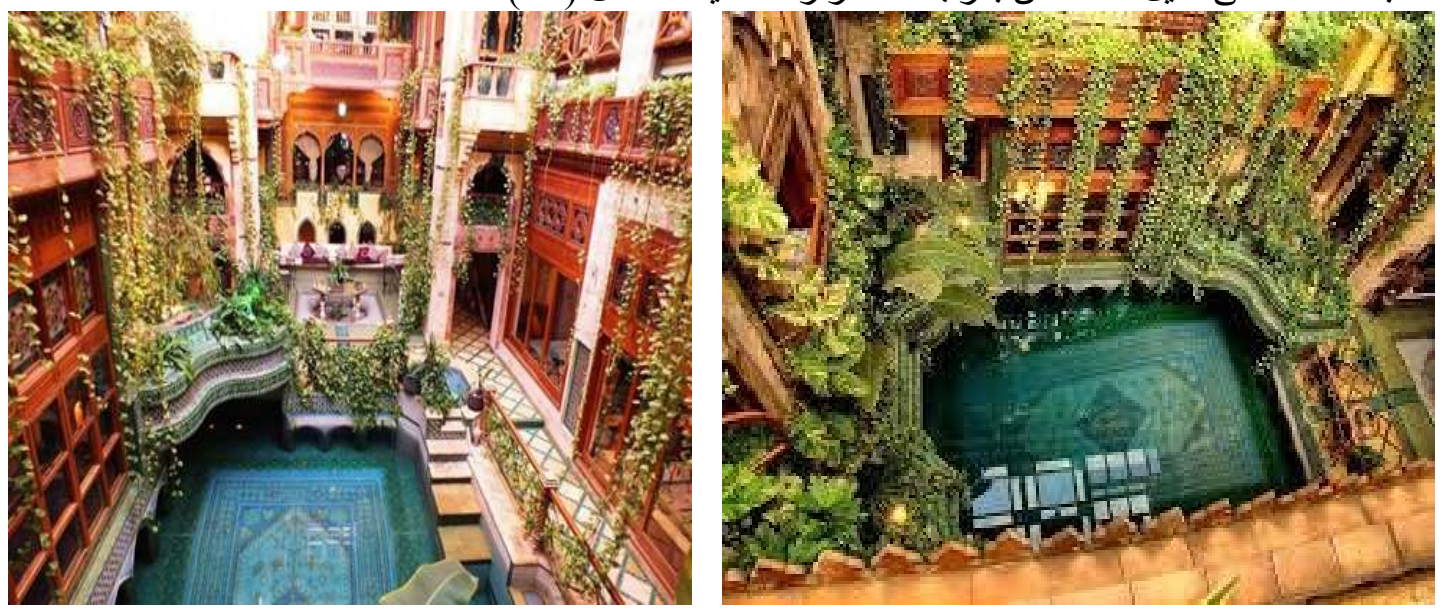

شكل (Y^) امتزاج الخضرة والماء داخل المنزل مما خلق بيئة حرارية داخلية مناسبة. 
THE INNER COURTYARD AND ITS ROLE IN ACTIVATING THE SUSTAINABLE DIMENSION OF RESIDENTIAL BUILDINGS IN HOT REGIONS

\section{جدول (ז) تقييم لمنزل د/ سامى العنقاوى ـ للمعمارى سامى العنقاوى - جدة ـ المملكة العربية السعودية.}

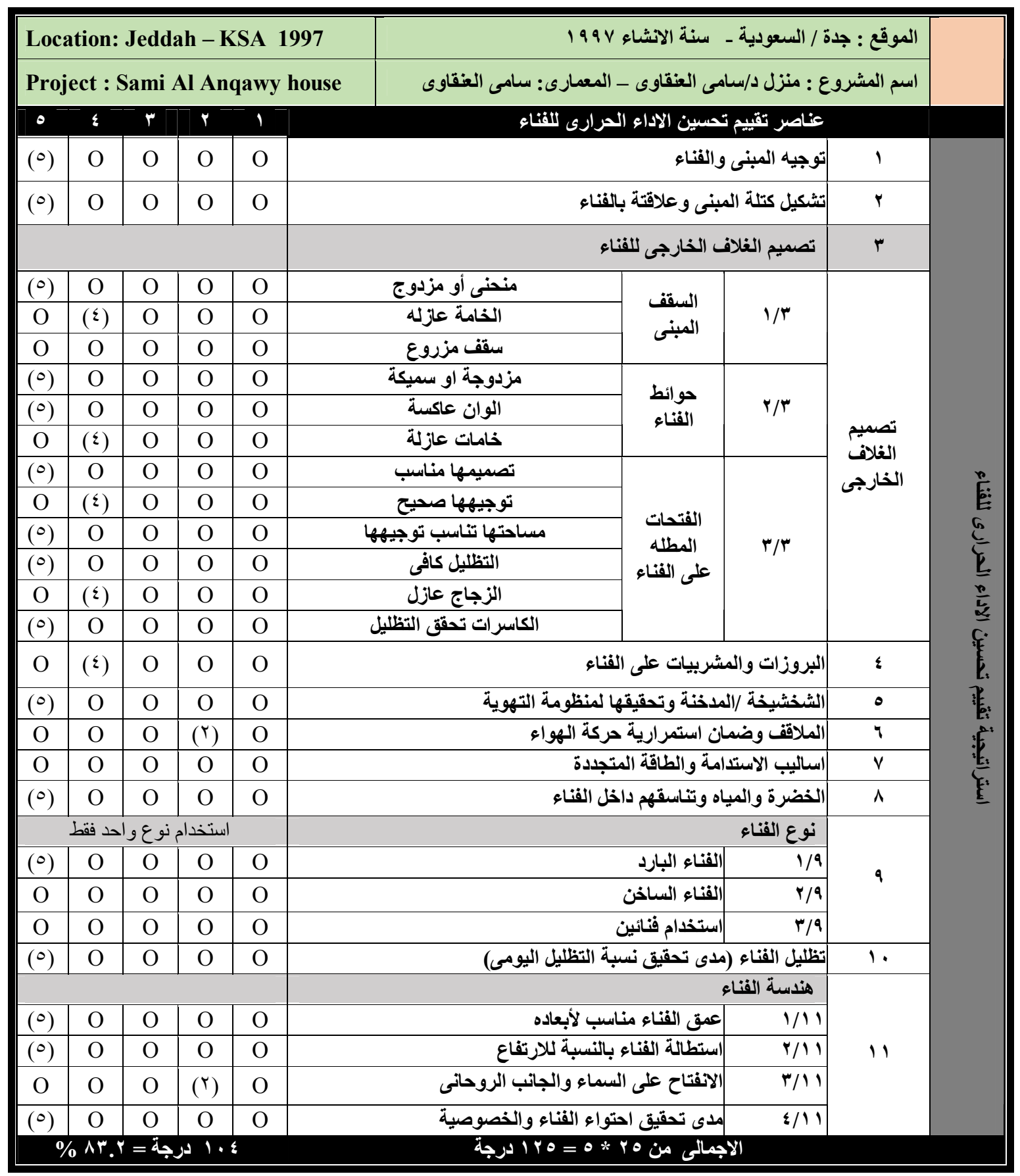

المحور الثالث : الفناء الداخلى فى مدينة مكة المكرمة :

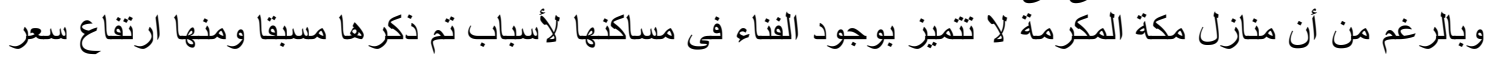

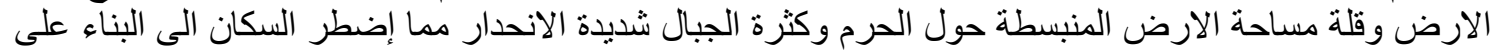

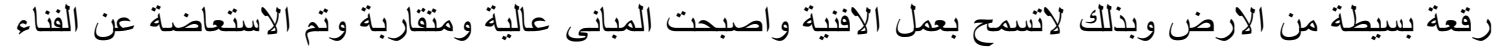

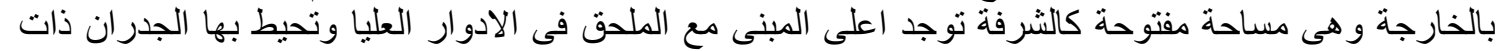

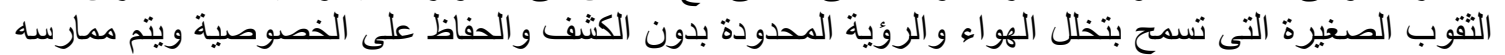

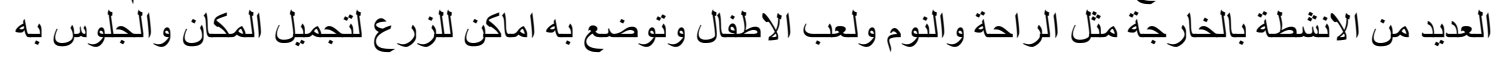


THE INNER COURTYARD AND ITS ROLE IN ACTIVATING THE SUSTAINABLE DIMENSION OF RESIDENTIAL BUILDINGS IN HOT REGIONS

عند اعتدال الطقس كذلك فإن الخارجة هى مكان جيد لممارسة المرأة نشاطها بحرية تامة خاصة مع ارتفاع دروة السطح. (Angawi, 2016)

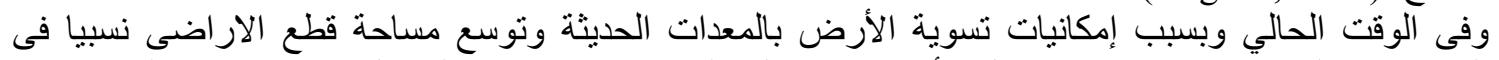

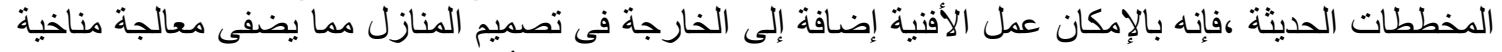

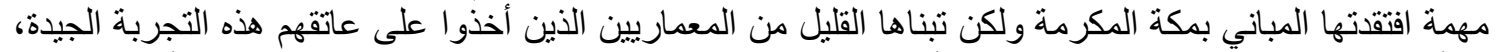

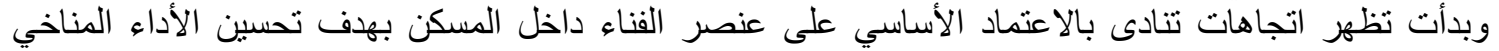

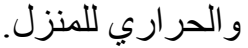

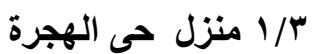
الموقع : مكة المكرمة المجرة المملكة العربية السعودية

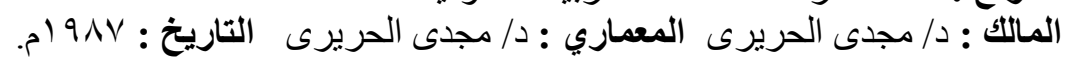

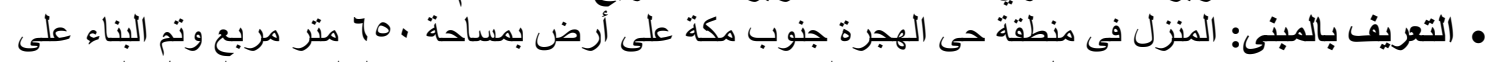

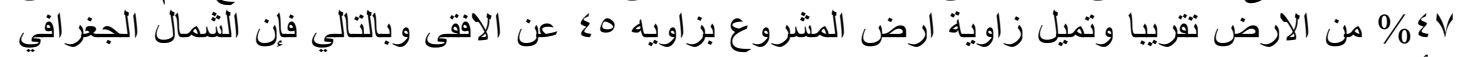

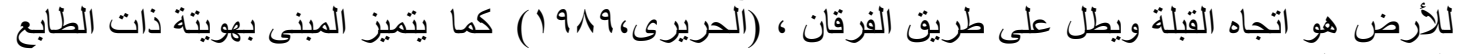

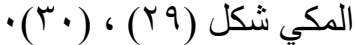

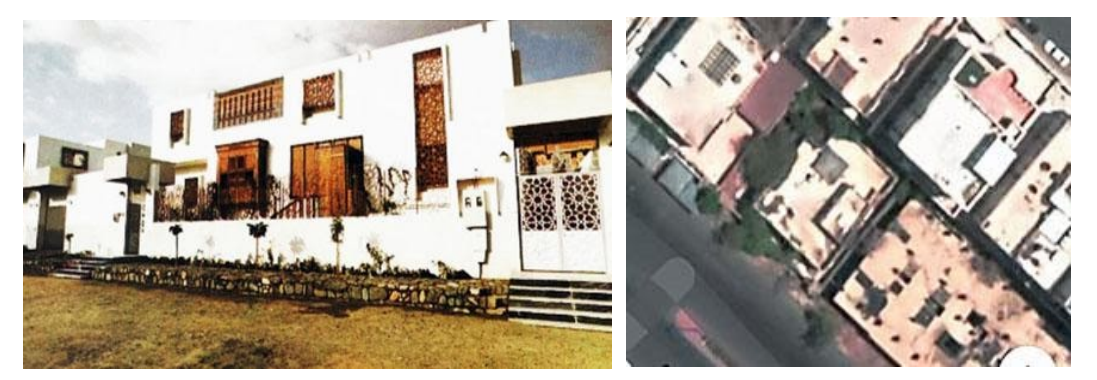

شكل (9 ؟) الموقع العام للمنزل والطابع العام للمنزل يحاكى منازل مكة المكرمة ـ د/مجدى الحريرى ـ مكة المكرمه.
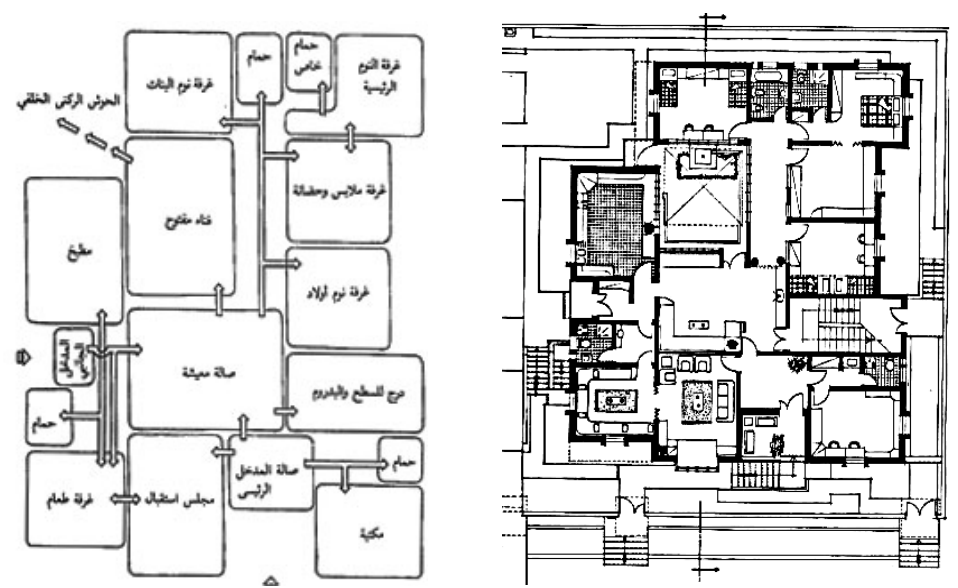

شكل (·r ) المساقط الأفقية لمنزل حى الهجرة بمكة المكرمة و إلتفاف عناصر المسكن على الفناء الاخلي.

الثبابيك والرواثنين المطله على الفناء الداخلى هى طبقة من الزجاج وطبقة من الخشب المتحرك بمغناطيس

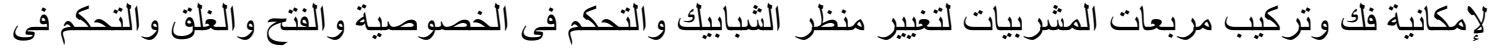

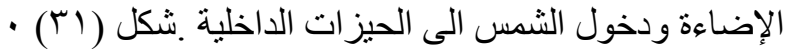


THE INNER COURTYARD AND ITS ROLE IN ACTIVATING THE SUSTAINABLE DIMENSION OF RESIDENTIAL BUILDINGS IN HOT REGIONS
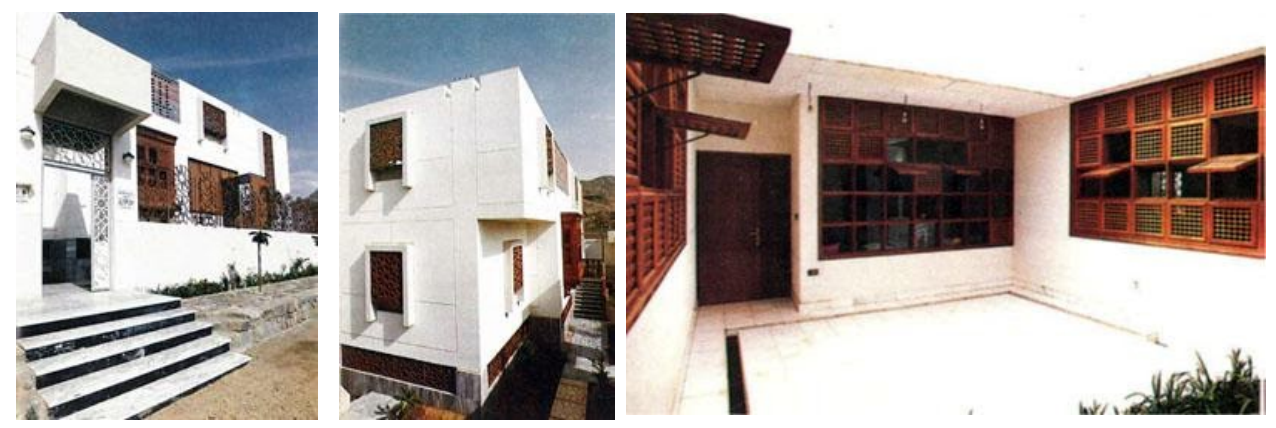

شكل ( آس) يوضح استخدام الزجاج والخشب المتحرك فى نوافة الرواشين بالقناء

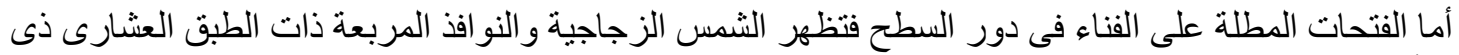

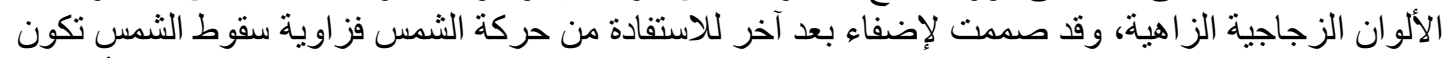

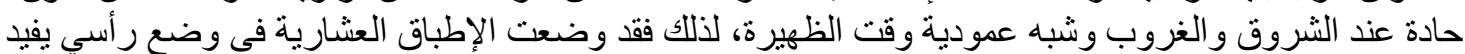

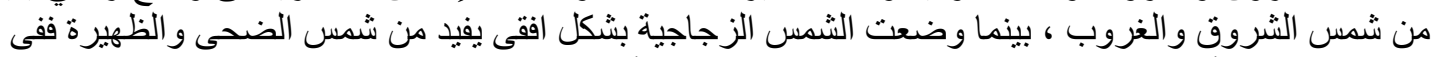

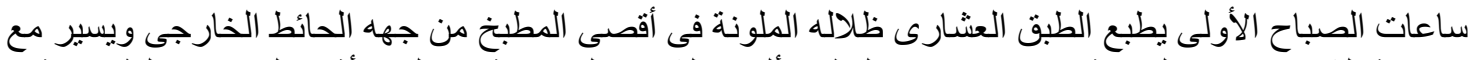

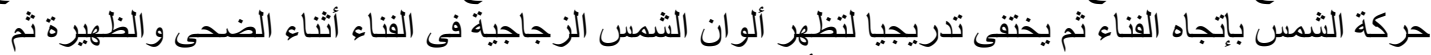

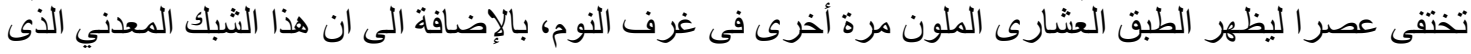

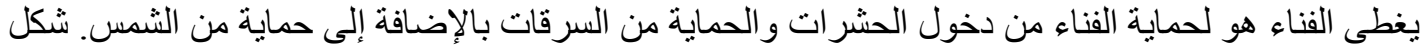

$(r r)$
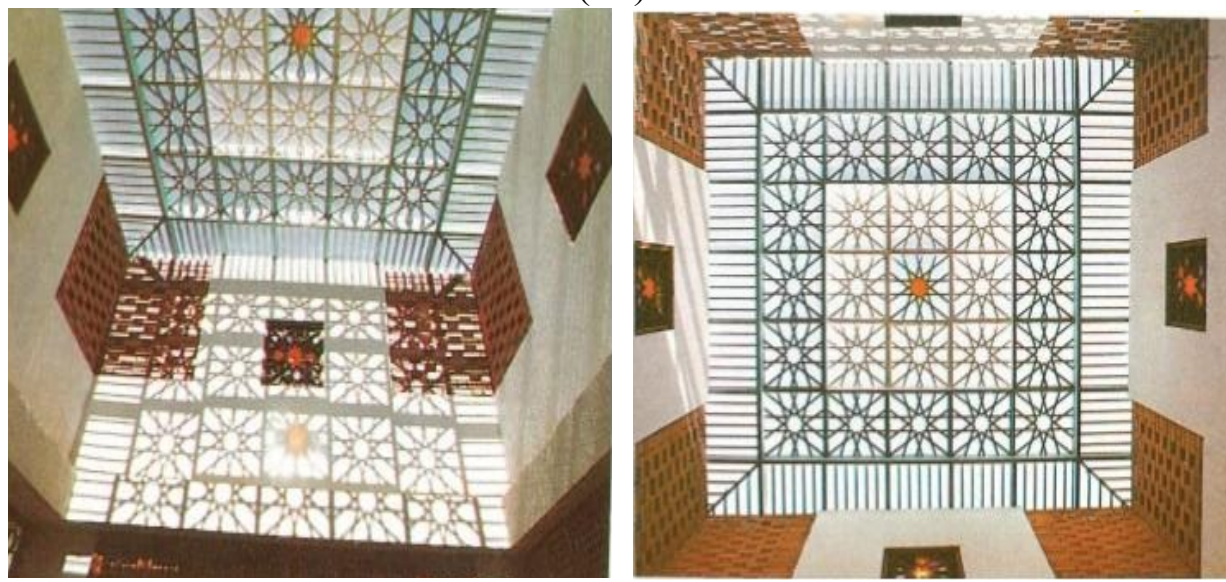

شكل (rr) يظهر تفطية الفناء بتثكيلات هندسية مثل الثكل العشارى والنجمة الثمسية التى تتحرك بظلالها . مما يحسن الأداء الجمالي والحراري للفناء.

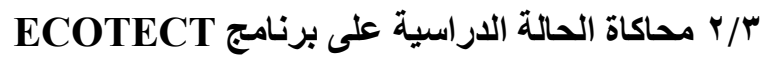
تم عمل نموذج مجسم ثلاثي الإبعاد يحاكى كتلة المبنى القائم ببرنامج ريفيت Revit شكل (سب) . 
THE INNER COURTYARD AND ITS ROLE IN ACTIVATING THE SUSTAINABLE DIMENSION OF RESIDENTIAL BUILDINGS IN HOT REGIONS
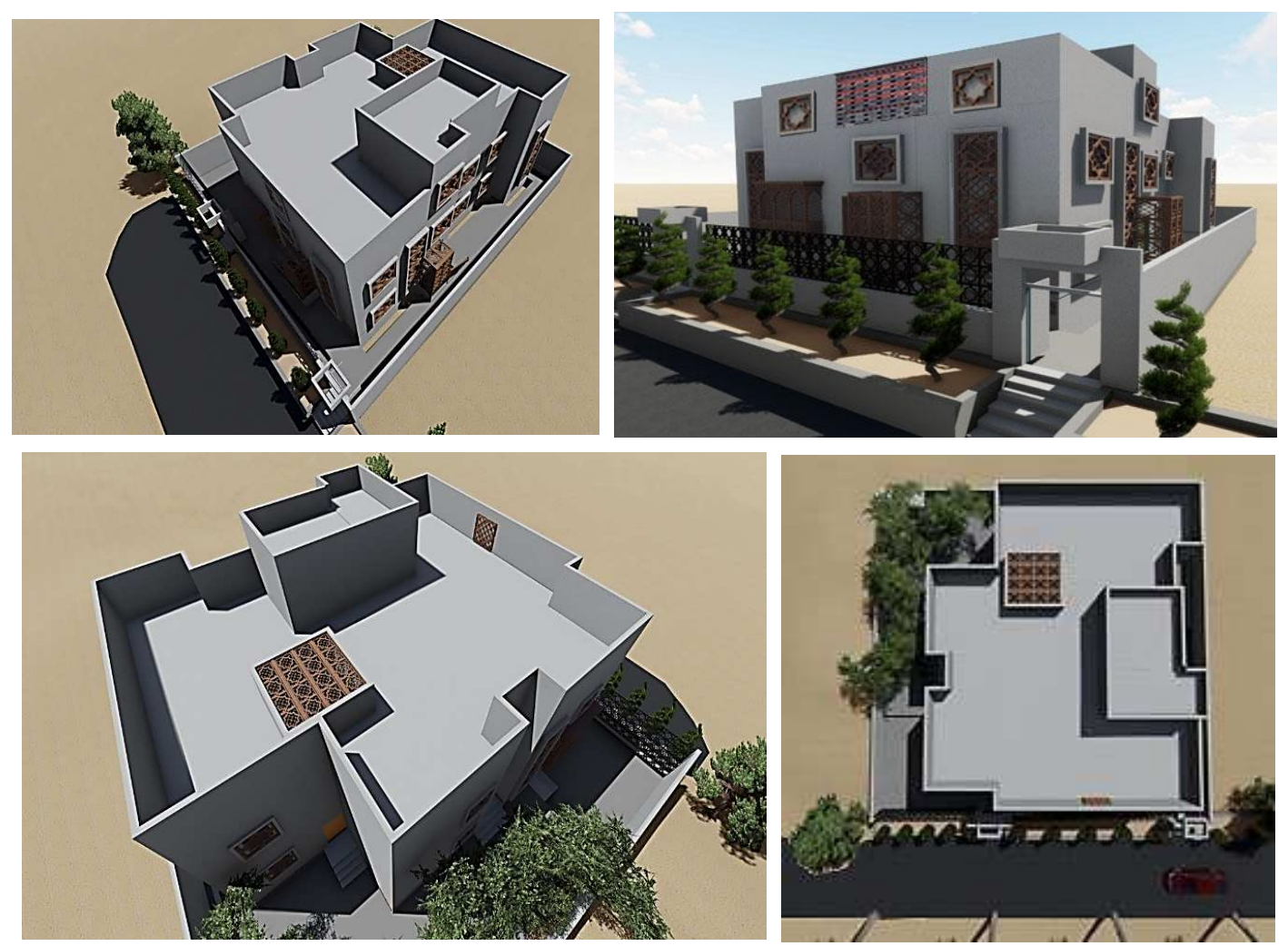

REVIT شكل (Tr) تمثيل المجسم ثلاثى الابعاد على برنامج

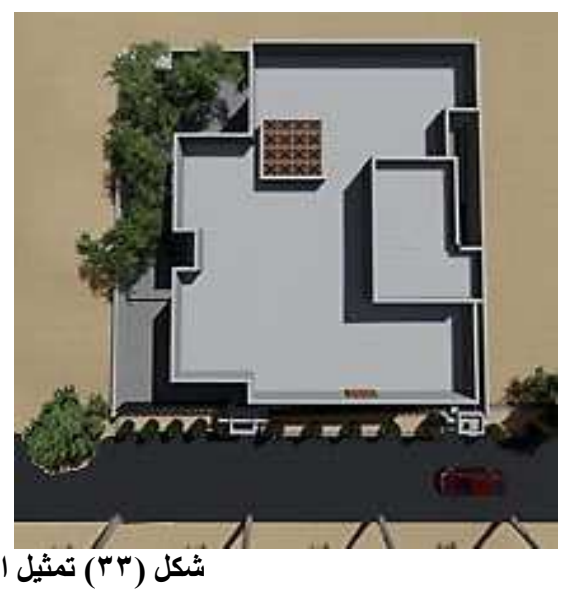

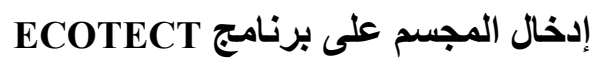

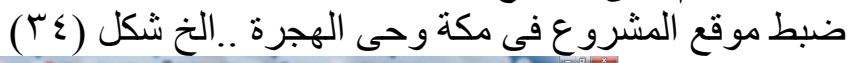

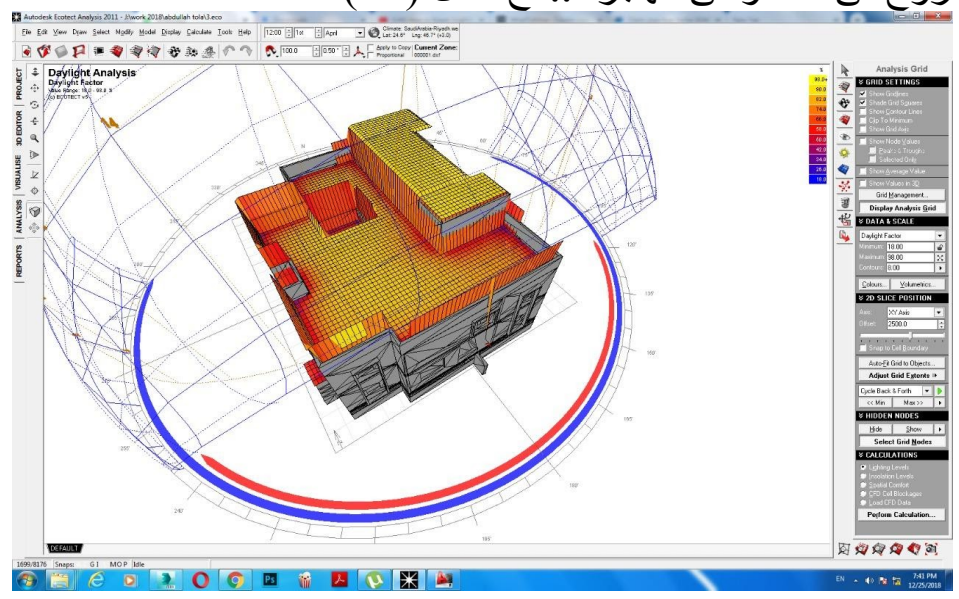

شكل ( ؟ "ا) الخال المجسم على برنامج ECOTECT (التحليل الضوئى) .

تحليل المنزل حراريا:

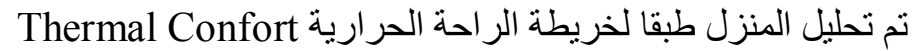

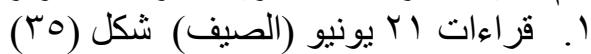

\begin{tabular}{|c|c|c|}
\hline متوسط درجة الحرارة داخليا & متوسط درجة الحرارة فى القناء & متوسط درجة الحرارة خارجيا \\
\hline$r \cdot-r V$ & $\varepsilon_{Z} r Y$ & $\leqslant 7-\leqslant 0$ \\
\hline
\end{tabular}


THE INNER COURTYARD AND ITS ROLE IN ACTIVATING THE SUSTAINABLE DIMENSION OF RESIDENTIAL BUILDINGS IN HOT REGIONS

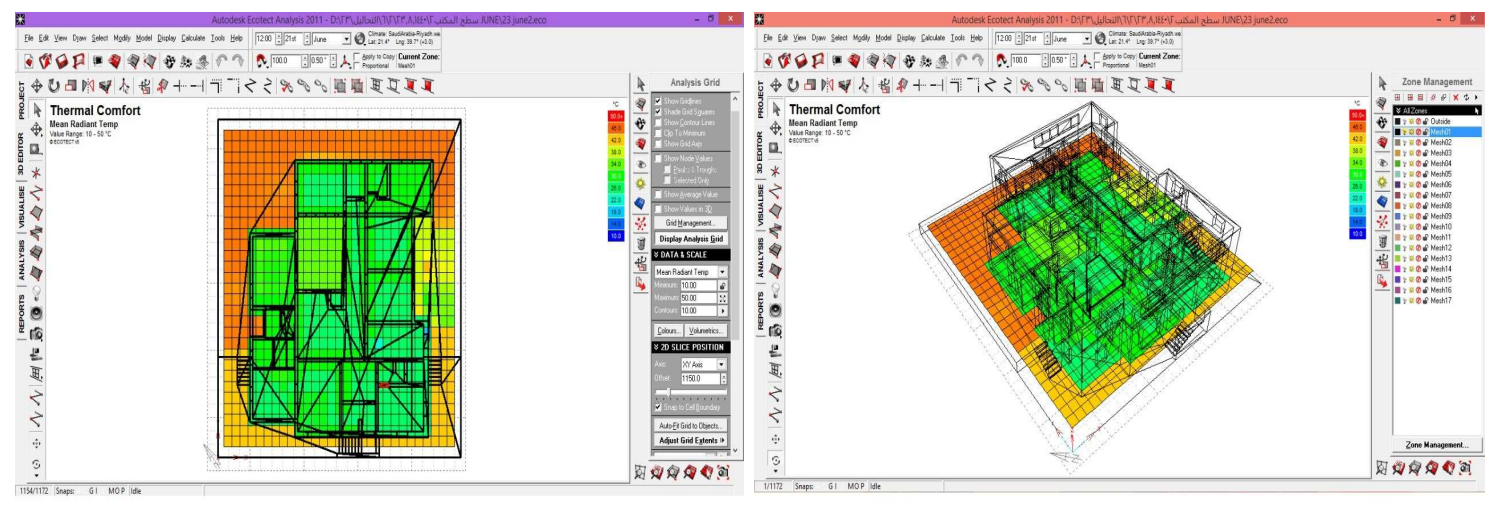

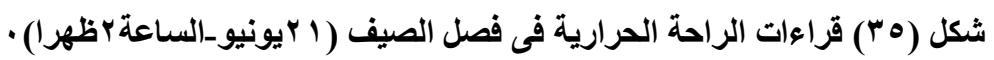

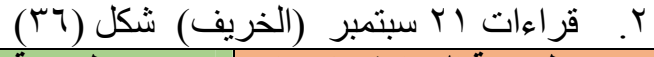

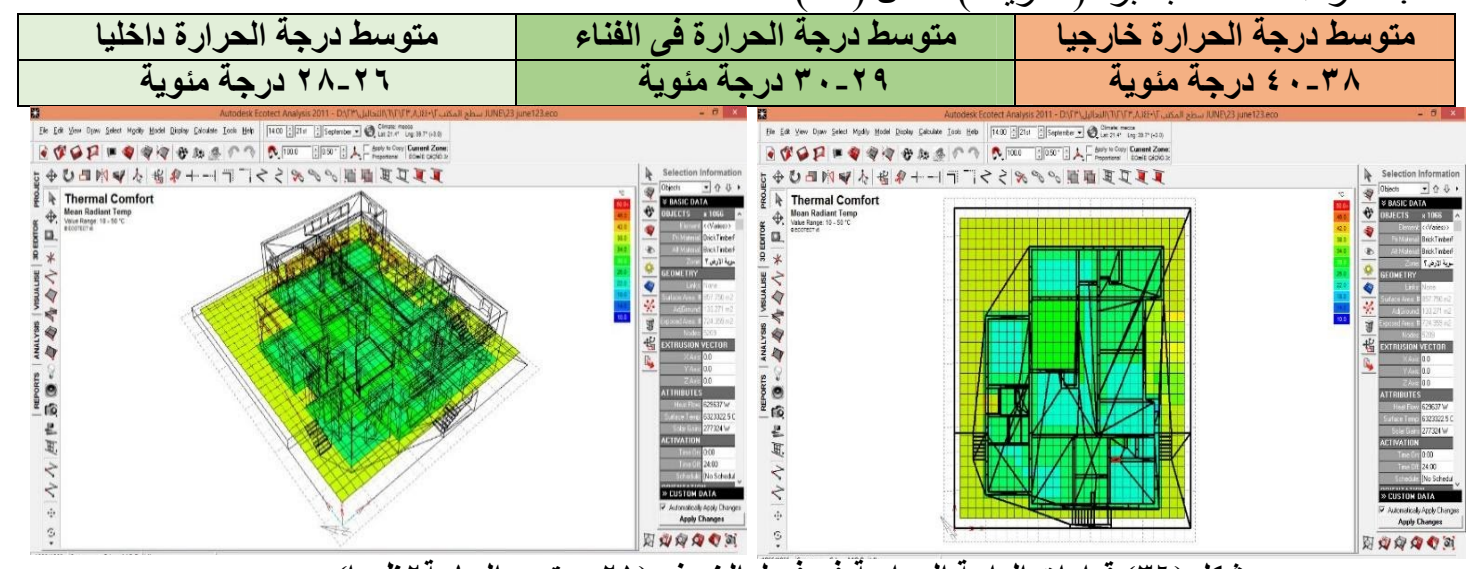

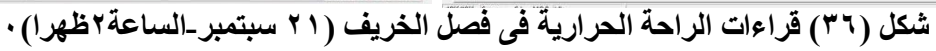

ج ـ قر اءات آ ب ديسمبر (الثتاء) شكل (rV)

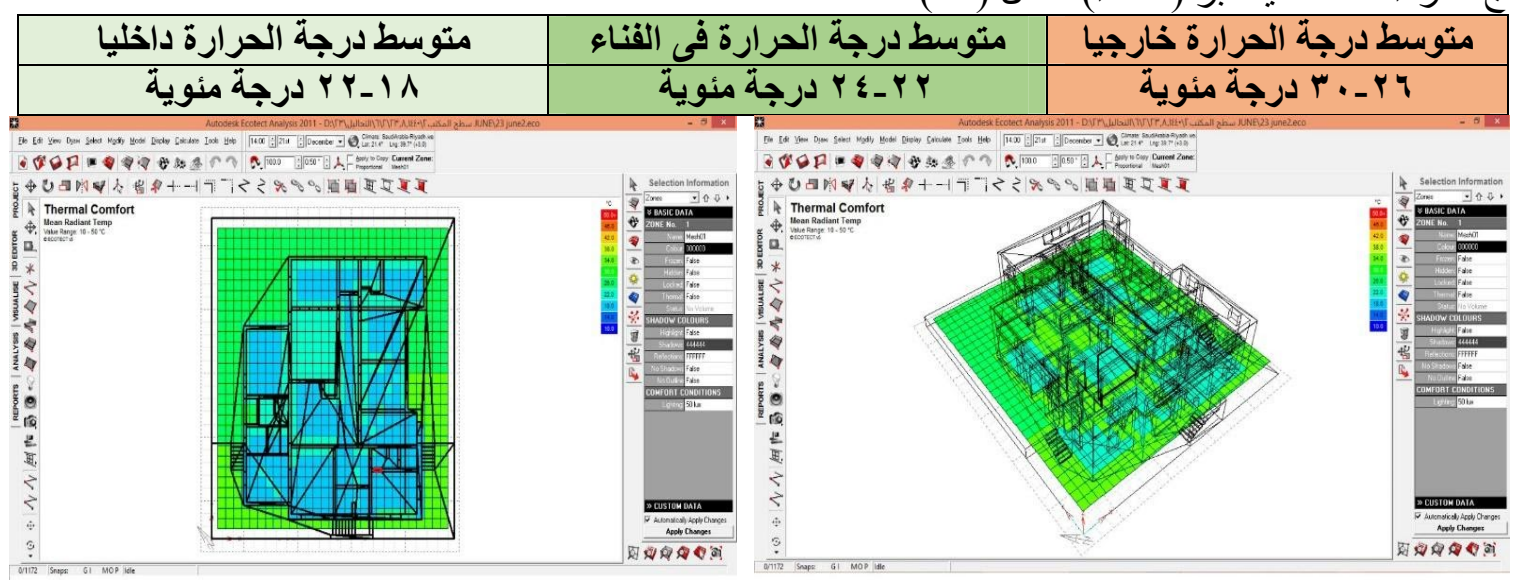

شكل (V) قراعات الراحة الحرارية فى فصل الثتاء ( آديسمبر -الساعة بظهرا) .

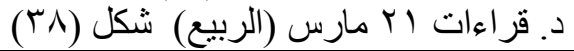

\begin{tabular}{|c|c|c|}
\hline متوسط درجة الحرارة داخليا & متوسط درجة الحرارة في الفناء & متوسط درجة الحرارة خارجيا \\
\hline
\end{tabular}


THE INNER COURTYARD AND ITS ROLE IN ACTIVATING THE SUSTAINABLE DIMENSION OF RESIDENTIAL BUILDINGS IN HOT REGIONS

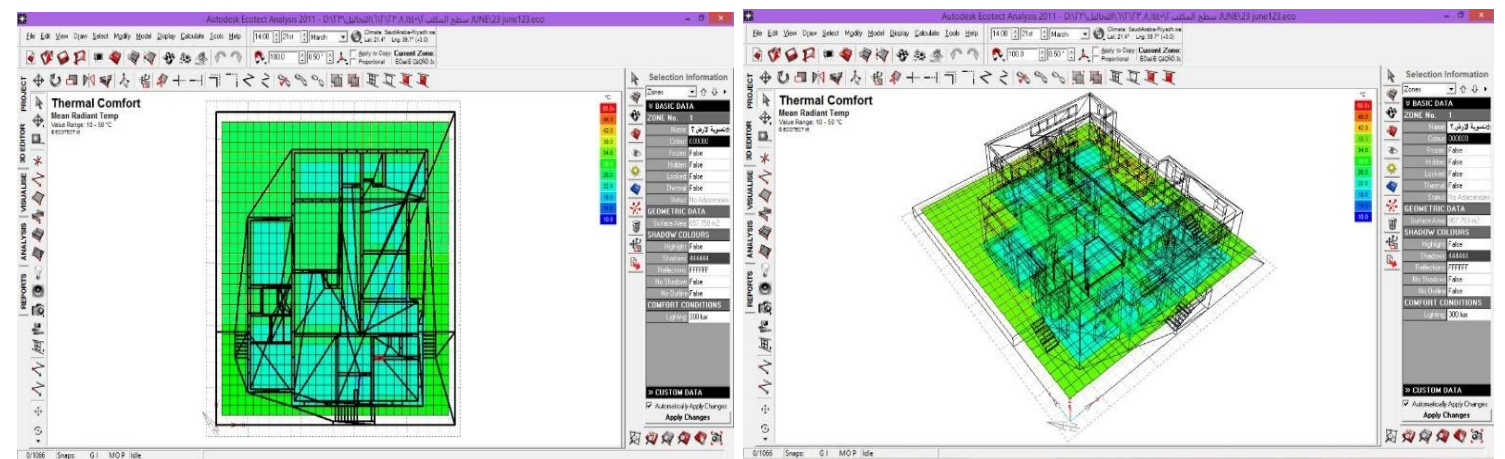

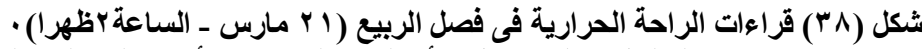

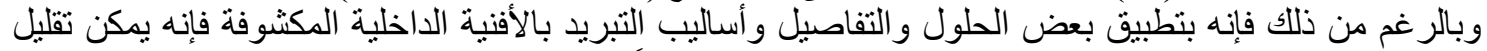

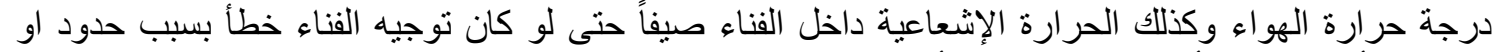

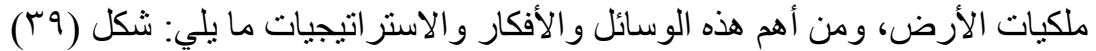

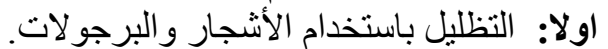

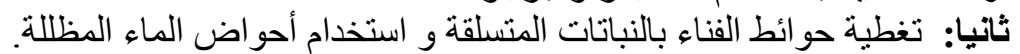

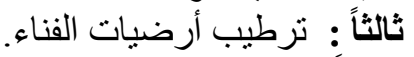
رابعاً : المعالجات للأسقف و الحو ائط و ومعالجات الفاء الفتحات.

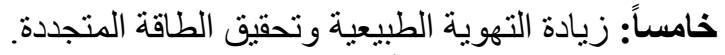

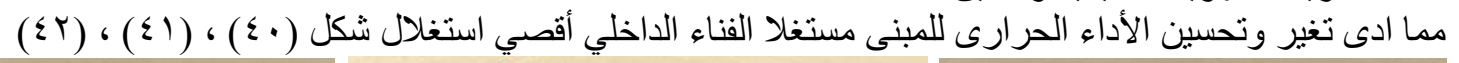
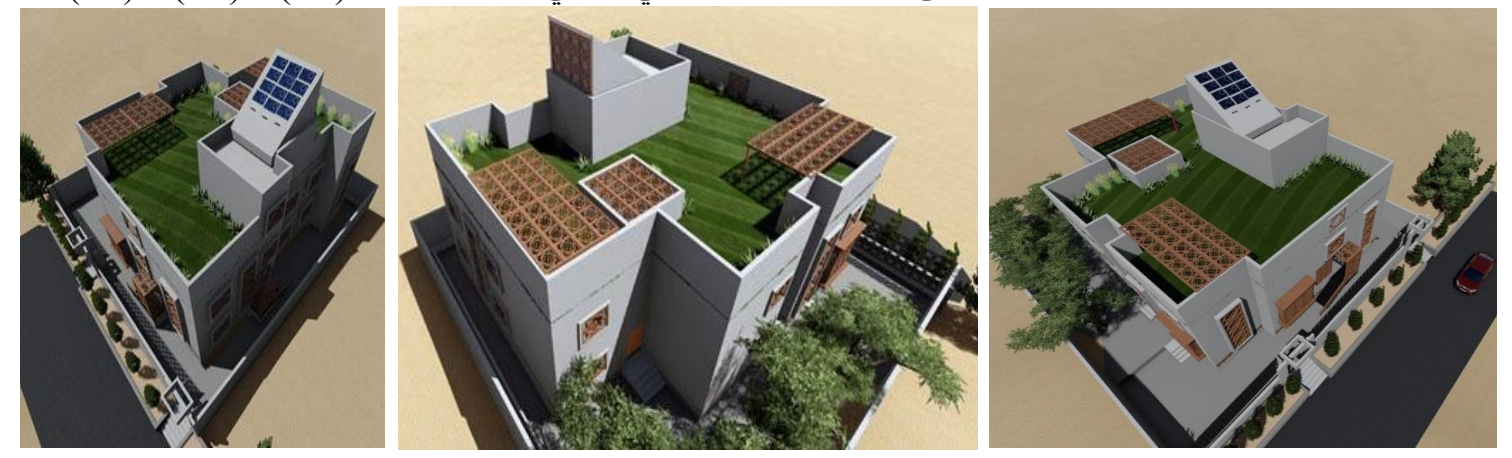

شكل ( (r) مقترح رفع سقف بيت الارج وخلق ملقف هواء لزيادة سرعة الهواء وتجديد هواء الفناء.

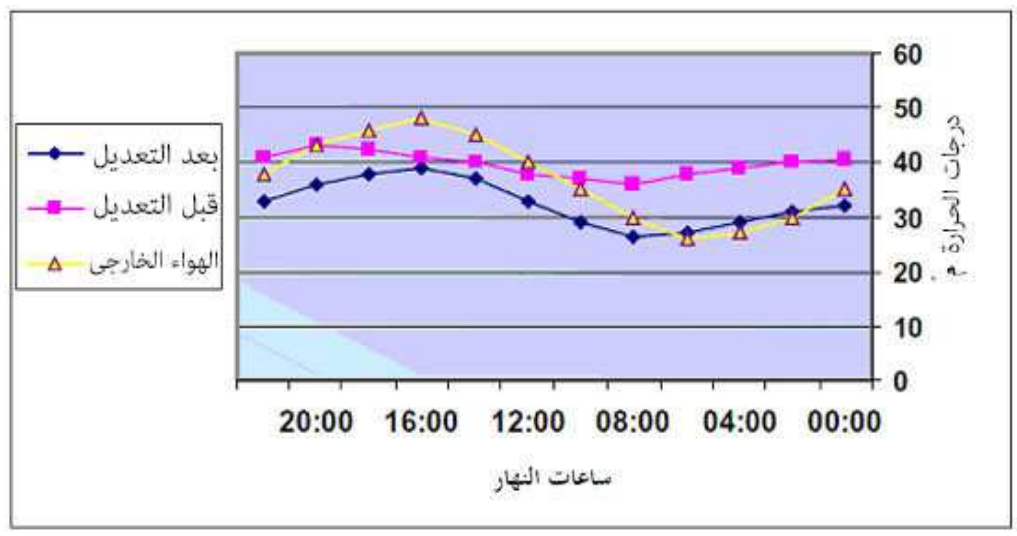

شكل ( • ؛ ) مخطط مقارنة متوسط درجات الحرارة داخل الفناء على مدار العام قبل وبعد تأهيلة. 
THE INNER COURTYARD AND ITS ROLE IN ACTIVATING THE SUSTAINABLE DIMENSION OF RESIDENTIAL BUILDINGS IN HOT REGIONS

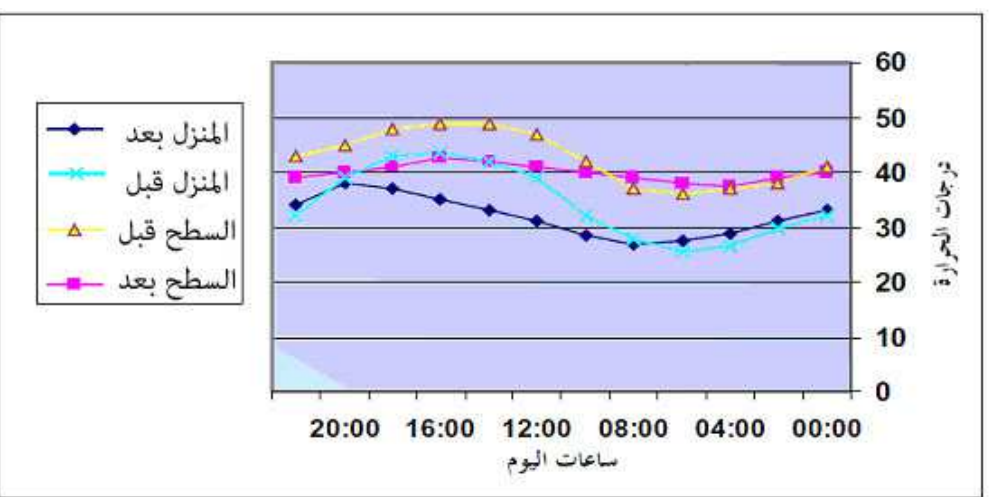

شكل ( 1 §) مخطط مقارنة متوسط درجات الحرارة داخل المنزل والسطح على مدار العام قبل وبعد تأهيله
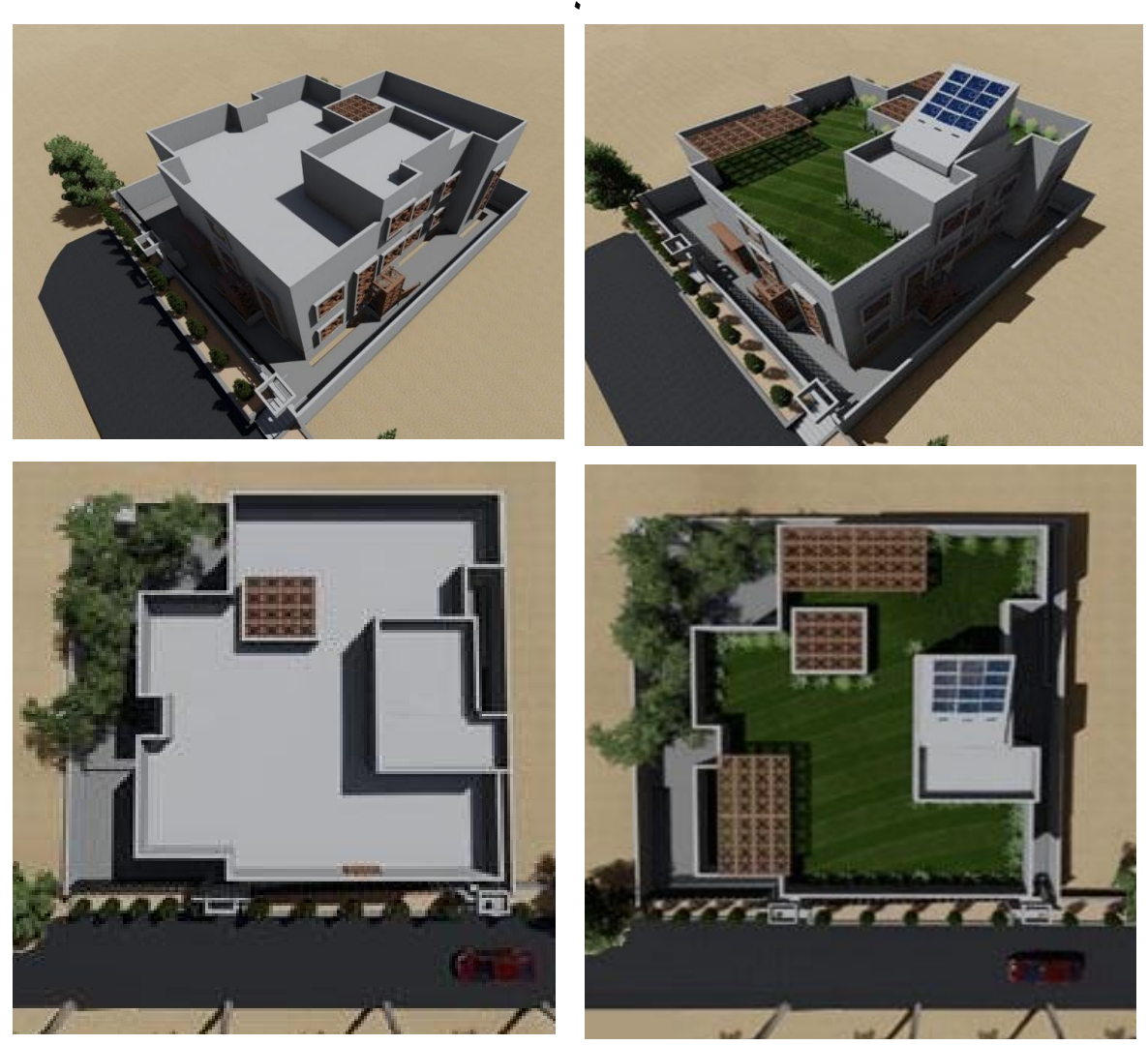

شكل (r §) التغير فى شكل المبنى بعد التأهيل وإستراتيجية التغير الى المبنى المستدام . 
THE INNER COURTYARD AND ITS ROLE IN ACTIVATING THE SUSTAINABLE DIMENSION OF RESIDENTIAL BUILDINGS IN HOT REGIONS

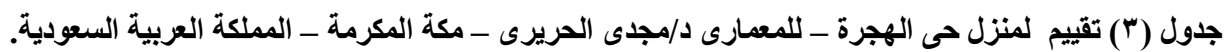

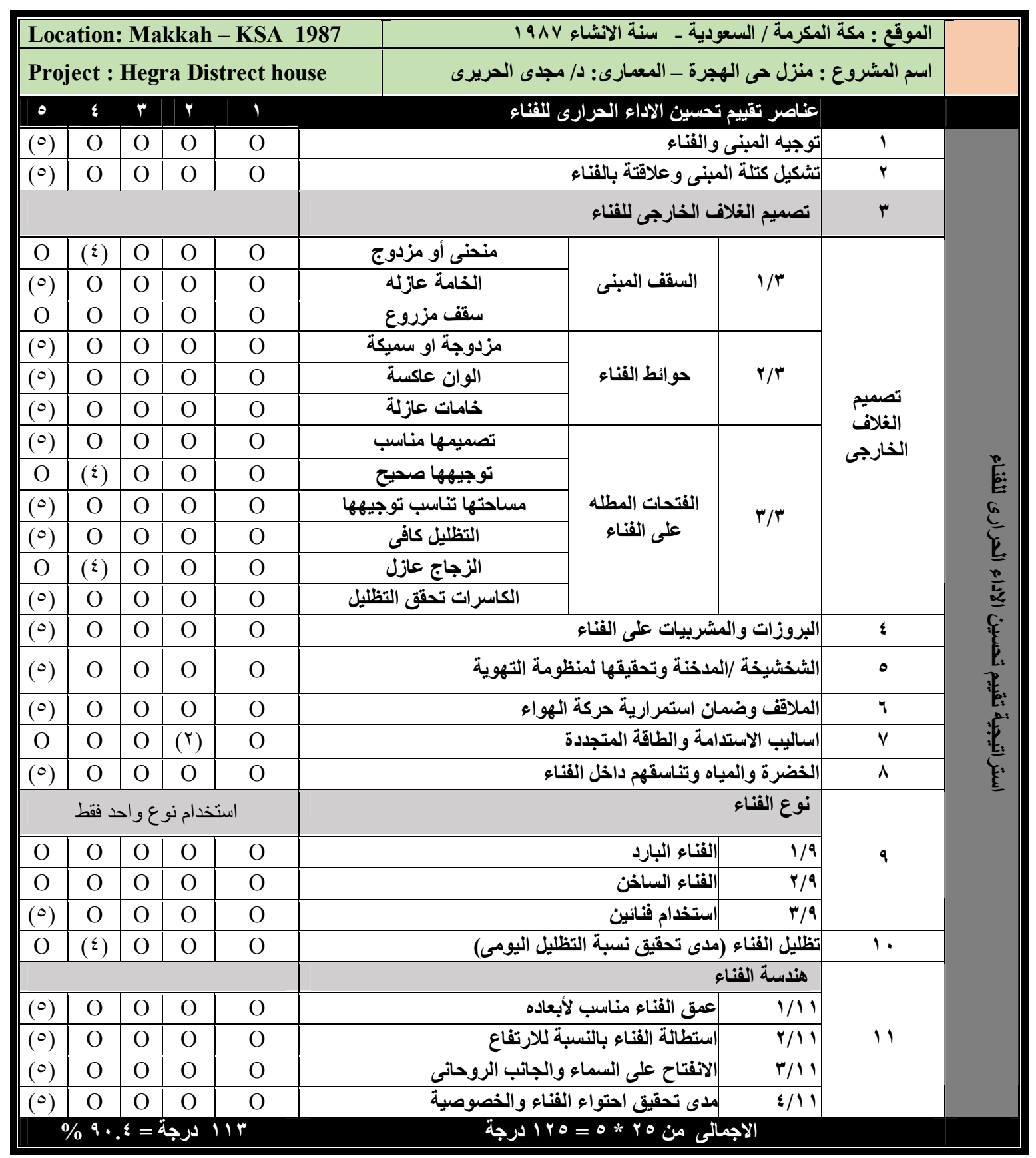

النتائج :

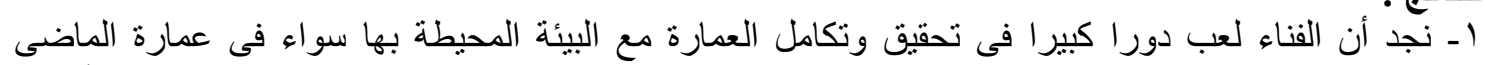

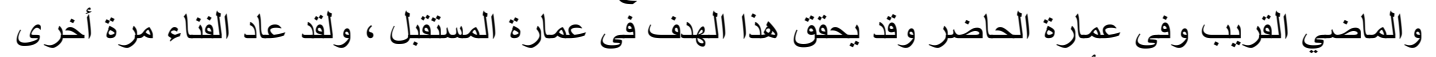

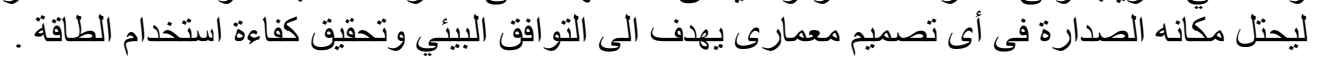

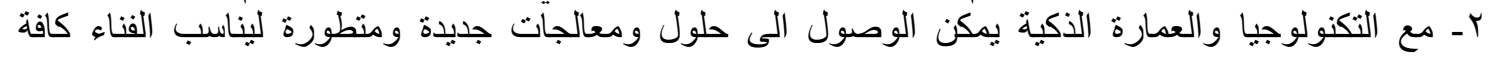

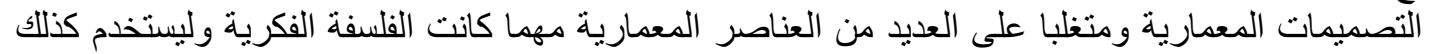

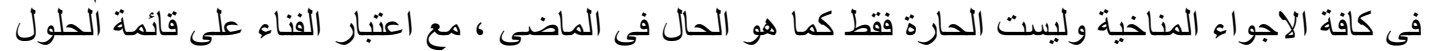

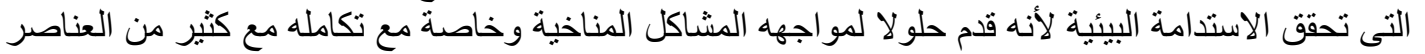


THE INNER COURTYARD AND ITS ROLE IN ACTIVATING THE SUSTAINABLE DIMENSION OF RESIDENTIAL BUILDINGS IN HOT REGIONS

الاخرى مثل الملقف والثخشيخة والمشربيات و الافنية المتعددة الخ من العناصر التى تتكامل مع الفناء لتحقق

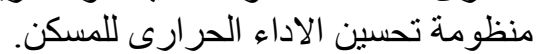

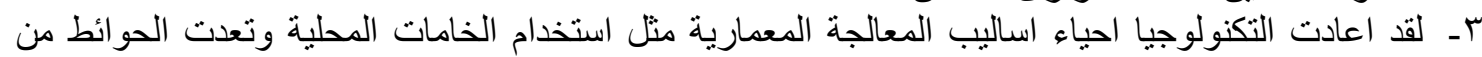

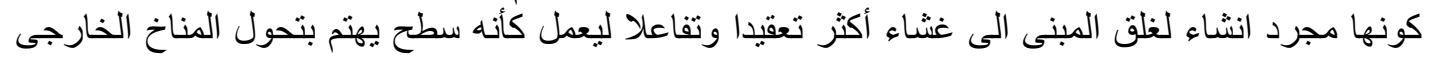

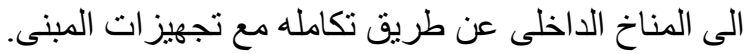

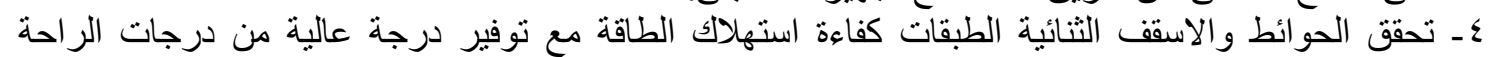

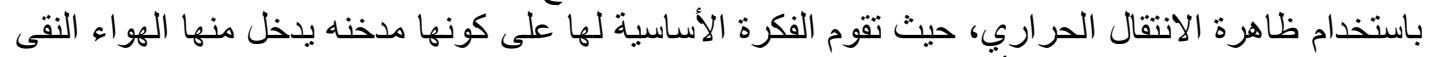

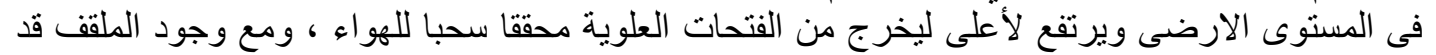

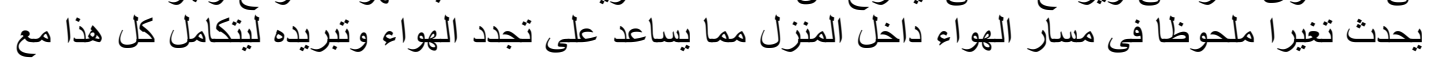

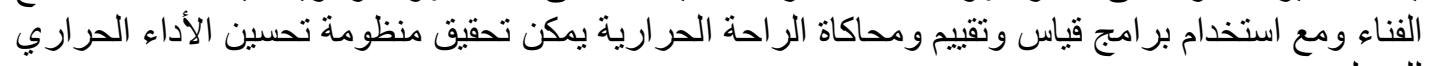
للمنزل.

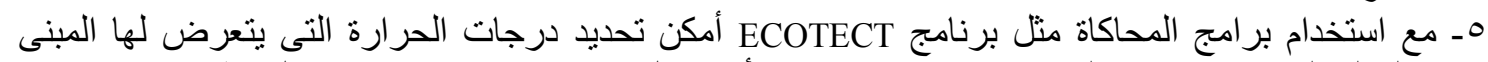

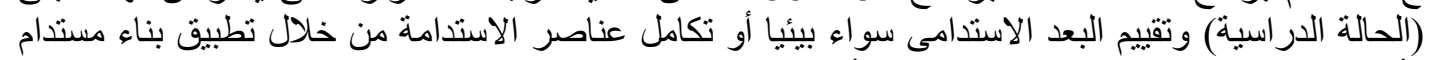

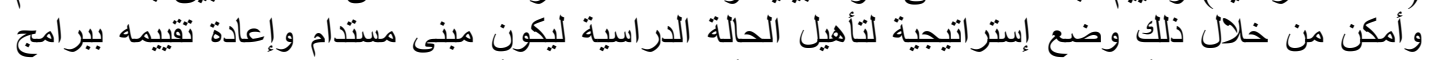

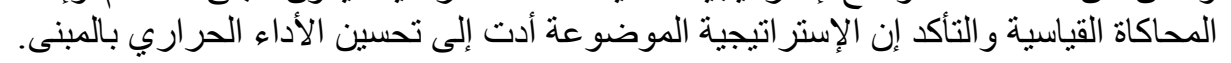

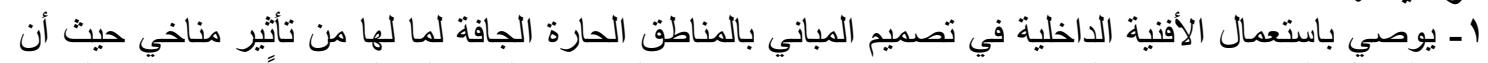

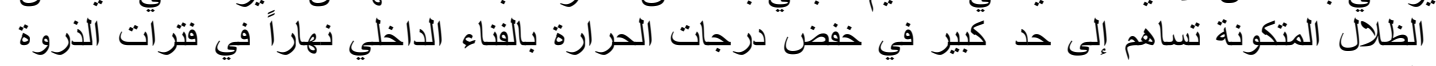
الحرارية.

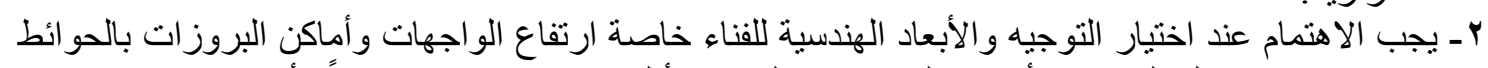

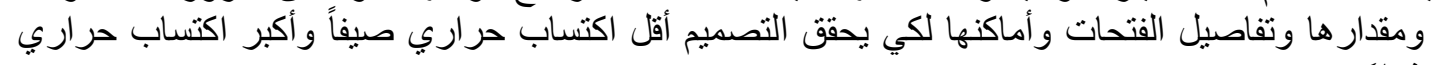
شتاءً. rـ أول مرِحلة من مر احل التصميم الثمسي تكون بحساب كميات الإشعاع الثمسي المستقبلة بواسطة الأسطح

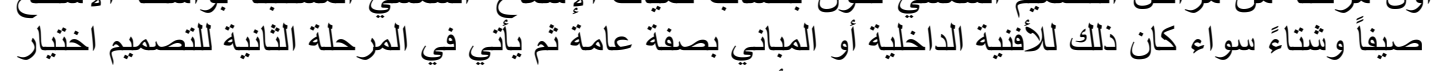

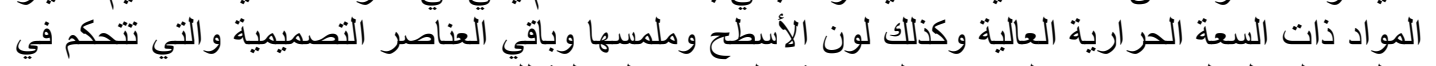

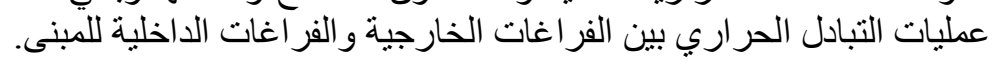

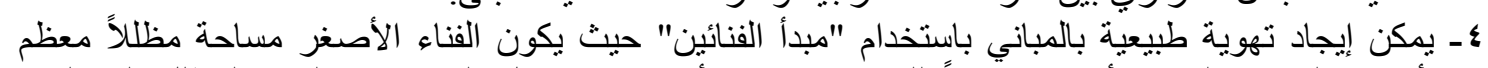

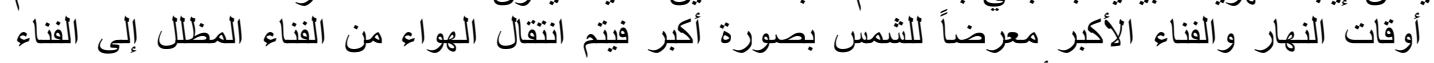

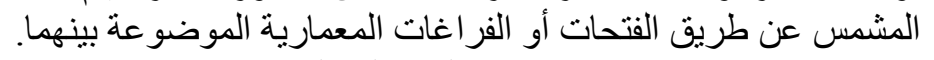

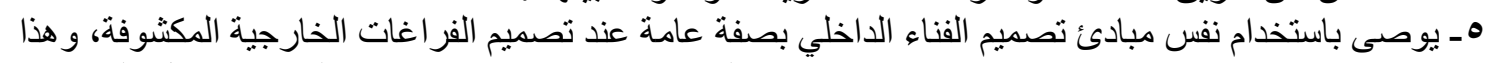

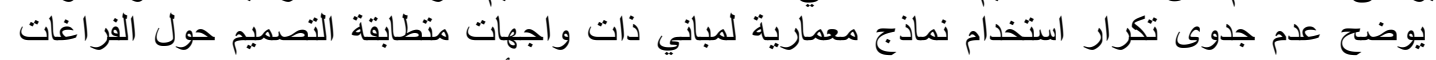

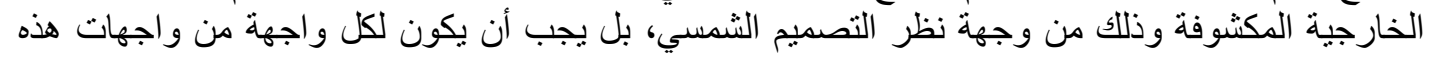

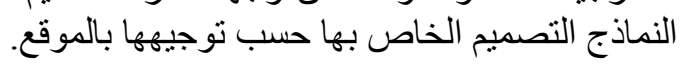

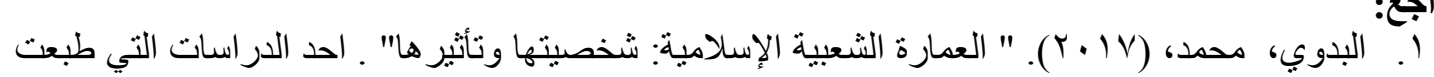

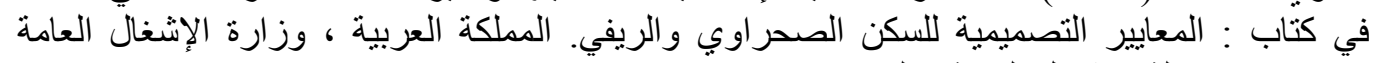

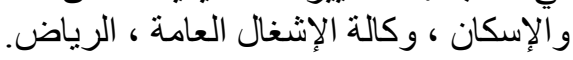

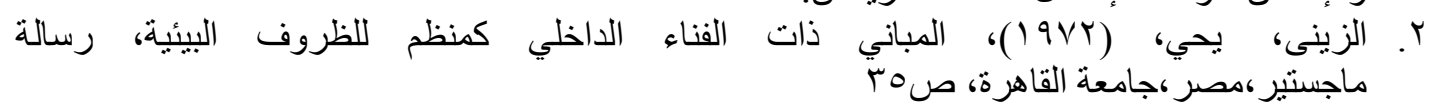

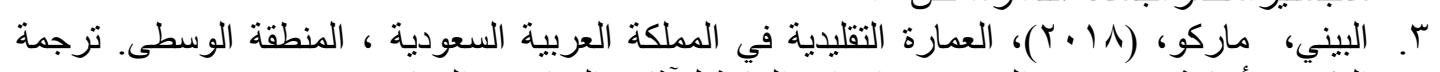

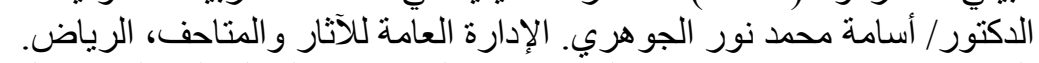

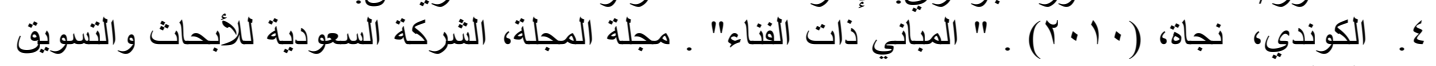

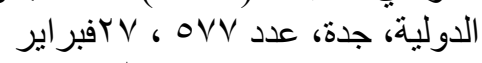

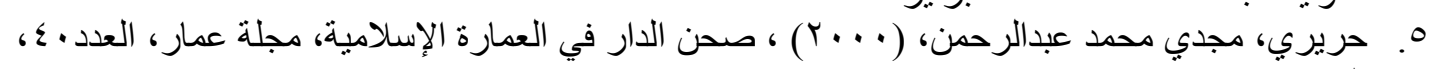
الكويت. 
THE INNER COURTYARD AND ITS ROLE IN ACTIVATING THE SUSTAINABLE DIMENSION OF RESIDENTIAL BUILDINGS IN HOT REGIONS

T. حريرى، (1999) مجدى." المسكن في العمارة الإسلامية صحن الدار والتطلع للسماء" ـ دار النشر

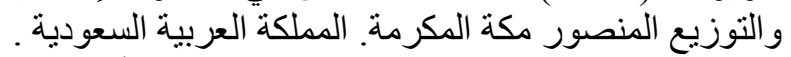

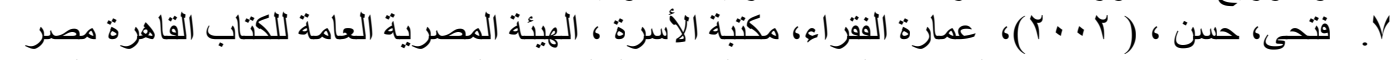

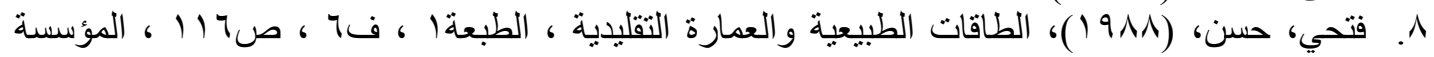

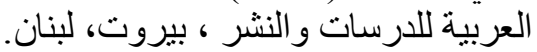

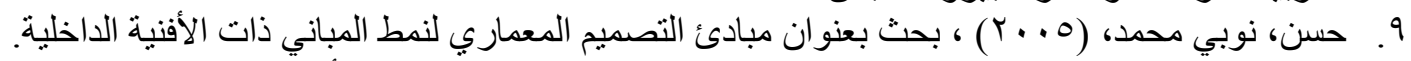

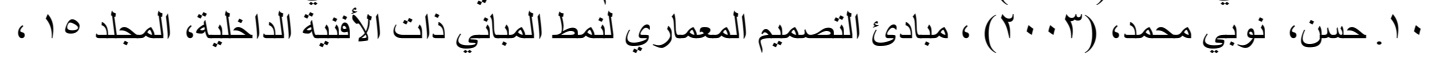

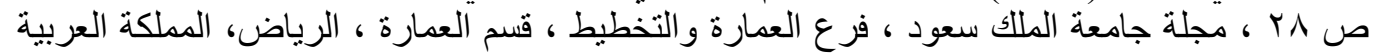
السعودية.

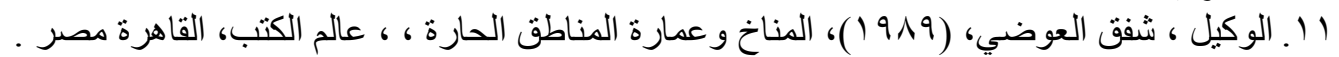

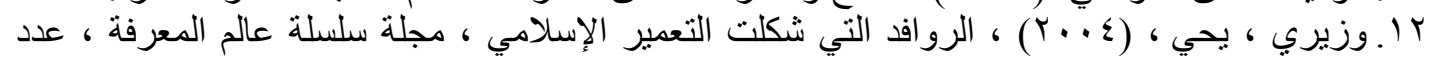

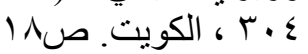

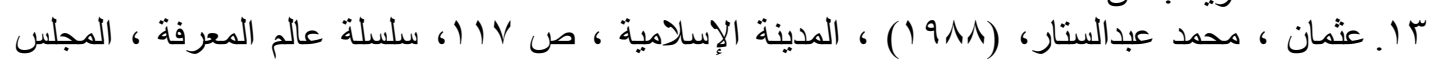

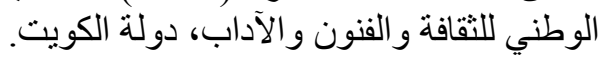

14. Angawi, Sami, (2016) M. Al-Makkiyah Residential Villa. archnet. [Online] 12 25, 2016. [Cited: 12 25, 2016.]

15. Chadirji, Rifat, (2008) Preface of Traditional Houses. By J. Warren \& I. Fethi. Coach Publishing House Ltd., Hoursham, England.

16. Ching, (2010) Francis D. K \& Mark Jarzombek A Global History of Architecture , 2nd Edition, ISBN 9780-470-40257-3, WILY, USA

17. Fletcher, Sir Banister , (2000). History of Architecture . University of London, The Athlone Press . $18^{\text {th }}$ ed.

18. Saini, Balwant Singh, (2010) . Building in Hot Dry Climates . John Wiley \& Sons Ltd., New York .

http://archnet.org/system/publications/contents/1574/original/FLS1818.pdf?13847 507341980.

19. Elborombaly, Hossam Hassan, (2015) "Adaptation of Vernacular Designs for Contemporary Sustainable Architecture in Middle East and Neotropical region"Asian Journal of Computer Science and Information Technology,p25 